UNIVERSIDADE DE SÃO PAULO

FFCLRP - DEPARTAMENTO DE BIOLOGIA

PROGRAMA DE PÓS-GRADUACÃO EM ENTOMOLOGIA

\title{
Restabelecimento das interações entre plantas e visitantes florais em áreas restauradas de Floresta Estacional Semidecidual
}

\author{
Fabiana Palmeira Fragoso
}

Tese apresentada à Faculdade de Filosofia, Ciências e Letras de Ribeirão Preto da USP, como parte das exigências para a obtenção do título de Doutor em Ciências, Área: Entomologia.

RIBEIRÃO PRETO - SP 
UNIVERSIDADE DE SÃO PAULO

FFCLRP - DEPARTAMENTO DE BIOLOGIA

PROGRAMA DE PÓS-GRADUACÃO EM ENTOMOLOGIA

\title{
Restabelecimento das interações entre plantas e visitantes florais em áreas restauradas de Floresta Estacional Semidecidual
}

\author{
Fabiana Palmeira Fragoso \\ Orientadora: Profa. Dra. Elenice Mouro Varanda
}

Tese apresentada à Faculdade de Filosofia, Ciências e Letras de Ribeirão Preto da USP, como parte das exigências para a obtenção do título de Doutor em Ciências, Área: Entomologia.

RIBEIRÃO PRETO - SP 
Autorizo a reprodução e divulgação total ou parcial deste trabalho, por qualquer meio convencional ou eletrônico, para fins de estudo e pesquisa, desde que citada a fonte.

FICHA CATALOGRÁFICA

Fragoso, Fabiana Palmeira

Restabelecimento das interações entre plantas e visitantes florais em áreas restauradas de Floresta Estacional Semidecidual. Ribeirão Preto, 2014.

97p.: il.; $30 \mathrm{~cm}$

Tese de Doutorado apresentada à Faculdade de Filosofia, Ciências e Letras de Ribeirão Preto/USP. Área de concentração: Entomologia.

Orientadora: Varanda, Elenice Mouro

1. Restauração ecológica. 2. Visitantes florais. 3. Redes de interação. 4. Polinização. 5. Floresta Estacional Semidecidual 
Aos meus pais, Luís Roberto e Célia Regina, com amor e gratidão 


\section{AGRADECIMENTOS}

À Faculdade de Filosofia, Ciências e Letras de Ribeirão Preto e ao Programa de Pós-graduação em Entomologia pela oportunidade.

Ao CNPq pelo apoio financeiro.

Ao CEEFLORUSP pela organização, integração e estímulo das atividades de pesquisa, extensão e educação na área de restauração ecológica.

À Elenice Mouro Varanda pela orientação e amizade, pela confiança depositada em mim e pelas muitas lições ensinadas ao longo desses anos de convivência. Por me incentivar em participar de atividades diversas e por buscar sempre a formação mais completa possível de seus alunos. Por todas as oportunidades de crescimento profissional e pessoal, serei sempre grata.

A todas as pessoas que me auxiliaram de alguma forma a encontrar meus locais de estudo: Luís Fernando Zorzenon e Carlos Gaeta Filho por encaminharem meus e-mails; Deborah Furtado, Michel Siqueira, Gustavo Cunha, Scheilla Bolonhezi Verdade, Rodnei Barbosa Correa, Thais Zepponi, Cintia Yokoji e Carina Spindola por responderem estes e-mails me indicando diversos reflorestamentos e quando necessário repassando os contatos dos proprietários; Deborah, Rodnei, Carina e Beto, especialmente, pela boa vontade em irem a campo me mostrar as áreas e pela gentileza em compartilhar as informações requisitadas.

À Biosev (Unidade Santa Elisa), Ricardo Bueno, Roberto Vantini e Isildo por permitirem a realização da pesquisa nas áreas restauradas de suas propriedades.

À Cláudia Inês da Silva pelas dicas preciosas sobre a melhor maneira de trabalhar com os grãos de pólen.

Ao Sidnei Mateus pela ajuda na identificação das abelhas e prontidão em responder qualquer pergunta.

Às secretárias Renata e Vera pela paciência em responder dúvidas e resolver problemas.

Aos colegas do laboratório Ricardo, Mônica, Luiz Henrique, Rodolfo, Luanne, Sabrina, Laura, Polyana e Helijone pela convivência tranquila, discussões enriquecedoras e muitas risadas descontraídas. E aos muitos outros que fizeram parte do laboratório, por períodos curtos ou longos, e que contribuíram de alguma forma. Em especial ao Rodolfo pelo auxilio inestimável na confecção das lâminas de pólen e triagem de insetos; ao José Pepi pelas incalculáveis horas na lupa; à Luanne pela revisão de texto e comentários valiosos; à Mônica pelas conversas sempre tranquilizadoras; e ao Ricardo pela disposição inesgotável em qualquer situação. 
Aos colegas "figólogos" Sergio, Larissa, Fernando, Paulo e Priscila pelos muitos bate-papos durante incontáveis cafés.

Aos amigos Laura, Sergio, Larissa e Mariela, por compartilharem suas percepções sobre os altos e baixos da vida de pós-graduando em inúmeras conversas, pela prazerosa acolhida em suas casas e pela companhia em viagens memoráveis que renovaram as energias e aumentaram o ânimo para seguir em frente com este trabalho.

A toda minha família, em particular meus pais Luís e Célia e meus irmãos Alex, Thaís e Beatriz por sempre me apoiarem mesmo que à distância e entenderem minha ausência em tantas ocasiões.

Ao meu marido, melhor amigo e companheiro incansável Luciano, por tantas coisas que eu não conseguiria enumerá-las. Mas principalmente pela ajuda indispensável no trabalho de campo, pelas numerosas e enriquecedoras discussões dentro e fora da universidade, pelas sugestões e críticas preciosas ao longo de todo este trabalho e pelo apoio e incentivo incondicionais. 

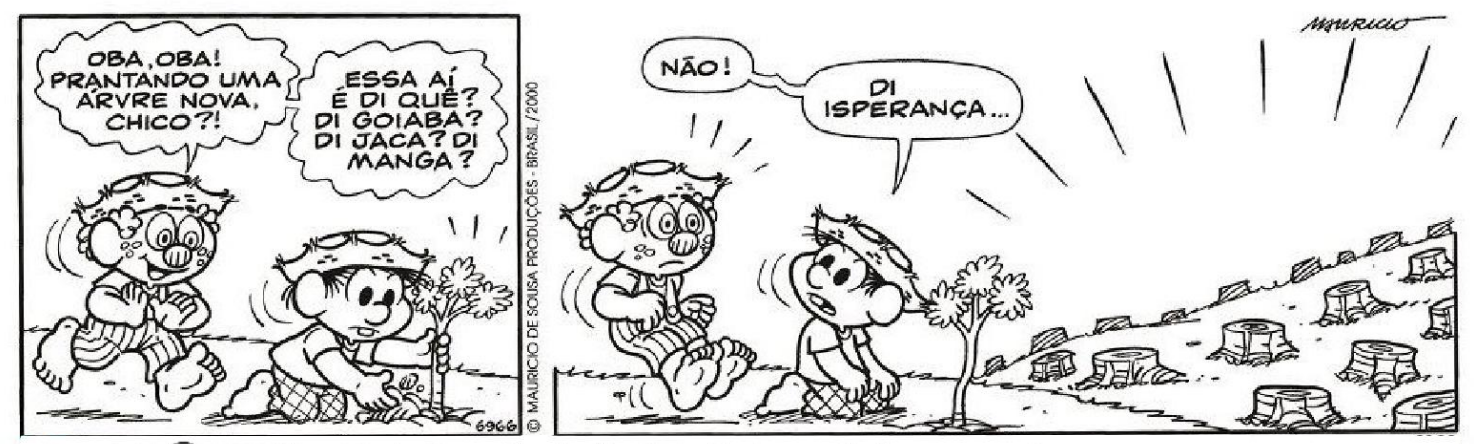

Copyright (C) 2000 Mauricio de Sousa Produçóes Ltda. Todos os direitos reservados.

6986 


\section{RESUMO}

FRAGOSO, F.P. Restabelecimento das interações entre plantas e visitantes florais em áreas restauradas de Floresta Estacional Semidecidual. 2014. Tese de Doutorado - Faculdade de Filosofia, Ciências e Letras de Ribeirão Preto, Universidade de São Paulo, São Paulo.

A restauração ecológica, ao buscar a manutenção de processos ecológicos e serviços ecossistêmicos, vem exercendo um importante papel na recuperação de ecossistemas degradados e conservação da biodiversidade. Restabelecer as interações entre organismos pode, contudo, ser uma tarefa mais árdua em ambientes de alta diversidade com complexas relações ecológicas como as florestas tropicais. Neste trabalho, investigamos a resposta dos insetos visitantes florais à restauração por plantio de mudas de espécies de Floresta Estacional Semidecidual, uma vez que o restabelecimento do processo de polinização é imprescindível para a perpetuação da floresta implantada. Para isso, foram examinados diferentes aspectos das comunidades de plantas e visitantes florais em seis áreas em processo de restauração. Primeiramente, buscou-se analisar a estrutura da comunidade de visitantes florais e seus padrões de visita às flores, avaliando-se também se a proximidade de fragmentos de vegetação nativa é importante na determinação da estrutura destas comunidades. Além disso, investigamos as espécies vegetais que florescem nos estágios iniciais de restauração para verificarmos se a comunidade de plantas se restabelecendo em cada local é importante na determinação da comunidade de visitantes. Por fim, avaliamos o restabelecimento do processo de polinização ao averiguar o transporte de pólen ocorrendo nas áreas restauradas e ao examinar a robustez das redes formadas frente à extinção simulada de espécies. Todas as áreas analisadas apresentaram redes de interação planta-visitante floral com estrutura e atributos comuns a outras redes mutualísticas de polinização, indicando que o processo deve estar se restabelecendo. A diferença na composição de espécies de visitantes não resultou em diferenças nos atributos das redes e a distância das áreas restauradas a fragmentos de vegetação nativa não influenciou a composição da comunidade de visitantes. Por outro lado, a vegetação regenerante composta por espécies ruderais aumentou a diversidade de visitantes e também a complexidade das redes de interação plantavisitante floral, afetando a composição e provavelmente o funcionamento das comunidades. Embora tanto as redes de visitação quanto as de transporte de pólen revelem comunidades funcionalmente complexas com um número relativamente diverso de interações entre plantas e potenciais polinizadores, os dados de visitação demonstraram que nem todas as áreas possuem o mesmo padrão de resposta à extinção simulada de espécies. A presença massiva de gramíneas é provavelmente um fator determinante da robustez destas redes já que ela dificulta a regeneração natural das espécies ruderais que contribuem para o maior aporte de recursos florais para os insetos visitantes. Este trabalho demonstra a importância de se avaliar a recuperação dos aspectos funcionais de ecossistemas restaurados e tem implicações práticas para o manejo de áreas restauradas onde houver preocupação particular com a recuperação das interações planta-polinizador. Enfatizamos a importância do monitoramento constante de áreas restauradas para melhor entendermos as trajetórias de recuperação das florestas tropicais e recomendamos estudos multidisciplinares que integrem diversas áreas de conhecimento para aperfeiçoarmos as ações de restauração.

Palavras-chave: restauração ecológica, visitantes florais, redes de interação, polinização, florestas tropicais 


\section{ABSTRACT}

FRAGOSO, F.P. Re-establishment of plant-flower visitor interactions in restored areas of Atlantic Semi-deciduous Forest. 2014. Tese de Doutorado - Faculdade de Filosofia, Ciências e Letras de Ribeirão Preto, Universidade de São Paulo, São Paulo.

Ecological restoration plays an essential role in recovering degraded ecosystems and maintaining biodiversity. Restoration initiatives aiming to restore ecological processes and ecosystem services are increasing rapidly worldwide. However, the high diversity and complexity of interactions among organisms in tropical ecosystems make their restoration a challenge. Since pollination is one ecosystem process that must be reinstated in order to perpetuate restored forests, we investigated flower visitors response to habitat restoration. In six areas of Atlantic Semi-deciduous Forest undergoing restoration, blooming plants (introduced and spontaneously regenerated), flower visitors and their interactions were recorded bimonthly during one year. We used the data to analyze the patterns of insect visitation in each area and to evaluate whether remnant habitat proximity is important in determining the structure of flower-visitor communities. We also examined the role of early-successional plant community in determining richness and composition of flower-visitor communities. To decide whether pollination has been successfully reinstated, we evaluated the patterns of pollen movement and the robustness of interaction networks to species loss. Our results suggest that plant-pollinator communities were equally established on all restored sites. There were no differences in the metrics of flower-visitor networks between forest categories, showing that habitat proximity had no effect on visitation webs. On the other hand, spontaneously regenerated plants (mostly weeds) were responsible to increase the diversity of flower-visiting insects as well as the complexity of visitation webs, hence having a crucial role on ecosystem functioning during early stages of forest restoration. We also found that despite having a relatively complex network structure and diverse community of potential pollinators, not all areas show the same resilience to species extinction. Still, the removal of the most connected plants and pollinators first from the network caused the higher number of secondary extinctions. The robustness of pollination networks to species loss seems to be related to the occurrence of alien grasses in some of the restored areas. As alien grass invasion inhibits natural regeneration of weeds, it also decreases the availability of floral resources to insects foraging in those areas. Our findings have practical implications for the management of restored forests, mainly those with specific targets such as recovering pollinator-friendly environments. Additionally, this study demonstrates the importance of evaluating functional aspects of biodiversity in restored areas. We highlight the relevance of monitoring restored communities at different successional stages to improve our understanding of restoration trajectories. We further recommend future research to be more integrative, so that the information produced will help to better planning restoration activities.

Keywords: ecological restoration, flower visitors, mutualistic networks, pollination, tropical forests 


\section{SUMÁRIO}

CAPÍTULO 1.

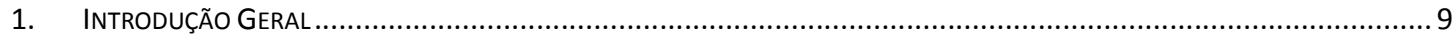

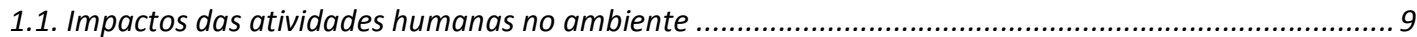

1.2. Restauração ecológica e a conservação da biodiversidade ............................................................. 10

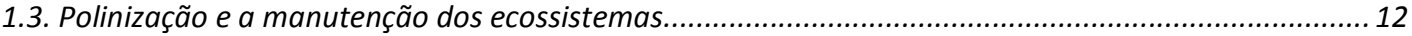

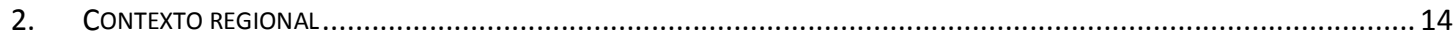

2.1. A degradação ambiental e o papel da restauração no Estado de São Paulo ....................................... 14

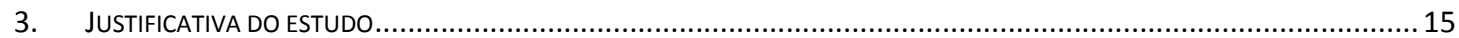

3.1. Porque investigar a polinização e os polinizadores na restauração de florestas tropicais .................... 15

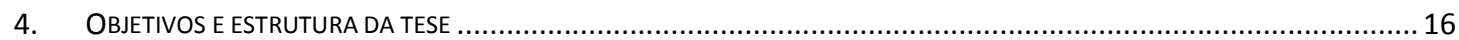

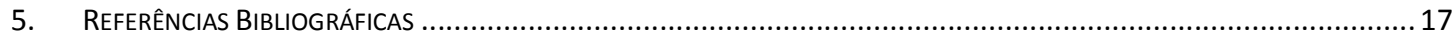

CAPÍTULO 2

AVALIAÇÃo dA ESTRUTURA dA COMUNIDADE DE PLANTAS E SEUS VISITANTES FLORAIS EM ÁREAS RESTAURADAS DE FLORESTA ESTACIONAL SEMIDECIDUAL

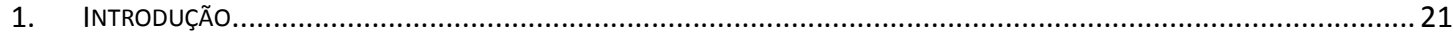

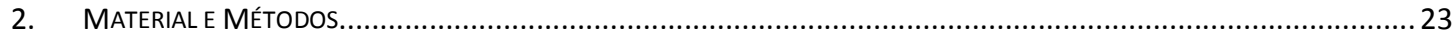

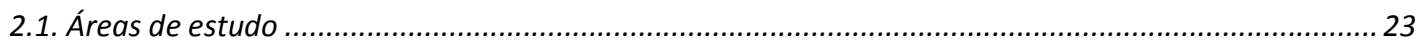

2.2. Amostragem

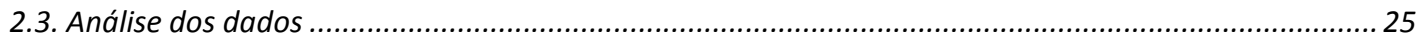

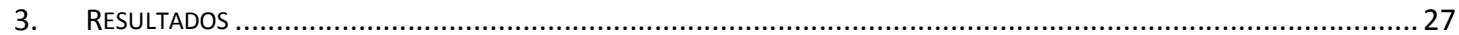

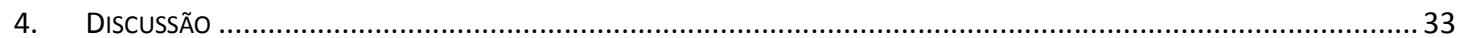

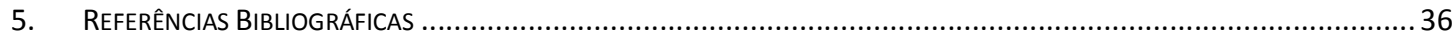

CAPÍTULO 3.

A INFLUÊNCIA DA COMUNIDADE DE PLANTAS NO ESTABELECIMENTO DA COMUNIDADE DE VISITANTES FLORAIS DURANTE OS ESTÁGIOS INICIAIS DA RESTAURAÇÃO

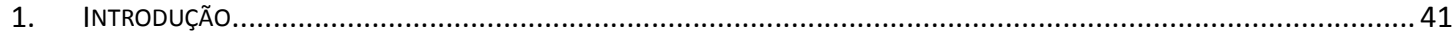

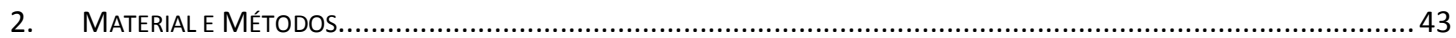

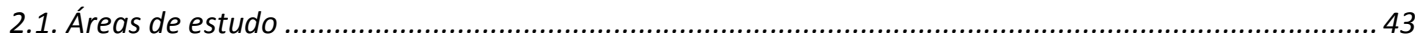

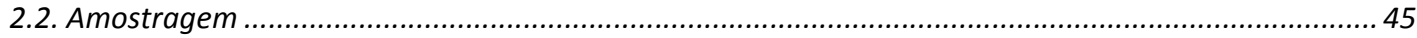

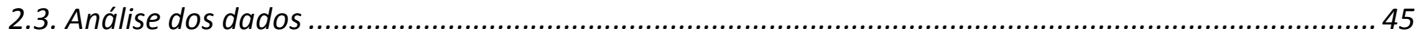

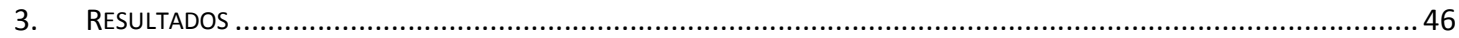

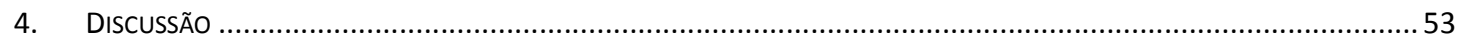

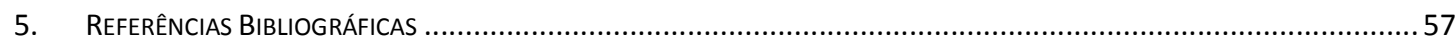

CAPÍTULO 4

RESTAURANDO PROCESSOS ECOLÓGICOS: ESTRUTURA E ROBUSTEZ DAS REDES DE INTERAÇÃO PLANTA-POLINIZADOR EM FLORESTAS TROPICAIS RESTAURADAS

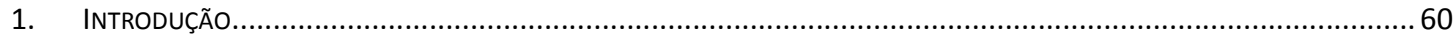

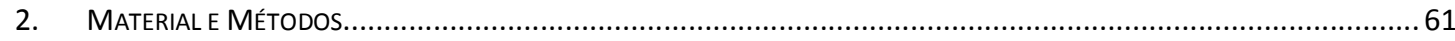




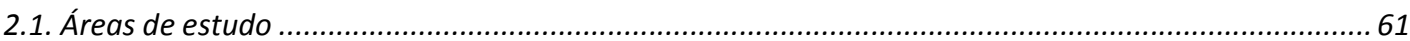

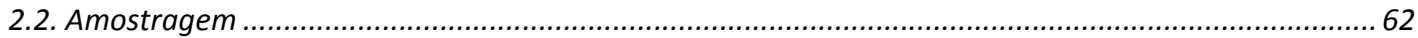

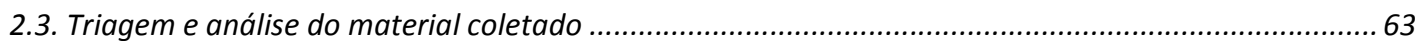

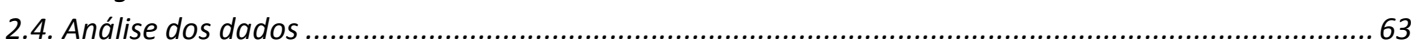

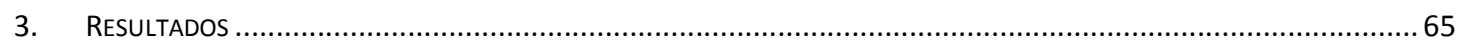

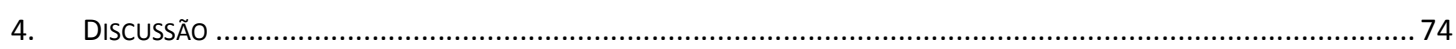

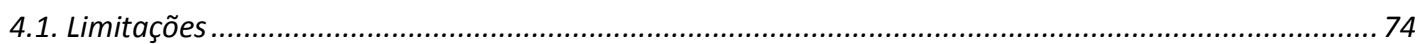

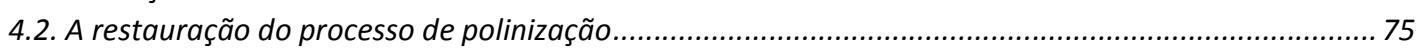

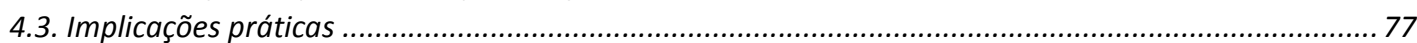

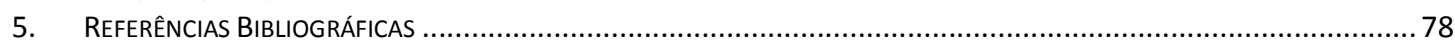

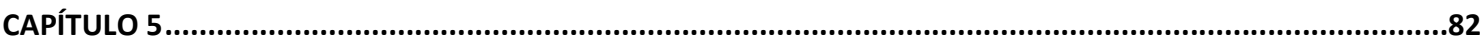

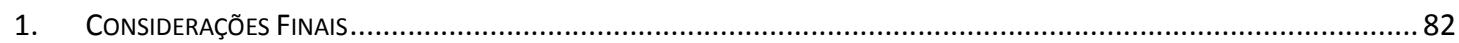

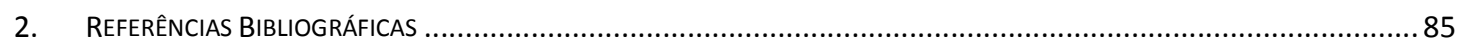

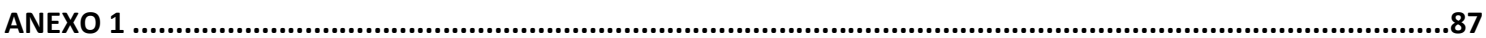

ESPÉCIES DE INSETOS VISITANTES FLORAIS NAS ÁREAS ESTUDADAS

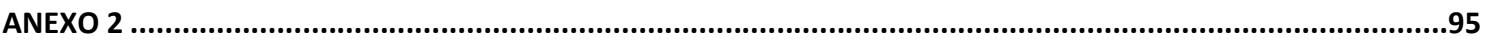

ESPÉCIES VEGETAIS EM FLORAÇÃO NAS ÁREAS ESTUDADAS 


\section{Introdução Geral}

\subsection{Impactos das atividades humanas no ambiente}

No mundo todo, ecossistemas diversos vêm sendo alterados por atividades humanas cujos impactos tendem somente a crescer. A conversão de ambientes naturais em áreas agrícolas e urbanas modifica continuamente a paisagem levando a perda, fragmentação e isolamento de habitats, fatores que, por sua vez, são os principais responsáveis pela diminuição da biodiversidade (Tabarelli et al. 2004; Fischer \& Lindenmayer 2007).

Somente as florestas, que cobrem 30 por cento da área terrestre do planeta, tiveram 13,5 milhões de hectares suprimidos por ano entre 2000 e 2005; considerando apenas as florestas tropicais, mais afetadas pelo desmatamento, a taxa é de 9,1 milhões de hectares por ano no mesmo período (FAO \& JRC 2012). No Brasil, a Mata Atlântica - um dos ecossistemas mais ricos em espécies e em taxas de endemismo do planeta - conta atualmente com apenas 11 por cento dos cerca de 150 milhões de hectares que ocupava originalmente (Ribeiro et al. 2009). Este processo destrutivo começa causando a extinção local de populações e acaba muitas vezes culminando na perda irreversível de espécies (Swift \& Hannon 2010).

Particularmente agravante é o fato de a biodiversidade não se referir apenas a uma coleção de espécies isoladas, mas englobar a variação taxonômica e genética dos organismos, bem como as funções ecológicas desempenhadas por eles. Portanto, embora diferentes espécies respondam de maneira diferente à fragmentação de habitats (Montoya et al. 2008), algumas sendo inclusive afetadas de maneira positiva, o impacto gerado sobre uma única espécie pode influenciar toda uma rede de interações bióticas que fundamenta a organização e a persistência da biodiversidade e, portanto, a estabilidade e a resiliência dos ecossistemas.

Com a perda da biodiversidade, muitos processos ecológicos indispensáveis à manutenção dos ecossistemas são afetados. Paralelamente, os chamados serviços ecossistêmicos - benefícios que os seres humanos obtêm dos ecossistemas - se degradam de forma rápida e extensiva. Tais serviços incluem provisionamento de alimentos, água, madeira e fibras; regulação da qualidade do ar, da água e do clima; polinização e controle de pestes; benefícios culturais relacionados à religião, recreação e educação; formação do solo e ciclagem de nutrientes, dentre outros.

Embora fundamentais para o bem-estar humano, sessenta por cento dos serviços ecossistêmicos avaliados pelo Millennium Ecosystem Assessment (2005) vem sendo degradados ou usados de maneira não sustentável; nos ultimos 50 anos, os seres humanos alteraram os ecossistemas mais rapidamente do que em qualquer outro periodo da história da humanidade. Em grande parte, esta degradacão vem 
ocorrendo em funcão da crescente demanda por alimentos, água, madeira e combustiveis, sendo a agricultura o motor principal da conversão de habitats. Embora os custos totais da perda destes serviços sejam difíceis de calcular, os impactos ambientais, econômicos e sociais de sua degradação irão certamente aumentar se as atividades humanas continuarem seguindo indiscriminadamente o modelo atual de expansão (Nellemann et al. 2009).

\subsection{Restauração ecológica e conservação da biodiversidade}

Diante das inevitáveis mudanças ambientais decorrentes da crescente degradação dos ecossistemas, a demanda pela restauração de ambientes degradados está aumentando rapidamente. Hoje, é aceito que a conservação da biodiversidade do planeta não será possível somente através da proteção de áreas críticas (Rodrigues et al. 2004), e que a restauração ecológica também deve fazer parte dos esforços e políticas conservacionistas.

A restauração ecológica é o processo de assistir na recuperação de um ecossistema que foi degradado, danificado ou destruído. Os princípios, atributos e objetivos da atividade foram estabelecidos no Society for Ecological Restoration International Primer on Ecological Restoration (2004), documento que instituiu os parâmetros básicos da atividade para os profissionais da área assim como as principais considerações teóricas do campo da ecologia da restauração. A ecologia da restauração, por sua vez, é uma área da ciência bastante jovem e em rápido desenvolvimento, cujo objetivo, além de avançar na ecologia teórica por meio da experimentação, é fornecer conceitos, modelos e metodologias para os praticantes da atividade.

Nem todas as atividades que buscam reparar um ecossistema (como recuperação e compensação, por exemplo) satisfazem necessariamente os atributos de um projeto de restauração ecológica. Para tanto, deve-se almejar atender condições específicas relativas à composição de espécies, funcionamento e estabilidade do ecossistema e a inserção da área restaurada no contexto da paisagem (Shackelford et al. 2013). Mais do que isso, um plano apropriado deve estabelecer metas que reflitam esses atributos e que possam ser avaliadas para se constatar o sucesso da restauração. No final, o êxito será alcançado se a restauração der início a processos autogênicos que permitiam a perpetuação do ecossistema restaurado.

Na prática, a maioria dos programas de restauração apresentam limitações diversas (e.g. custos, operacionalidade, nível de envolvimento das partes interessadas) que levam à implementação apenas de um conjunto mínimo de espécies vegetais; de fato, resgatar uma determinada composição de espécies é provavelmente um dos objetivos mais concretos da restauração ecológica e por isso mais facilmente implementado (Ruiz-Jaen \& Aide 2005). Frequentemente é então assumido que as demais espécies vegetais, a fauna e os processos ecológicos serão restabelecidos naturalmente seguindo o desenvolvimento da vegetação implantada. 
Apesar de razoável, essa premissa nem sempre é válida: embora alguns projetos sejam muito bem sucedidos, o resultado alcançado pela restauração é bastante variado e muitas vezes parcialmente efetivo dependendo dos parâmetros avaliados (Suding 2011). Rey Benayas e colaboradores (2009) realizaram uma meta-análise de 89 projetos de restauração e verificaram que, embora a restauração promova aumento da biodiversidade e dos serviços ecossistêmicos em relação ao estado previamente degradado, esta melhoria não atinge os níveis encontrados nos ecossistemas intactos usados como referência. Revisando a reintrodução de plantas em 249 projetos diferentes, Godefroid et al. (2011) encontraram que a sobrevivência e as taxas de floração e frutificação das espécies vegetais implantadas são geralmente muito baixas. No Brasil, em um levantamento feito em 2000, apenas duas entre 98 áreas reflorestadas foram consideradas bem sucedidas (Wuethrich 2007); em geral as falhas foram causadas por plantios de baixa diversidade numa época em que a importância de plantios de alta diversidade ainda não era bem entendida.

Mesmo havendo alguns reveses, as perspectivas de que poderemos promover a recuperação dos ecossistemas degradados são otimistas (Jones \& Schmitz 2009). A ecologia da restauração, apesar de ser uma ciência relativamente nova, já assumiu um papel central nos esforços de conservação da biodiversidade e dos serviços ecossistêmicos (Roberts et al. 2009). Hoje, pesquisadores da área concordam que, para tornar a ecologia da restauração uma ciência mais preditiva e a restauração ecológica uma prática mais efetiva, é preciso adotar metas mais realistas (Ehrenfeld 2000; Suding 2011). Ainda assim, embora a diversidade de condições onde a restauração é necessária demande flexibilidade de objetivos, existe também a necessidade de se estabelecer alguns princípios básicos sobre os quais estes objetivos devem ou não ser ajustados. Passados dez anos da publicação do Primer on Ecological Restoration da SER (2004), estes princípios nem sempre são seguidos, muitas vezes devido às dificuldades de entendimento dos processos ecológicos subjacentes ao desenvolvimento de um ecossistema.

Portanto, é fundamental que a ciência aproveite os cada vez mais numerosos projetos de restauração para abordar questões ecológicas básicas (Clewell \& Rieger 1997) e especialmente importantes frente às mudanças ambientais crescentes. Por exemplo, o estabelecimento de espécies apropriadas de plantas não resulta necessariamente na restauração dos processos ecológicos; assim, o foco puramente na composição de espécies deve ser convertido em uma maior preocupação com o restabelecimento dos processos ecológicos e serviços ecossistêmicos tão necessários à saúde dos ecossistemas e da sociedade (Ehrenfeld \& Toth 1997; Palmer \& Filoso 2009; Rey Benayas et al. 2009). Do mesmo modo, a maioria dos estudos feitos até hoje concentrou-se na investigação das condições locais (bióticas e abióticas) das áreas restauradas em detrimento de uma análise mais profunda sobre sua inserção na paisagem (Holl et al. 2003; Brudvig 2011); frente à acelerada fragmentação dos ambientes naturais, é imperativo entendermos como a geometria, a conectividade e a paisagem do entorno das áreas restauradas afetam o processo de restauração. Por último, as contínuas e inevitáveis 
mudanças ambientais mostram que adotar o objetivo de restaurar ecossistemas a estados históricos anteriores será cada vez mais impossível no futuro; uma tarefa crucial da ecologia da restauração será determinar quando a adoção de referências históricas é uma medida viável e quando estados alternativos - como ecossistemas híbridos ou novos - devem ser considerados (Hobbs et al. 2009; Jackson \& Hobbs 2009; Hobbs et al. 2011).

Sobretudo, o monitoramento das áreas restauradas é crucial para determinarmos o sucesso das práticas adotadas e melhorarmos os métodos empregados no futuro (Clewell \& Rieger 1997; Godefroid \& Vanderborght 2011). Não obstante, como a maioria das avaliações dos resultados alcançados pela restauração usa como critérios apenas aspectos da estrutura, composição e diversidade vegetal (Ruiz-Jaen \& Aide 2005; Brudvig 2011), é cada vez mais urgente a necessidade de se adotar uma abordagem mais integrativa que incorpore também a recuperação dos processos ecológicos e serviços ecossistêmicos (Chazdon 2008; Rey Benayas et al. 2009; Suding 2011), bem como as novas configurações ambientais que certamente influenciam a restauração ecológica.

\subsection{Polinização e a manutenção dos ecossistemas}

Os processos ecológicos são a base sobre a qual se sustentam os ecossistemas e, por isso, tanto ambientes naturais quanto restaurados requerem acima de tudo que todos estes processos funcionem de maneira equilibrada para sua autorrenovação e perpetuação. A polinização é um destes processos fundamentais porque garante a reprodução sexual das espécies vegetais e a manutenção do fluxo genético entre populações.

A grande maioria das plantas com flores é polinizada por insetos e outros animais $-87,5 \%$ das cerca de 352.000 espécies de angiospermas dependem de polinização biótica (Ollerton et al. 2011). A proporção é ainda maior nas florestas tropicais, onde mais de $90 \%$ das espécies vegetais são polinizadas por animais, principalmente abelhas (Bawa et al. 1985a; Bawa 1990), e elevados números de sistemas de polinização especializados (Ollerton et al. 2011) e mecanismos de incompatibilidade (Bawa et al. 1985b) são encontrados. Mesmo entre espécies capazes de se autopolinizar ou entre espécies com sistemas mistos de reprodução (permitindo tanto autopolinização quanto polinização cruzada), a polinização biótica é crucial tanto para mover o pólen das anteras para o estigma quanto para manter a variabilidade genética nas populações vegetais - já que a reprodução somente por autopolinização levaria certamente à depressão endogâmica no longo prazo.

A preocupação com o processo de polinização biótica na restauração de áreas degradadas tem dupla importância: ao mesmo tempo que os polinizadores são essenciais para a reprodução das espécies vegetais implantadas, e portanto para a perpetuação da área restaurada, o habitat criado na restauração auxilia na conservação de polinizadores responsáveis pela reprodução de espécies vegetais em ambientes nativos e cultivos agrícolas. Todas estas funções ecológicas exercidas pelos polinizadores constituem-se em um importantíssimo serviço ecossistêmico. A manutenção das 
populações vegetais nos ambientes terrestres não seria possível sem o auxílio destes organismos e, sem os frutos e sementes resultantes da polinização, estes e outros recursos provenientes das plantas não estariam disponíveis para muitas populações de animais, incluindo as populações humanas, que deles dependem.

Oitenta e sete dos principais cultivos agrícolas usados diretamente para consumo humano dependem da polinização realizada por animais, o que representa $35 \%$ da produção global de alimentos (Klein et al. 2007). Em termos econômicos, o valor da polinização realizada por insetos equivale a 153 bilhões de euros anualmente, o que corresponde a 9,5\% do valor da produção agrícola mundial voltada à alimentação humana (Gallai et al. 2009). Assim, uma parte considerável da produção e da diversidade da agricultura resulta do serviço realizado pelos polinizadores, sendo as abelhas sem dúvida alguma os principais agentes transportadores de pólen. No entanto, apesar das mais de 17.000 espécies de abelhas existentes no mundo (Michener 2007), apenas uma espécie - a abelha africanizada, Apis mellifera - é manejada comercialmente em grande escala tanto pelos seus serviços como polinizadora quanto pela produção de mel.

Tamanha dependência em uma única espécie como polinizadora da maior parte dos cultivos agrícolas dependentes de agentes bióticos apresenta, contudo, riscos crescentes (Winfree 2008; Aizen \& Harder 2009). O número de colônias de A. mellifera, tanto domesticadas quanto selvagens, tem caído regularmente ao menos nos Estados Unidos e em alguns países europeus (Allen-Wardell et al. 1998; Kearns et al. 1998), por motivos variados como infestação por ácaros parasitas (Varroa sp.), uso intensivo de pesticidas e, mais recentemente, a Desordem do Colapso das Colônias. Somado a isso, as populações de abelhas nativas também tem declinado por todo o mundo (Allen-Wardell et al. 1998; Kearns et al. 1998; Kremen \& Ricketts 2000; Biesmeijer et al. 2006) devido principalmente à perda e fragmentação de habitat e intensificação da agricultura (Ricketts et al. 2008; Winfree et al. 2009; Winfree et al. 2011). Paralelamente, nossa agricultura tem se tornado cada vez mais dependente dos polinizadores devido ao aumento desproporcional da área dedicada a cultivos que precisam destes agentes (Aizen et al. 2008); e embora o rendimento destes tipo de cultivos ainda não tenha sido afetado pelo declínio das abelhas (Aizen et al. 2008, 2009; Winfree 2008), é grande a preocupação com o risco crescente de escassez de alimentos provocado por uma eventual crise global de polinizadores.

Considerando que a biodiversidade é essencial para a conservação do serviço de polinização (Kremen et al. 2002), o papel da restauração ecológica neste contexto deve ser mais uma vez destacado: a recuperação da vegetação nativa proporciona locais de nidificação e recursos florais para abelhas nativas que irão utilizar também os recursos dos cultivos agrícolas, permitindo assim a manutenção da polinização em ecossistemas nativos, restaurados e manejados. 


\section{Contexto regional}

\subsection{A degradação ambiental e o papel da restauração no Estado de São Paulo}

São Paulo é o estado mais populoso, mais industrializado e com a maior economia do país. Seu histórico de ocupação e uso intensivo da terra levou à degradação acentuada da vegetação nativa e, por isso, a cobertura vegetal remanescente ocupa atualmente $14 \%$ da superfície do território e encontra-se altamente fragmentada (Instituto Florestal, 2005). Na região nordeste do estado, um importante polo agropecuário, a situação da vegetação nativa é ainda mais precária.

Em Ribeirão Preto por exemplo, um dos mais relevantes polos econômicos e também o mais populoso município da região, a maior parte da vegetação existente foi substituída ainda na época do ciclo do café no século XIX. Entre 1962 e 2000, houve redução de 70\% (ca. 6.700 ha) da vegetação natural restante (Kotchetkoff-Henriques 2003). Neste período, a intensificação da monocultura de cana-de-açúcar resultou na cobertura vegetal do município ficando restrita a apenas 3,89\% (ca. 2.535 ha) de sua área e dispersa, na sua maior parte, em fragmentos com área inferior a 10 ha (KotchetkoffHenriques, Joly \& Bernacci 2005). Com a monocultura de cana-de-açúcar sendo a principal atividade agrícola da região, a vegetação nativa dos demais municípios do nordeste paulista encontra-se em condições semelhantes (Rodrigues \& Hott 2010).

Frente a este quadro de degradação das matas nativas da região, a restauração ecológica precisa enfrentar não somente a ameaça da perda de espécies, mas também o risco crescente do desaparecimento da variabilidade genética dos organismos. Contudo, a disponibilidade de mudas de alta qualidade é ainda um grande gargalo nas atividades restauradoras. Uma iniciativa implantada na cidade de Ribeirão Preto entre 1998 e 2004, a Floresta da USP, teve como objetivo aumentar a cobertura vegetal do município (seus 75 ha representaram um aumento de $20 \%$ da área verde urbana) e formar um banco genético de espécies nativas que fornecesse mudas com qualidade genética para projetos de recomposição vegetal de toda a região. Infelizmente, a área de 45 ha que continha 3375 progênies diferentes - foram produzidas mudas de 75 matrizes para cada uma das 45 espécies implantadas - já sofreu dois incêndios de grandes proporções que juntos afetaram mais de $85 \%$ do único Banco Genético de Floresta Estacional Semidecidual do Brasil. Este exemplo, embora local, demonstra apenas alguns dentre os vários obstáculos que os praticantes da restauração enfrentam continuamente.

Estas e outras dificuldades reforçam a relevância e urgência de se assegurar o sucesso de programas de restauração não só nesta região, mas em todo o estado. Provavelmente por isso, São Paulo é hoje o único estado do país - e aparentemente o primeiro no mundo - onde existe legislação especifica para orientar e fiscalizar a restauração de áreas degradadas (Aronson et al. 2011). Com o objetivo de tornar mais efetiva a restauração de florestas tropicais como a Mata Atlântica, a resolução SMA 082008 (Secretaria de Meio Ambiente do Estado de São Paulo, 2008) estabelecia, entre outras coisas, 
requisitos quanto ao número mínimo de espécies nativas a ser atingido pela restauração e quanto à proporção de espécies pertencentes a determinados grupos funcionais e categorias de ameaça a serem plantadas.

A iniciativa inédita gerou, contudo, controvérsias entre os pesquisadores da área. Enquanto para alguns os instrumentos legais contribuem para o aperfeiçoamento e o estímulo das ações de restauração, servindo como mecanismo efetivo de política pública ambiental (Brancalion et al. 2010), para outros o rigor das normas constitui-se em barreira para a criatividade e iniciativa dos cientistas e restauradores, sendo o entendimento dos processos ecológicos envolvidos na restauração ainda longe de suficientemente completos para permitir legislar com segurança sobre o assunto (Durigan et al. 2010). O rico debate gerado em torno do tema (Aronson 2010; Aronson et al. 2011) permitiu, como já havia sendo feito desde as primeiras versões da resolução, continuar incorporando o conhecimento cientifico às políticas públicas: a resolução SMA 32-2014, vigente atualmente (Secretaria de Meio Ambiente do Estado de São Paulo, 2014), obedece aos mesmos princípios ecológicos da resolução anterior mas se tornou mais flexível, buscando superar os problemas apontados anteriormente.

Considerando-se o diálogo contínuo entre legisladores e cientistas na busca do aprimoramento de leis e políticas públicas - um evento, infelizmente, ainda raro em outros setores - e as iniciativas crescentes de restauração da Mata Atlântica (Rodrigues et al. 2009, 2011), a ecologia da restauração no estado de São Paulo encontra-se em um momento crítico. Quanto mais numerosas e melhores as avaliações das práticas e dos resultados da restauração, maiores serão as evidências disponibilizadas para contribuir na tomada de decisões.

\section{Justificativa do estudo}

\subsection{Porque investigar a polinização e os polinizadores na restauração de florestas tropicais}

O objetivo de qualquer ciência aplicada é o sucesso da prática que ela orienta. Mas para que se alcance o êxito esperado, uma grande quantidade de dados e informações precisa ser acumulada para melhor entendermos e orientarmos a prática. Lamentavelmente, a avaliação e o monitoramento de áreas restauradas ainda são raros, limitando a geração de informações potencialmente importantes para a ecologia da restauração.

Segundo o Primer on Ecological Restoration da SER (2004), existem três estratégias principais de avaliação de áreas restauradas: sua comparação direta com ecossistemas de referência, a análise de tendências que demonstrem a trajetória da restauração, e a análise de atributos. O presente estudo propôs utilizar esta última estratégia para avaliar e comparar um conjunto de áreas restauradas por meio do plantio de mudas de árvores nativas. Neste tipo de análise, os dados obtidos são avaliados para julgar quais atributos (dentre todos aqueles esperados de uma restauração) foram ou estão sendo alcançados durante a restauração. A análise de atributos é especialmente aplicável em áreas onde a 
paisagem altamente degradada dificulta a utilização de ecossistemas de referência para comparação. Além disso, a comparação entre áreas restauradas por técnicas similares permite observar possíveis restrições das condições abióticas, da paisagem ou do histórico de distúrbio que possam estar atuando no processo (Suding 2011).

Ecossistemas são, no entanto, muito complexos, e o número de variáveis que podem ser utilizadas em uma avaliação é grande demais para ser medido em período razoável de tempo ou com quantidade razoável de recursos. Neste trabalho escolhemos investigar a restauração do processo ecológico da polinização devido a sua extrema importância para o funcionamento de qualquer ecossistema e por sua relevância como serviço ecossistêmico (item 1.3). Além disso, a avaliação do resgate de funções, processos e serviços ecológicos é primordial para a ecologia da restauração visto que a maioria dos estudos até hoje tem focado na composição de espécies vegetais apenas (Ruiz-Jaen \& Aide 2005).

Como declarado nos apelos de Bawa et al. (2004) e Palmer et al. (2004), os impactos humanos no ambiente irão apenas crescer e a ciência ecológica precisa buscar urgentemente um melhor entendimento destes ecossistemas alterados bem como trabalhar em soluções de conservação, restauração e até mesmo invenção de sistemas ecológicos que forneçam serviços vitais. Este trabalho visa então estimular um pensamento mais holístico que permita incorporar a preocupação com a polinização e os polinizadores na restauração de florestas tropicais.

\section{Objetivos e estrutura da tese}

O objetivo deste trabalho é investigar a resposta dos insetos polinizadores e da polinização à restauração por plantio de mudas de Floresta Estacional Semidecidual. Para isso a tese foi dividida em cinco capítulos. Neste primeiro capítulo buscou-se apresentar um panorama geral da importância da restauração ecológica e do serviço de polinização para os ecossistemas e para a sociedade. Nos três capítulos seguintes, foram examinados diferentes aspectos das comunidades de plantas e visitantes florais em seis áreas em processo de restauração. O segundo capítulo procura analisar a estrutura da comunidade de visitantes florais e seus padrões de visita às flores, avaliando também se a proximidade de fragmentos de vegetação nativa é importante na determinação da estrutura das comunidades formada em cada área. $\mathrm{O}$ terceiro capítulo investiga as espécies vegetais que florescem nos estágios iniciais de restauração e verifica se a estrutura da comunidade de plantas se restabelecendo em cada local é importante na determinação da estrutura da comunidade de visitantes florais. O quarto capítulo avalia o restabelecimento do processo de polinização ao averiguar o transporte de pólen ocorrendo nas áreas restauradas e ao examinar a robustez das redes formadas à possível extinção de espécies. No quinto capítulo a tese é finalizada com uma discussão geral de todos os temas abordados. 


\section{Referências Bibliográficas}

Aizen, M.A., Garibaldi, L.A., Cunningham, S.A. \& Klein, A.M. (2008) Long-term global trends in crop yield and production reveal no current pollination shortage but increasing pollinator dependency. Current biology, 18, 1572-1575.

Aizen, M.A., Garibaldi, L.A, Cunningham, S.A. \& Klein, A.M. (2009) How much does agriculture depend on pollinators? Lessons from long-term trends in crop production. Annals of botany, 103, 15791588.

Aizen, M.A. \& Harder, L.D. (2009) The global stock of domesticated honey bees is growing slower than agricultural demand for pollination. Current biology, 19, 915-918.

Allen-Wardell, G., Bernhardt, P., Bitner, R., Burquez, A., Buchmann, S., Cane, J., Cox, P., Dalton, V., Feinsinger, P., Ingram, M., Inouye, D., Jones, E., Kennedy, K., Kevan, P., Koopowitz, H., Medelin, R., Medellin-Morales, S., Nabhan, G., Pavlik, B., Tepedino, V., Torchio, P. \& Walker, S. (1998) The potential consequences of pollinator declines on the conservation of biodiversity and stability of food crop yields. Conservation Biology, 12, 8-17.

Aronson, J. (2010) What can and should be legalized in ecological restoration? Revista Árvore, 34, 451454.

Aronson, J., Brancalion, P.H.S., Durigan, G., Rodrigues, R.R., Engel, V.L., Tabarelli, M., Torezan, J.M.D., Gandolfi, S., Melo, A.C.G., Kageyama, P.Y., Marques, M.C.M., Nave, A.G., Martins, S. V., Gandara, F.B., Reis, A., Barbosa, L.M. \& Scarano, F.R. (2011) What role should government regulation play in ecological restoration? Ongoing debate in São Paulo State, Brazil. Restoration Ecology, 19, 690-695.

Bawa, K. (1990) Plant-pollinator interactions in tropical rain forests. Annual Review of Ecology and Systematics, 21, 399-422.

Bawa, K., Bullock, S., Perry, D., Coville, R. \& Grayum, M. (1985a) Reproductive biology of tropical lowland rain forest trees. II: Pollination systems. American journal of botany, 72, 346-356.

Bawa, K., Kress, W., Nadkarni, N., Lele, S., Raven, P., Janzen, D., Lugo, A., Ashton, P. \& Lovejoy, T. (2004) Tropical ecosystems into the 21st century. Science, 306, 21-24.

Bawa, K., Perry, D. \& Beach, J. (1985b) Reproductive biology of tropical lowland rain forest trees. I. Sexual systems and incompatibility mechanisms. American journal of botany, 72, 331-345.

Biesmeijer, J.C., Roberts, S.P.M., Reemer, M., Ohlemüller, R., Edwards, M., Peeters, T., Schaffers, A.P., Potts, S.G., Kleukers, R., Thomas, C.D., Settele, J. \& Kunin, W.E. (2006) Parallel declines in pollinators and insect-pollinated plants in Britain and the Netherlands. Science, 313, 351-354.

Brancalion, P.H.S., Rodrigues, R., Gandolfi, S., Kageyama, P., Nave, A., Gandara, F., Barbosa, L. \& Tabarelli, M. (2010) Instrumentos legais podem contribuir para a restauração de florestas tropicais biodiversas. Revista Árvore, 34, 455-470.

Brudvig, L.A. (2011) The restoration of biodiversity: where has research been and where does it need to go? American journal of botany, 98, 549-558.

Chazdon, R. (2008) Beyond deforestation: restoring forests and ecosystem services on degraded lands. Science, 320, 1458-1460. 
Clewell, A. \& Rieger, J.P. (1997) What practitioners need from restoration ecologists. Restoration Ecology, 5, 350-354.

Durigan, G., Engel, V.L., Torezan, J.M, Melo, A.C.G, Marques, M.C.M, Martins, S.V., Reis, A. \& Scarano, F.R. (2010) Normas jurídicas para a restauração ecológica: uma barreira a mais a dificultar o êxito das iniciativas. Revista Árvore, 34, 471-485.

Ehrenfeld, J.G. (2000) Defining the limits of restoration: the need for realistic goals. Restoration Ecology, 8, 2-9.

Ehrenfeld, J.G. \& Toth, L. A. (1997) Restoration ecology and the ecosystem perspective. Restoration Ecology, 5, 307-317.

FAO \& JRC (2012) Global forest land-use change 1990-2005, by E.J. Lindquist, R. D’Annunzio, A. Gerrand, K. MacDicken, F. Achard, R. Beuchle, A. Brink, H.D. Eva, P. Mayaux, J. San-Miguel-Ayanz \& H-J. Stibig. FAO Forestry Paper No. 169. Food and Agriculture Organization of the United Nations and European Commission Joint Research Centre. Rome, FAO.

Fischer, J. \& Lindenmayer, D.B. (2007) Landscape modification and habitat fragmentation: a synthesis. Global Ecology and Biogeography, 16, 265-280.

Gallai, N., Salles, J.-M., Settele, J. \& Vaissière, B.E. (2009) Economic valuation of the vulnerability of world agriculture confronted with pollinator decline. Ecological Economics, 68, 810-821.

Godefroid, S., Piazza, C., Rossi, G., Buord, S., Stevens, A.-D., Aguraiuja, R., Cowell, C., Weekley, C.W., Vogg, G., Iriondo, J.M., Johnson, I., Dixon, B., Gordon, D., Magnanon, S., Valentin, B., Bjureke, K., Koopman, R., Vicens, M., Virevaire, M. \& Vanderborght, T. (2011) How successful are plant species reintroductions? Biological Conservation, 144, 672-682.

Godefroid, S. \& Vanderborght, T. (2011) Plant reintroductions: the need for a global database. Biodiversity and Conservation, 20, 3683-3688.

Hobbs, R.J., Hallett, L.M., Ehrlich, P.R. \& Mooney, H. A. (2011) Intervention Ecology: applying ecological science in the twenty-first century. BioScience, 61, 442-450.

Hobbs, R., Higgs, E. \& Harris, J. (2009) Novel ecosystems: implications for conservation and restoration. Trends in ecology \& evolution, 24, 599-605.

Holl, K., Crone, E. \& Schultz, C. (2003) Landscape restoration: moving from generalities to methodologies. BioScience, 53, 491-502.

Instituto Florestal (2005) Inventário florestal da vegetação natural do Estado de São Paulo. São Paulo: Imprensa oficial.

Jackson, S.T. \& Hobbs, R.J. (2009) Ecological restoration in the light of ecological history. Science, 325, 567-569.

Jones, H.P. \& Schmitz, O.J. (2009) Rapid recovery of damaged ecosystems. PloS one, 4, e5653.

Kearns, C., Inouye, D. \& Waser, N. (1998) Endangered mutualisms: the conservation of plant-pollinator interactions. Annual Review of Ecology and Systematics, 29, 83-112.

Klein, A.-M., Vaissière, B.E., Cane, J.H., Steffan-Dewenter, I., Cunningham, S.A, Kremen, C. \& Tscharntke, T. (2007) Importance of pollinators in changing landscapes for world crops. Proceedings of The Royal Society B: Biological sciences, 274, 303-313. 
Kotchetkoff-Henriques, O. (2003) Caracterização da vegetação natural em Ribeirão Preto, SP: bases para conservação. Tese (Doutorado em Biologia Comparada) - Faculdade de Filosofia, Ciências e Letras de Ribeirão Preto, Ribeirão Preto, 221p.

Kotchetkoff-Henriques, O., Joly, C. \& Bernacci, L. (2005) Relação entre o solo ea composição florística de remanescentes de vegetação natural no município de Ribeirão Preto, SP. Revista Brasileira de Botanica, 28, 541-562.

Kremen, C. \& Ricketts, T. (2000) Global perspectives on pollination disruptions. Conservation Biology, 1226-1228.

Kremen, C., Williams, N.M. \& Thorp, R.W. (2002) Crop pollination from native bees at risk from agricultural intensification. Proceedings of the National Academy of Sciences of the United States of America, 99, 16812-16816.

Michener, C. (2007) The Bees of the World, second ed. The Johns Hopkins University Press, Baltimore.

Millennium Ecosystem Assessment (2005) Ecosystems and Human Well-being: Synthesis. Island Press, Washington, DC.

Montoya, D., Zavala, M., Rodríguez, M. \& Purves, D. (2008) Animal versus wind dispersal and the robustness of tree species to deforestation. Science, 320, 1502-1504.

Nellemann, C., MacDevette, M., Manders, T., Eickhout, B., Svihus, B., Prins, A. G., Kaltenborn, B. P. (Eds) (2009) The environmental food crisis - The environment's role in averting future food crises. A UNEP rapid response assessment. United Nations Environment Programme, GRIDArendal, www.grida.no

Ollerton, J., Winfree, R. \& Tarrant, S. (2011) How many flowering plants are pollinated by animals? Oikos, 120, 321-326.

Palmer, M., Bernhardt, E., Chornesky, E., Collins, S., Dobson, A., Duke, C., Gold, B., Jacobson, R., Kingsland, S., Kranz, R., Mappin, M., Martinez, M.L., Micheli, F., Morse, J., Pace, M., Pascual, M., Palumbi, S., Reichman, O.J., Simons, A., Townsend, A. \& Turner, M. (2004) Ecology for a crowded planet. Science, 304, 1251-1252.

Palmer, M. A \& Filoso, S. (2009) Restoration of ecosystem services for environmental markets. Science, 325, 575-576.

Rey Benayas, J.M., Newton, A.C., Diaz, A. \& Bullock, J.M. (2009) Enhancement of biodiversity and ecosystem services by ecological restoration: a meta-analysis. Science, 325, 1121-1124.

Ribeiro, M.C., Metzger, J.P., Martensen, A.C., Ponzoni, F.J. \& Hirota, M.M. (2009) The Brazilian Atlantic Forest: How much is left, and how is the remaining forest distributed? Implications for conservation. Biological Conservation, 142, 1141-1153.

Ricketts, T.H., Regetz, J., Steffan-Dewenter, I., Cunningham, S. A, Kremen, C., Bogdanski, A., GemmillHerren, B., Greenleaf, S.S., Klein, A.M., Mayfield, M.M., Morandin, L. A, Ochieng', A., Potts, S.G. \& Viana, B.F. (2008) Landscape effects on crop pollination services : are there general patterns? Ecology letters, 11, 499-515.

Roberts, L., Stone, R. \& Sugden, A. (2009) The rise of restoration ecology. Science, 325, 555.

Rodrigues, A., Andelman, S. \& Bakarr, M. (2004) Effectiveness of the global protected area network in representing species diversity. Nature, 428, 640-643. 
Rodrigues, R.R., Gandolfi, S., Nave, A.G., Aronson, J., Barreto, T.E., Vidal, C.Y. \& Brancalion, P.H.S. (2011) Large-scale ecological restoration of high-diversity tropical forests in SE Brazil. Forest Ecology and Management, 261, 1605-1613.

Rodrigues, C. \& Hott, M. (2010) Dinâmica da vegetação natural no nordeste do estado de São Paulo, entre 1988 e 2003. Revista Árvore, 34, 881-887.

Rodrigues, R.R., Lima, R. A. F., Gandolfi, S. \& Nave, A.G. (2009) On the restoration of high diversity forests: 30 years of experience in the Brazilian Atlantic Forest. Biological Conservation, 142, $1242-1251$.

Ruiz-Jaen, M.C. \& Aide, T.M. (2005) Restoration success: How is it being measured? Restoration Ecology, 13, 569-577.

Secretaria de Meio Ambiente do Estado de São Paulo (2008) Resolução no 08 de 31 de janeiro de 2008. Fixa a orientação para o reflorestamento heterogêneo de áreas degradadas e dá providências correlatas. Diário Oficial do Estado de São Paulo, São Paulo, 01/02/2008.

Secretaria de Meio Ambiente do Estado de São Paulo (2014) Resolução no 32 de 03 de abril de 2014. Estabelece as orientações, diretrizes e critérios sobre restauração ecológica no Estado de São Paulo, e dá providências correlatas. Diário Oficial do Estado de São Paulo, São Paulo, 05/04/2014.

Shackelford, N., Hobbs, R.J., Burgar, J.M., Erickson, T.E., Fontaine, J.B., Laliberté, E., Ramalho, C.E., Perring, M.P. \& Standish, R.J. (2013) Primed for change: developing ecological restoration for the 21st Century. Restoration Ecology, 21, 297-304.

Society for Ecological Restoration International Science and Policy Working Group (2004) The SER International Primer on Ecological Restoration. Society for Ecological Restoration International, Tucson, AZ.

Suding, K.N. (2011) Toward an era of restoration in ecology: successes, failures, and opportunities ahead. Annual Review of Ecology, Evolution, and Systematics, 42, 465-487.

Swift, T.L. \& Hannon, S.J. (2010) Critical thresholds associated with habitat loss: a review of the concepts, evidence, and applications. Biological reviews of the Cambridge Philosophical Society, $85,35-53$.

Tabarelli, M., Silva, J. da \& Gascon, C. (2004) Forest fragmentation, synergisms and the impoverishment of neotropical forests. Biodiversity \& Conservation, 13, 1419-1425.

Winfree, R. (2008) Pollinator-dependent crops: an increasingly risky business. Current biology, 18, R968-969.

Winfree, R., Aguilar, R., Vázquez, D., LeBuhn, G. \& Aizen, M.A. (2009) A meta-analysis of bees' responses to anthropogenic disturbance. Ecology, 90, 2068-2076.

Winfree, R., Bartomeus, I. \& Cariveau, D.P. (2011) Native Pollinators in Anthropogenic Habitats. Annual Review of Ecology, Evolution, and Systematics, 42, 1-22.

Wuethrich, B. (2007) Reconstructing Brazil's Atlantic Rainforest. Science, 315, 1070-1072. 


\section{AVALIAÇÃO DA ESTRUTURA DA COMUNIDADE DE PLANTAS E SEUS VISITANTES FLORAIS EM ÁREAS RESTAURADAS DE Floresta Estacional Semidecidual}

\section{Introdução}

A restauração ecológica vem exercendo um importante papel na recuperação de ecossistemas degradados e na conservação da biodiversidade, permitindo a manutenção de processos ecológicos e serviços ecossistêmicos (Chazdon 2008; Palmer \& Filoso 2009; Rey Benayas et al. 2009) essenciais para a continuação da vida na Terra. Para cumprir tal tarefa, a ecologia da restauração vem crescendo rapidamente nos últimos anos e, apesar de ainda bastante jovem, já alterou seu foco primário na recuperação dos aspectos estruturais da biodiversidade para o resgate de aspectos funcionais (Hobbs et al. 2009, 2011, Suding 2011).

Na prática, contudo, restaurar a composição de espécies vegetais é um dos objetivos mais concretos da restauração e talvez por isso continue sendo o mais implementado e avaliado (Ruiz-Jaen \& Aide 2005). Ainda assim, embora as metas específicas das atividades restauradoras variem amplamente (Ehrenfeld 2000), recuperar funções e processos ecológicos é imprescindível se almejarmos a construção de um ecossistema sustentável. A restauração das interações plantapolinizador, por exemplo, é indispensável para qualquer ambiente restaurado pois a polinização cruzada realizada pelos polinizadores permite a reprodução vegetal e a manutenção da variabilidade genética nas populações de plantas. Aproximadamente $90 \%$ das espécies de angiospermas dependem de polinização biótica (Ollerton et al. 2011), e o serviço fornecido pelos polinizadores inclui não somente a polinização de plantas nativas em ambientes naturais e restaurados, mas também a polinização de cultivos agrícolas. Trinta e cinco por cento da produção global de alimentos é dependente da polinização realizada por animais (Klein et al. 2007), dependência que só tem aumentado nas últimas décadas (Aizen et al. 2008, 2009). O papel da restauração ecológica em recuperar interações planta-polinizador é então importante não só para conservar a biodiversidade de ambientes primários, mas também para aumentar nossa segurança alimentar.

As interações entre plantas e seus polinizadores podem, todavia, não se restabelecerem automaticamente nas áreas restauradas se as populações de polinizadores não encontrarem lá todos os requisitos ambientais necessários à sua sobrevivência. As abelhas, por exemplo - que são sem dúvida o grupo mais importante de polinizadores - requerem locais e materiais adequados para 
construção de ninhos e reprodução, além de pólen e néctar como alimento (Kevan \& Baker 1983; Winfree 2010). Durante os estágios iniciais de desenvolvimento das áreas sob restauração, diversas espécies vegetais pioneiras e alógamas já florescem (Fragoso 2009; Fragoso \& Varanda 2011) e, caso seus polinizadores não encontrem na área todos os recursos necessários, precisarão buscá-los em áreas próximas.

Contudo, estudos indicam que a abundância, a riqueza e a frequência de visitas às flores por polinizadores nativos diminuem com o aumento da distância entre estas flores e os ambientes naturais (Steffan-Dewenter \& Tscharntke 1999; Ricketts 2004; Ricketts et al. 2008; Carvalheiro et al. 2010; Viana et al. 2012; Ferreira et al. 2013). Em cultivos agrícolas, as taxas de visitação e a riqueza de visitantes declinam à sua metade a $600 \mathrm{~m}$ e $1500 \mathrm{~m}$ de distância de habitats naturais, respectivamente (Ricketts et al. 2008). Mesmo em áreas ricas em biodiversidade, abundância e riqueza de visitantes caem mais de $80 \%$ quando distantes mais de $500 \mathrm{~m}$ dos ambientes nativos (Carvalheiro et al. 2010). Embora abelhas maiores sejam capazes de voar maiores distâncias (Steffan-Dewenter \& Tscharntke 1999; Araújo et al. 2004; Greenleaf et al. 2007), a distância usual de forrageamanento de muitas abelhas costuma ser bem menor do que seu alcance máximo de voo (Pasquet et al. 2008; Zurbuchen et al. 2010). Além do tamanho do corpo, distâncias de forrageamento típicas também podem ser influenciadas por características de história de vida tais como socialidade e níveis de especialização, o que demonstra que a proximidade de poucas centenas de metros entre ninhos e recursos é crucial para a manutenção das populações de abelhas (Zurbuchen et al. 2010).

Todos estes dados mostram que os resultados alcançados pela restauração serão influenciados não só pelo histórico e características locais da área recuperada, mas também - e talvez principalmente pela composição da paisagem ao redor e conectividade entre a área restaurada e outros fragmentos (Holl et al. 2003; Brudvig 2011). Considerando que estes elementos são ainda raramente incorporados no planejamento da restauração, é de extrema importância investigar quais interações biológicas se restabelecem durante o processo de restauração para determinar se as áreas restauradas serão naturalmente colonizadas ou se reintroduções serão necessárias para recompor algumas populações. Neste trabalho, procurou-se investigar a resposta dos polinizadores à restauração de Floresta Estacional Semidecidual em seis áreas na região de Ribeirão Preto, nordeste do Estado de São Paulo, Brasil. Os objetivos específicos foram: (1) determinar a abundância, riqueza e composição de espécies de visitantes florais bem como os padrões de visitas às flores pelos insetos em cada área; (2) analisar se os padrões de visitação e a composição da comunidade de visitantes de áreas restauradas pela mesma técnica são similares e (3) avaliar se a proximidade de habitat nativo é importante na determinação da estrutura da comunidade de visitantes florais nas áreas restauradas. 


\section{Material e Métodos}

\section{1. Áreas de estudo}

As seis áreas de estudo estão localizadas em quatro municípios da região de Ribeirão Preto, nordeste do Estado de São Paulo, Brasil. A paisagem na região é altamente devastada - com menos de 17\% da área coberta por vegetação nativa (Rodrigues \& Hott 2010) - e a terra é primariamente ocupada pelo cultivo de cana-de-açúcar. Nos municípios onde o estudo foi realizado a vegetação é ainda mais fragmentada, com a área dos municípios coberta por vegetação nativa variando entre 1,57\% e 4,71\% (Instituto Florestal 2005; tabela 2.1). Todas as áreas foram previamente ocupadas por cultivos agrícolas (na maior parte do tempo cana-de-açúcar) e posteriormente abandonadas à invasão por gramíneas exóticas. Em todas elas a restauração foi iniciada por meio do plantio de mudas de espécies arbóreas nativas de Floresta Estacional Semidecidual, fisionomia pertencente ao bioma Mata Atlântica e caracterizada por demarcada sazonalidade climática (verão chuvoso seguido de prolongado período de estiagem). $\mathrm{Na}$ época do estudo as idades dos locais variavam de 5 a 10 anos e, dentre as espécies plantadas, apenas algumas do estágio pioneiro de sucessão já apresentavam flores; as demais espécies floridas consistiam em arbustos e herbáceas regenerantes. Metade das áreas restauradas foi implantada a uma distância linear maior que 1000 m do fragmento remanescente mais próximo (daqui em diante chamadas de RD1, RD2 e RD3) e a outra metade foi implantada imediatamente ao lado de fragmentos pré-existentes (chamadas de RA1, RA2 e RA3, figura 2.1).

Tabela 2.1. Localização e características das áreas restauradas.

\begin{tabular}{|c|c|c|c|c|c|}
\hline Código & Latitude & Longitude & $\begin{array}{c}\text { Data de } \\
\text { plantio }\end{array}$ & $\begin{array}{l}\text { Distância ao } \\
\text { fragmento mais } \\
\text { próximo }(\mathrm{m})\end{array}$ & $\begin{array}{c}\text { Localização (\% de } \\
\text { cobertura vegetal do } \\
\text { município*) }\end{array}$ \\
\hline RA 1 & $21^{\circ} 5.816^{\prime} \mathrm{S}$ & $48^{\circ} 4.737^{\prime} \mathrm{O}$ & 2003 & 0 & Sertãozinho $(2,32)$ \\
\hline RA 2 & $21^{\circ} 15.642^{\prime} \mathrm{S}$ & $48^{\circ} 26.453^{\prime} \mathrm{O}$ & 2007 & 0 & Monte Alto $(4,71)$ \\
\hline RA 3 & $21^{\circ} 17.970 ' S$ & $48^{\circ} 21.001^{\prime} \mathrm{O}$ & 2006 & 0 & Jaboticabal $(1,57)$ \\
\hline $\mathrm{RD} 1$ & $21^{\circ} 15.349^{\prime} \mathrm{S}$ & $48^{\circ} 24.856^{\prime} \mathrm{O}$ & 2007 & 1158 & Jaboticabal $(1,57)$ \\
\hline $\mathrm{RD} 2$ & $21^{\circ} 9.003^{\prime S}$ & $47^{\circ} 51.759^{\prime} \mathrm{O}$ & 2002 & 3000 & Ribeirão Preto $(3,28)$ \\
\hline RD 3 & $21^{\circ} 17.508^{\prime} \mathrm{S}$ & $48^{\circ} 20.992^{\prime} \mathrm{O}$ & 2005 & 1050 & Jaboticabal $(1,57)$ \\
\hline
\end{tabular}

*Dados retirados de Instituto Florestal (2005). 


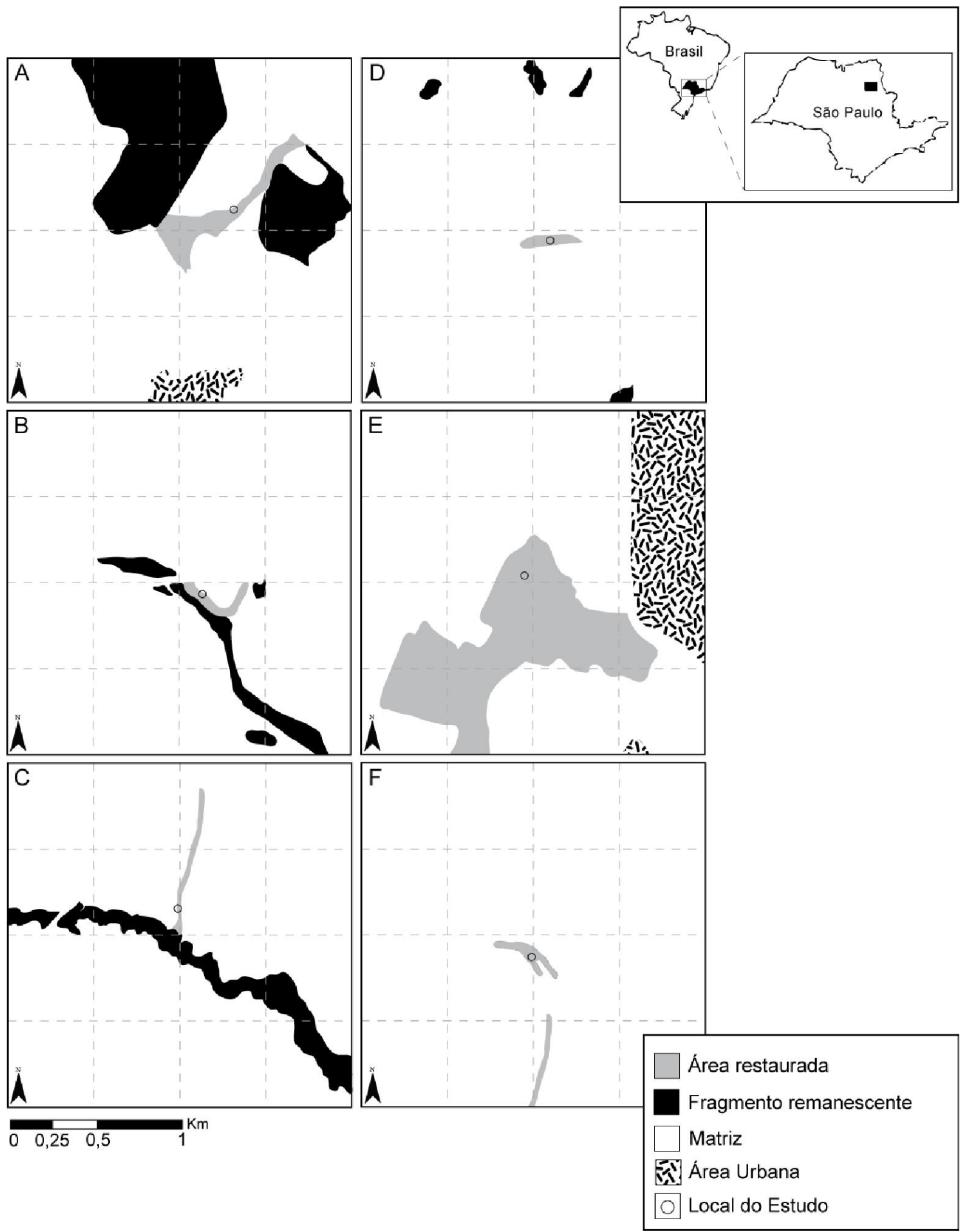

Figura 2.1. Mapa das áreas de estudo na região nordeste do Estado de São Paulo, Brasil. A- C são áreas implantadas imediatamente ao lado de fragmentos pré-existentes (RA1, RA2 e RA3 respectivamente) e D-F são áreas implantadas a uma distância linear maior que $1000 \mathrm{~m}$ do fragmento remanescente mais próximo (RD1, RD2 e RD3 respectivamente). A matriz é composta predominantemente por cultivos de cana-de-açúcar. Outras informações a respeito das áreas encontram-se na tabela 2.1. 


\subsection{Amostragem}

Plantas floridas, visitantes florais e suas interações foram registrados entre dezembro de 2011 e outubro de 2012 em expedições de campo bimestrais. Em cada local foram estabelecidos 5 transectos de aproximadamente 50 metros, totalizando cerca de 250 metros, situados sempre perpendicularmente à borda para que em todos os locais fossem amostradas proporções semelhantes de borda e interior de cada área. As amostragens foram todas realizadas em dias secos, ensolarados e com ventos moderados. Imediatamente antes de cada sessão de coleta, foram registradas as espécies em floração em cada transecto; quando possível as espécies foram identificadas in situ e para as demais foram preparadas exsicatas para posterior identificação. Após este registro, dois coletores caminharam pelos transectos alternadamente durante períodos de 30 minutos a cada hora entre 07h30 e 16h30; quando não era possível completar todos os transectos dentro de 30 minutos, a amostragem no próximo período continuava do ponto onde havia parado no período anterior. Os visitantes observados nas flores foram capturados com rede entomológica na ordem em que foram avistados e cada coletor permaneceu no máximo cinco minutos em cada planta florida. Os insetos coletados foram colocados em câmaras mortíferas contendo acetato de etila e a espécie vegetal sendo visitada foi registrada para se obter os dados de visitação. Em laboratório, todos os espécimes foram triados e identificados até o menor nível taxonômico possível.

\subsection{Análise dos dados}

Os dados bimestrais coletados em cada área foram agrupados e usados para construir seis redes de interação planta-visitante floral. A utilização de redes de interação tem se mostrado uma ferramenta bastante útil nos estudos de restauração das interações entre plantas e seus polinizadores (Forup \& Memmott 2005; Forup et al. 2008; Bazarian 2010; Williams 2011; Devoto et al. 2012). Para caracterizar a estrutura de cada rede foram calculadas as seguintes métricas: (1) riqueza de plantas floridas e de insetos visitantes; (2) abundância de insetos visitantes; (3) conectância; (4) diversidade de interações; (5) equabilidade de interações; (6) número de compartimentos; (7) aninhamento e (8) nível de especialização.

A conectância mede a proporção entre o número de interações realizadas e o número total de interações possíveis, gerando uma medida de generalização de cada rede. Ela tem sido utilizada para caracterizar as redes de interação em comunidades diversas em vários tipos de ambiente (Biesmeijer et al. 2005; Forup \& Memmott 2005; Forup et al. 2008; Pigozzo \& Viana 2010; Williams 2011). A diversidade de interações é medida aplicando-se o índice de diversidade de Shannon à matriz de interação e considerando cada interação (que ocorre em diferentes frequências na rede) como uma espécie em dada comunidade (que ocorre em diferentes abundâncias). Da mesma maneira, a equabilidade de interações é calculada aplicando-se a equabilidade de Shannon às ligações da matriz, e pode ser considerada como uma medida de uniformidade do fluxo de energia dentro da rede 
(Tylianakis et al. 2007). O número de compartimentos é uma medida da modularidade da rede; cada compartimento é um subgrupo da rede não conectado com outro compartimento e representa portanto um grupo de espécies que são mais ligadas entre si (Lewinsohn \& Prado 2006). O aninhamento está relacionado à organização das redes mutualísticas, que em geral são altamente aninhadas (Bascompte et al. 2003) porque os especialistas interagem com espécies que formam subgrupos bem definidos das espécies com as quais os generalistas interagem. Aqui, o aninhamento é expresso como temperatura (Dormann et al. 2008), com valores variando de 0 (alto aninhamento) a 100 (organização aleatória). Por fim, o nível de especialização (H2') é uma medida que descreve até que ponto as interações observadas se desviam do total de interações esperado para cada espécie (Blüthgen et al. 2006), variando de 0 (sem especialização) a 1 (completa especialização).

Todas as seis matrizes de interação inseto-planta foram testadas entre si por meio do Teste de Mantel (Legendre \& Legendre 1998), o qual estima a associação entre matrizes independentes descrevendo o mesmo conjunto de entidades. Todos os testes foram realizados utilizando-se o índice de correlação de Spearman e 20.000 permutações. A variação na comunidade de visitantes florais das diferentes áreas foi visualizada por meio de análise de correspondência $(C A)$ seguida de análise de agrupamento hierárquico com o intuito de identificar similaridades na composição de espécies de visitantes entre as áreas de estudo. A matriz de entrada para a análise foi construída com o índice de dissimilaridade de Bray-Curtis e o método de agrupamento escolhido foi o da distância média (UPGMA - unweighted pair group method using arithmetic average). Após a ordenação e classificação das comunidades de visitantes, a significância dos grupos formados - bem como dos dois grupos de áreas delimitadas para o estudo - foi testada por meio do procedimento de permutação com múltiplas respostas (MRPP), também utilizando o índice de Bray-Curtis como medida de dissimilaridade para a abundância de espécies.

Para avaliar se a proximidade de habitat nativo foi importante na determinação da estrutura da comunidade de visitantes florais, abundância e riqueza de espécies foram comparadas entre áreas adjacentes e distantes de fragmentos por meio de testes $t$ pareados. As demais métricas das redes foram comparadas entre as duas categorias de áreas restauradas utilizando-se o teste de Wilcoxon. Para avaliar o impacto das espécies raras nos resultados obtidos, todos os testes foram realizados duas vezes, a primeira com matrizes de interação incluindo todas as morfoespécies presentes e a segunda sem as morfoespécies de ocorrência única (singletons). Como os resultados não se alteraram, são apresentados apenas aqueles incluindo todas as morfoespécies.

Todas as análises estatísticas foram efetuadas no programa R (R Development Core Team 2012), utilizando-se os pacotes bipartite (Dormann et al. 2008) para a construção das redes e cálculo de suas métricas; vegan (Oksanen 2013) para o cálculo dos índices de similaridade, testes de Mantel e MRPP; e ca (Nenadic \& Greenacre 2007), factomineR e vcd para as análises de correspondência e agrupamento. 


\section{Resultados}

No geral, foram registradas 94 espécies de plantas floridas sendo visitadas por 1244 insetos pertencentes a 224 morfoespécies, 4 ordens e 26 famílias. A riqueza de plantas floridas bem como abundância e riqueza de insetos não diferiram entre as áreas próximas e distantes de fragmentos de vegetação nativa (tabela 2.2; riqueza de plantas $t=2,87, p=0,10$; abundância de insetos $t=0,06, p=$ 0,95 ; riqueza de insetos $t=1,28, p=0,32$ ).

Insetos das ordens Hymenoptera e Diptera foram as espécies de visitantes florais dominantes em todas as áreas estudadas (figura 2.2a). Abelhas e dípteros somaram mais de $70 \%$ da abundância total de visitantes em todos os locais (figura 2.2b); dentre as abelhas, a espécie exótica Apis mellifera $\mathrm{L}$. representou grande parte da abundância total encontrada (figura 2.2c). Riqueza e abundância relativas de abelhas, vespas, dípteros e lepidópteros não diferiram entre as duas categorias de áreas de estudo (testes t: riqueza $p>0,21$; abundância $p>0,18$ ).

Os padrões de visitação de cada comunidade estudada encontram-se ilustrados nas figuras 2.3 e 2.4. Em todas as redes é aparente a grande quantidade de espécies pouco abundantes ou de ocorrência única (singletons). A diversidade de interações nas redes se relacionou à riqueza e abundância de visitantes florais, e por isso foi maior nas áreas RA3 e RD3 (tabela 2.2). A conectância foi relativamente baixa em todas as áreas, com $5 \%$ a $23 \%$ das interações possíveis sendo realizadas; os maiores valores encontrados nas áreas RD1 e RD2 provavelmente refletem a menor riqueza de plantas floridas nestes locais. 0 mesmo pode ser afirmado a respeito do aninhamento das redes, já que as maiores temperaturas - indicando redes menos aninhadas - foram encontradas nestas mesmas áreas. Os resultados sugerem que as redes de interação estão se restabelecendo igualmente em todas as áreas restauradas, já que não foram encontradas diferenças significativas entre as métricas das redes dos dois grupos de áreas restauradas (tabela 2.2; Wilcoxon $p>0,10$ ).

Considerando as interações registradas globalmente, as espécies vegetais que mais receberam visitantes foram Schinus terebinthifolius Raddi. (Anacardiaceae, nas figuras 2.3 e 2.4 registrada como p3), Croton urucurana Baill. (Euphorbiaceae, p12) e Stachytarpheta cayennensis (L.C.Rich.) Vahl (Verbenaceae, p24), que receberam 72, 64 e 35 espécies de visitantes respectivamente. No extremo oposto, 19 espécies de planta receberam visitas de apenas uma espécie de inseto e 14 espécies de planta receberam visitas de apenas duas espécies de insetos. Do ponto de vista dos visitantes florais, as abelhas Apis mellifera L. e Trigona spinipes Fabricius foram as espécies mais generalistas, tendo visitado 20 e 16 espécies de plantas respectivamente. Dentre as 224 espécies de insetos coletadas, $67 \%$ foram coletadas visitando apenas uma espécie de planta. No entanto, mais do que refletir grau de especialização, estes dados provavelmente se relacionam com a raridade das espécies coletadas, sendo a amostragem insuficiente para capturar espécies menos abundantes. Do mesmo modo, o alto valor de H2' (medida de especialização) encontrado para a rede de visitação da área RD1 
provavelmente está mais ligado à baixa riqueza de plantas e visitantes florais da área do que a uma real especialização trófica dos visitantes florais coletados.

A análise dos testes de Mantel comparando os padrões de visitação das seis áreas de estudo entre si demonstrou que todas as correlações foram significativas $(p<0,0001)$ e positivas, embora pequenas (Mantel $r<0,35$ ); o menor coeficiente foi encontrado entre RA3 e RD3 enquanto os maiores foram aqueles medidos entre RA1-RD1 e RA1-RD2 (tabela 2.3). Assim, cada matriz de interação não difere significativamente das outras cinco matrizes, e o fato de as matrizes mais relacionadas (RA1-RD1 e RA1-RD2) e menos relacionadas (RA3-RD3) entre si pertencerem a categorias distintas de áreas (implantadas próximas e distantes de fragmentos) corrobora o fato de que a estrutura das comunidades estudadas não está relacionada às distâncias entre reflorestamentos e fragmentos.

A ordenação das áreas de estudo baseada apenas na comunidade de visitantes florais demonstrou que duas áreas distantes (RD1 e RD2) e uma próxima (RA2) de fragmentos apresentaram composições de insetos visitantes muito mais semelhante entre sim do que às demais áreas (figura 2.5). De fato, a análise de agrupamento demonstrou que estas três áreas formaram um grupo distinto junto a mais dois outros grupos, o segundo formado apenas por RA1 e o terceiro por RA3 e RD3. Quando testada a relevância estatística da formação destes grupos pelo procedimento de permutação com múltiplas respostas (MRPP), houve separação marginalmente significativa entre estes conjuntos de áreas (MMRP: $A=0,11, p=0,09$ ), principalmente quando comparado aos resultados do mesmo procedimento para os grupos de áreas distantes e próximas de fragmentos (MRPP: $A=-0,02, p=0,82$ ).

Tabela 2.2. Métricas das redes de interação planta-visitante floral nas áreas restauradas.

\begin{tabular}{lcccccccc}
\hline & RA1 & RA2 & RA3 & M \pm DP & RD1 & RD2 & RD3 & M \pm DP \\
\hline riqueza de plantas floridas & 16 & 14 & 30 & $20,0 \pm 8,7$ & 7 & 10 & 27 & $14,7 \pm 10,8$ \\
riqueza de insetos visitantes & 72 & 65 & 77 & $71,3 \pm 6,0$ & 26 & 59 & 75 & $53,3 \pm 25,0$ \\
abundância de insetos visitantes & 203 & 198 & 219 & $206,7 \pm 11,0$ & 167 & 227 & 230 & $208,0 \pm 35,5$ \\
conectância & 0,09 & 0,10 & 0,05 & $0,08 \pm 0,0$ & 0,18 & 0,23 & 0,06 & $0,16 \pm 0,1$ \\
diversidade de interações & 4,15 & 3,82 & 4,47 & $4,15 \pm 0,3$ & 2,28 & 4,08 & 4,47 & $3,61 \pm 1,2$ \\
equabilidade de interações & 0,59 & 0,56 & 0,58 & $0,58 \pm 0,0$ & 0,44 & 0,64 & 0,59 & $0,55 \pm 0,1$ \\
número de compartimentos & 4,00 & 4,00 & 6,00 & $4,67 \pm 1,2$ & 4,00 & 1,00 & 6,00 & $3,67 \pm 2,5$ \\
aninhamento & 9,33 & 11,04 & 4,86 & $8,41 \pm 3,2$ & 24,36 & 29,19 & 3,94 & $19,16 \pm 13,4$ \\
especialização (H2') & 0,56 & 0,53 & 0,47 & $0,52 \pm 0,0$ & 0,72 & 0,18 & 0,55 & $0,48 \pm 0,3$ \\
\hline
\end{tabular}


- coleópteros vespas $\square$ lepidópteros $\square$ dípteros $\square$ abelhas

(a)

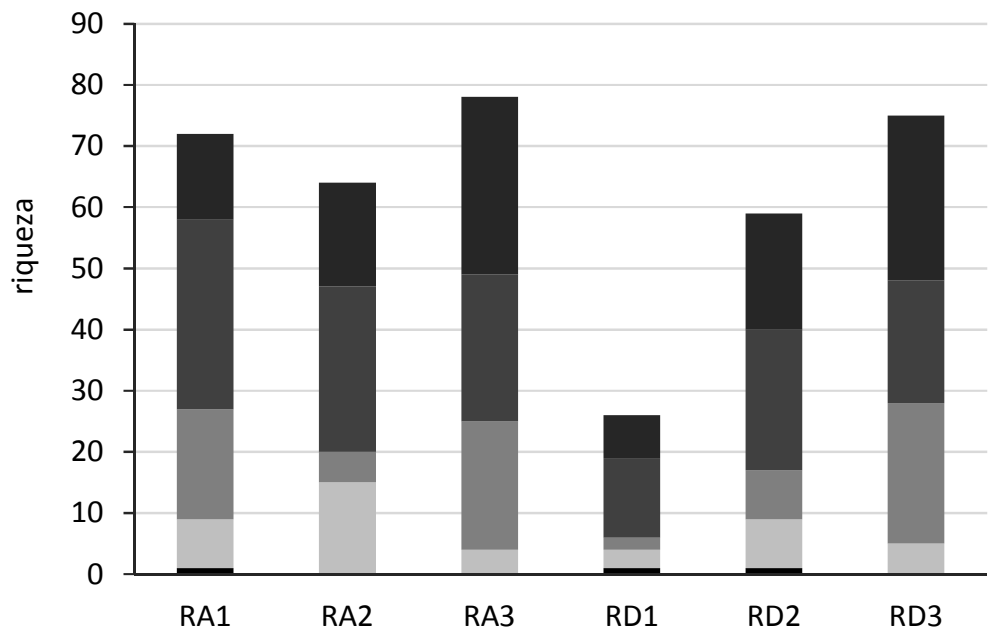

(b)

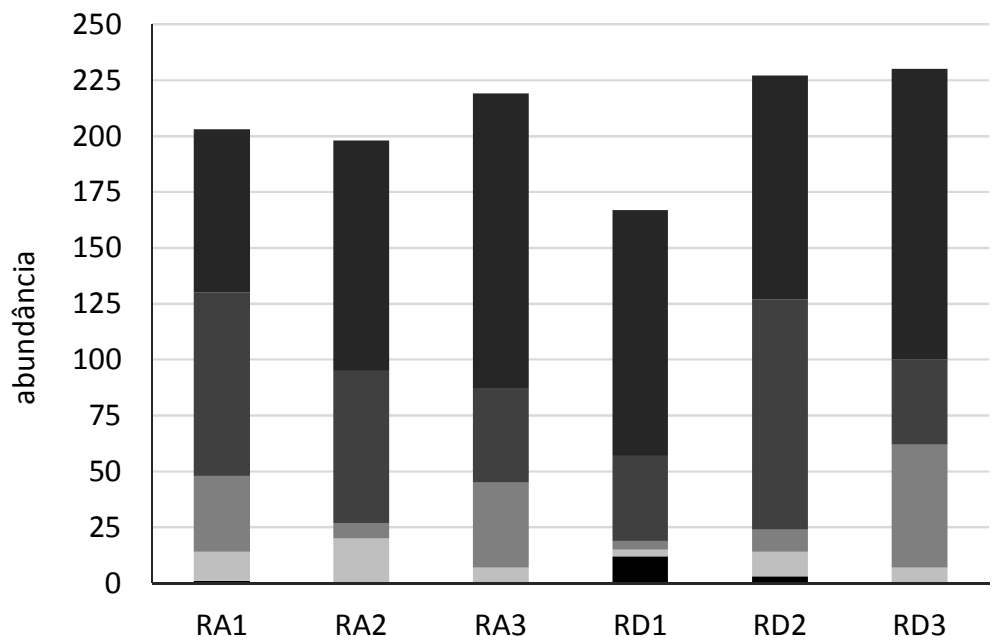

(c)

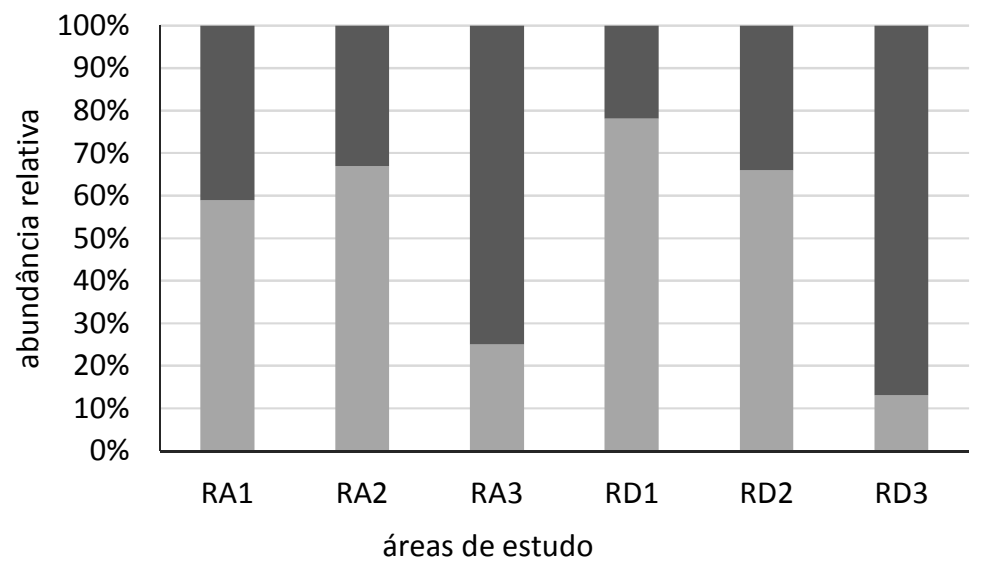

Figura 2.2. Riqueza (a) e abundância (b) de diferentes grupos de insetos visitantes em seis áreas restauradas de Floresta Estacional Semidecidual. A. melifera foi a espécie mais abundante dentre as abelhas em quatro dos seis locais de estudo (c). 


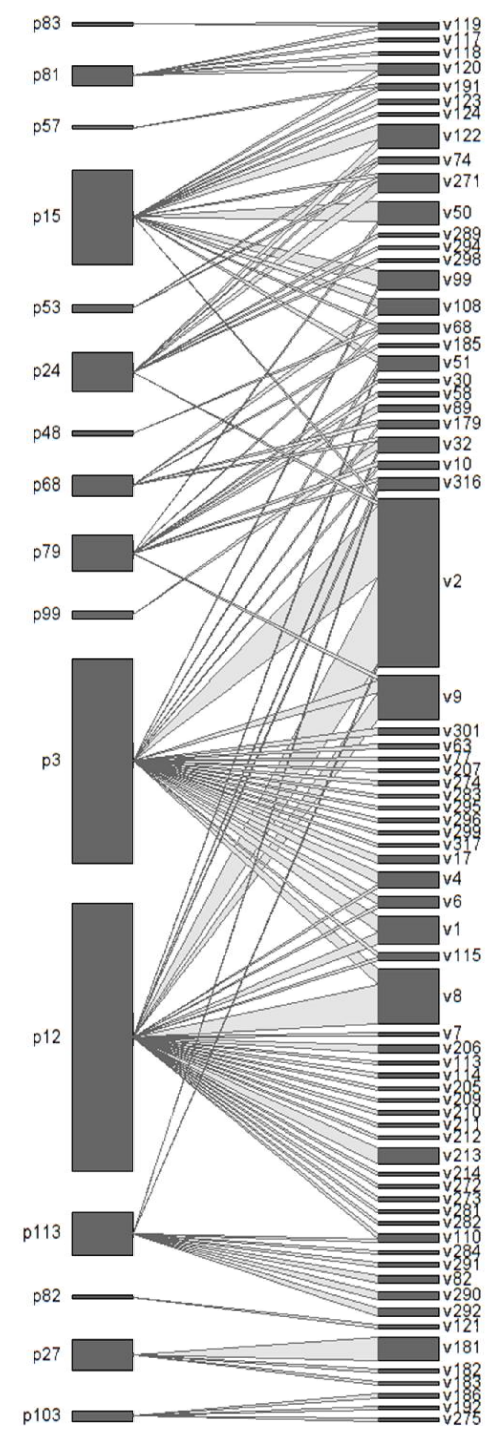

RA1

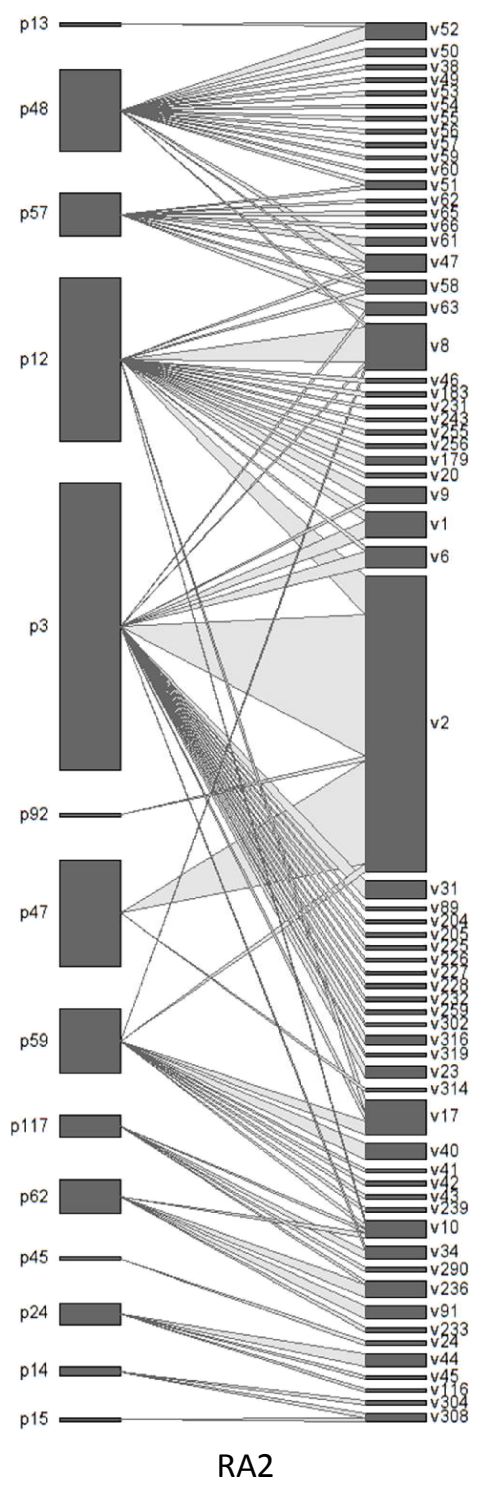

RA2

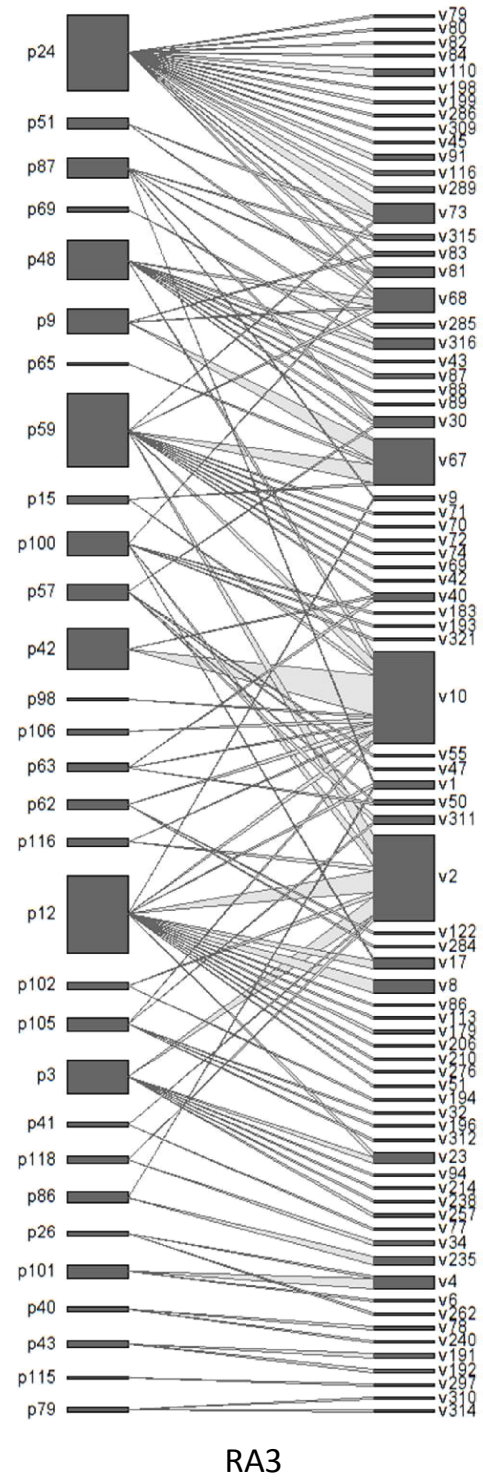

RA3

Figura 2.3. Redes de interação planta-visitante floral nas áreas implantadas imediatamente ao lado de fragmentos pré-existentes. Os retângulos à esquerda representam as espécies de plantas e os retângulos à direita representam as espécies de insetos que visitam as flores. As interações são representadas pelas ligações entre os retângulos e a frequência de cada interação é indicada pela espessura da linha. As identidades das espécies de inseto (aqui codificada por $v$ ) e de planta ( $p$ ) encontram-se listadas nos anexos 1 e 2 respectivamente. 


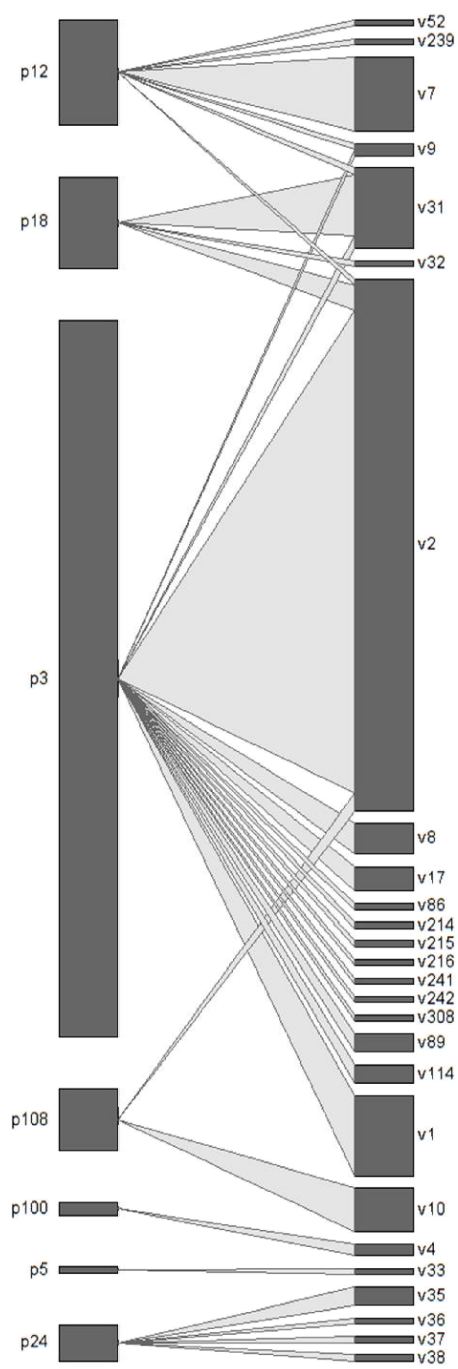

RD1

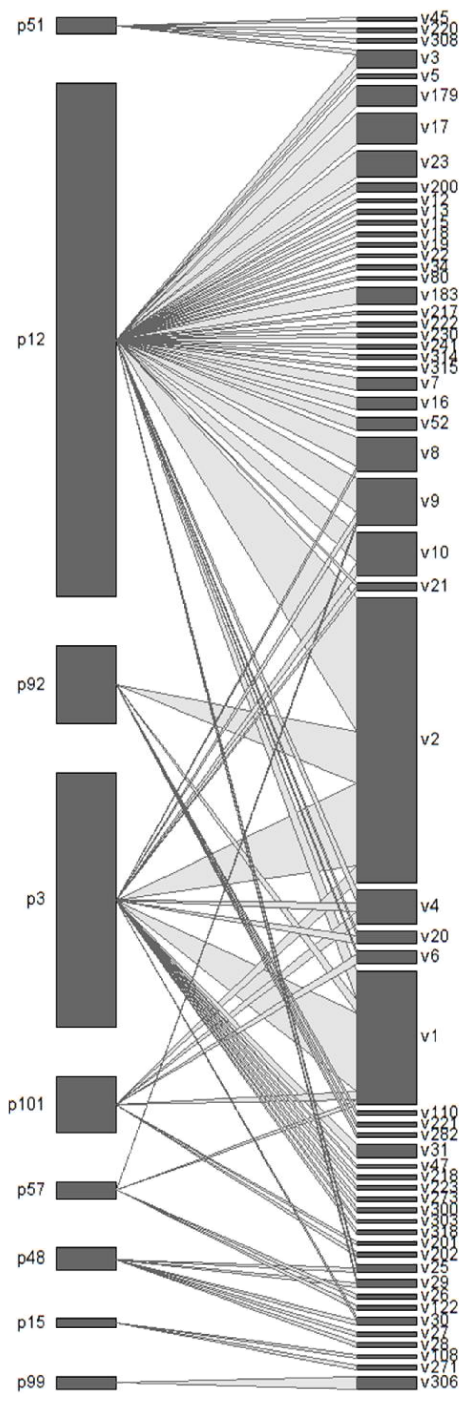

RD2

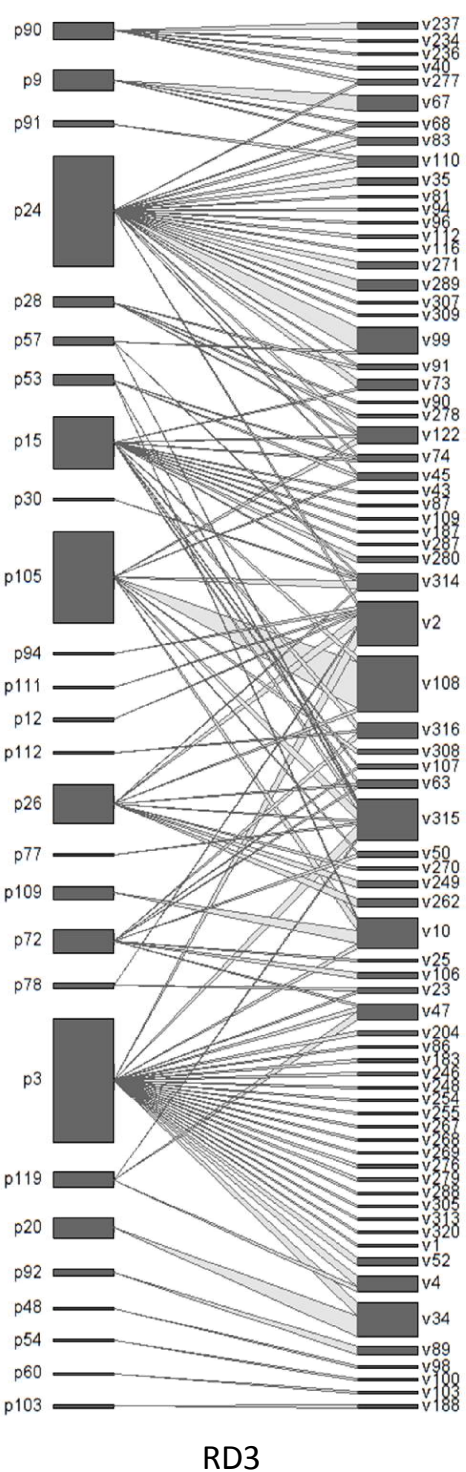

RD3

Figura 2.4. Redes de interação planta-visitante floral nas áreas implantadas a uma distância linear maior que $1000 \mathrm{~m}$ do fragmento remanescente mais próximo. Os retângulos à esquerda representam as espécies de plantas e os retângulos à direita representam as espécies de insetos que visitam as flores. As interações são representadas pelas ligações entre os retângulos e a frequência de cada interação é indicada pela espessura da linha. As identidades das espécies de inseto (aqui codificada por v) e de planta (p) encontram-se listadas nos anexos 1 e 2 respectivamente. 
Tabela 2.3. Coeficientes de correlação significativos (Mantel $r, p<0,0001$ ) dos testes de Mantel comparando os padrões de visitação das seis áreas de estudo.

\begin{tabular}{llllll}
\hline & RA1 & RA2 & RA3 & RD1 & RD2 \\
\hline RA2 & 0.2664 & & & & \\
RA3 & 0.1540 & 0.3148 & & & \\
RD1 & 0.3547 & 0.2385 & 0.1454 & & \\
RD2 & 0.3551 & 0.2982 & 0.2405 & 0.3090 & \\
RD3 & 0.1716 & 0.1068 & 0.08617 & 0.2025 & 0.1107 \\
\hline
\end{tabular}
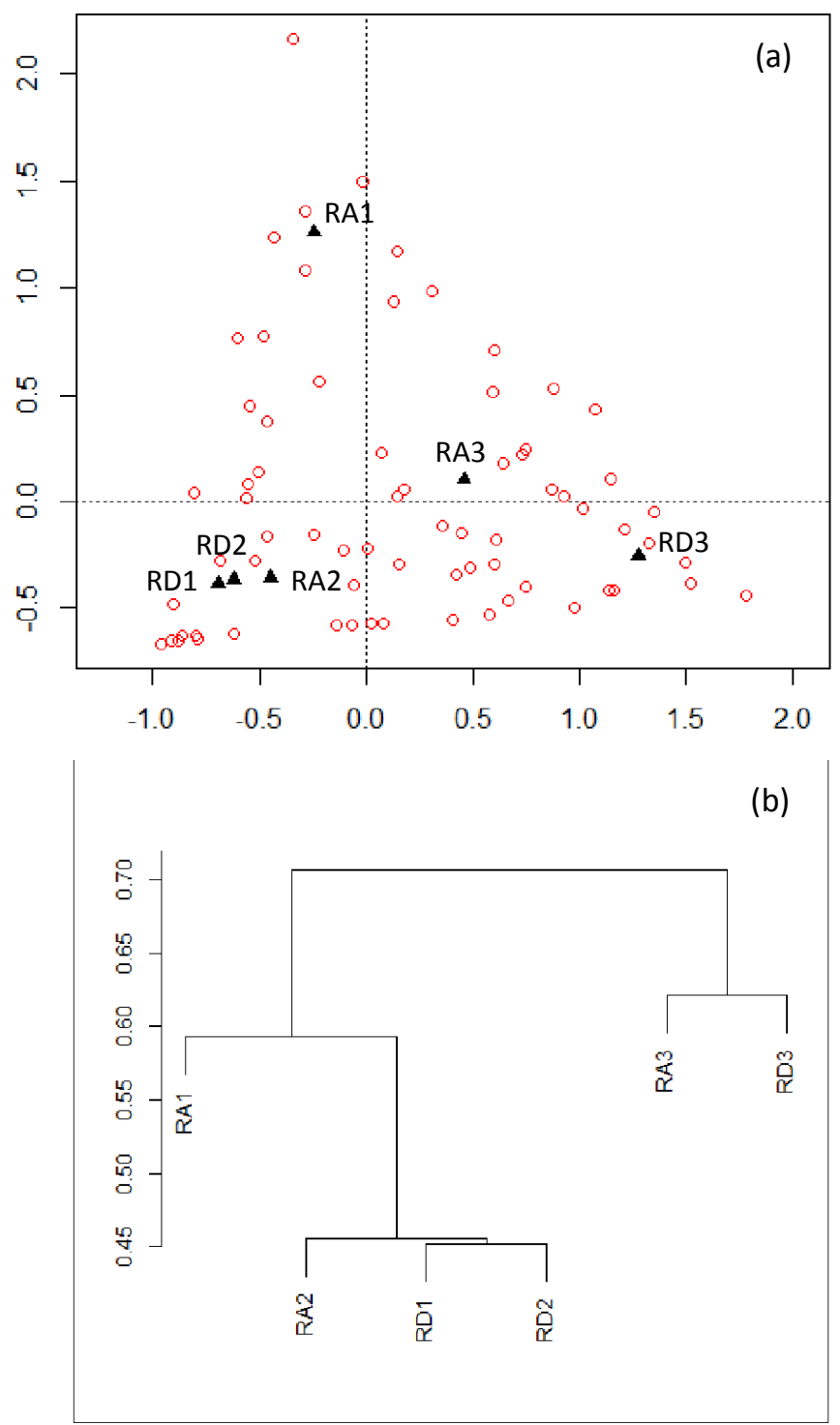

Figura 2.5. Diagrama de ordenação (a) e dendrograma dos grupos formados (b) pelas seis áreas de estudo em relação às comunidades de visitantes florais. Em (a) o eixo horizontal explica $43,44 \%$ da variação e o eixo vertical 28,45\%; círculos representam as espécies de visitantes florais e triângulos representam as áreas de estudo. Em (b) o agrupamento foi baseado no índice de dissimilaridade de Bray-Curtis utilizando o método UPGMA. 


\section{Discussão}

Nossos dados sugerem que as redes de interação planta-visitante floral estão se restabelecendo de maneira similar em todas as seis áreas estudadas. Embora estas redes não representem redes de polinização - uma vez que foram registrados visitantes e não polinizadores - elas nos dão uma ideia da base alimentar sobre a qual os insetos forrageiam bem como estimativas quantitativas dos potenciais polinizadores presentes nos locais. Se as considerarmos como uma aproximação das redes completas de interação entre plantas e polinizadores, pode-se dizer que o transporte de pólen está ocorrendo e o processo de polinização vem sendo restaurado nas áreas estudadas.

Todas as redes de interação obtidas neste estudo apresentam em suas estruturas as propriedades mais comuns e características de redes mutualísticas de polinização (Memmott 1999; Olesen et al. 2006). Como na maioria das redes já publicadas, existe um grande número de interações de baixa frequência e poucas interações muito frequentes em cada uma das comunidades. A assimetria de interações, ou seja, espécies especialistas interagindo com generalistas (Vázquez \& Aizen 2004), também parece marcante. No entanto, cabe ressaltar que nem todas as interações registradas como ocorrendo uma vez ou em baixa frequência se devem a espécies especialistas; mais provavelmente, muitas delas são espécies raras no ambiente ou simplesmente sub-amostradas. De fato, este é um problema comum quando utilizamos as métricas usuais no estudo de redes, sendo espécies raramente observadas inevitavelmente consideradas como especialistas e levando a estimativas tendenciosas de especialização (Blüthgen et al. 2008). Neste trabalho, esta tendência ficou mais acentuada na área $\mathrm{RD} 1$, onde a aparente especialização da comunidade indicada por $\mathrm{H} 2$ ' resulta na verdade da baixa riqueza de plantas floridas e visitantes florais, tornando o efeito das espécies raras mais pronunciado.

Conectância, diversidade e equabilidade de interações, aninhamento e modularidade foram outros atributos medidos que recentemente foram apontados como importantes para a conservação da estabilidade de redes (Tylianakis et al. 2010). Maiores conectância e riqueza de interações favorecem o funcionamento dos processos ecológicos e conferem maior segurança ao sistema em caso de extinção de espécies (Dunne et al. 2002); redes mais aninhadas e compartimentalizadas permitem o amortecimento dos efeitos de possíveis extinções secundárias e a propagação mais lenta de distúrbios pela rede, diminuindo a probabilidade de um evento de extinção em cascata (Tylianakis et al. 2010). No caso específico de redes de interação planta-polinizador, por exemplo, maior riqueza de interações na rede pode levar ao aumento tanto da complementaridade quanto da redundância das espécies. Restaurar o máximo possível de grupos funcionais de polinizadores (maximizando complementaridade funcional) é interessante quando se busca recuperar a polinização de toda a comunidade de plantas; por outro lado, restaurar múltiplas espécies de polinizadores capazes de polinizar a mesma planta (maximizando a redundância funcional) é importante se almejarmos a restauração específica de uma planta em particular (Devoto et al. 2012). Embora as áreas estudadas não tenham apresentado diferenças significativas nestes atributos, o aninhamento ligeiramente menor das redes nas áreas RD1 
e RD2 ou a ocorrência de um único compartimento na rede em RD2 poderiam indicar maior fragilidade nestas áreas e a possível necessidade futura de atividades de manejo específicas.

O foco puramente na conservação e restauração de espécies sozinhas não irá necessariamente preservar a estrutura de redes interativas, uma vez que estas são mais do que a soma de suas partes componentes (Lewinsohn \& Prado 2006). Todas as espécies interagem com outras em redes antagonistas ou mutualísticas; mesmo que por simplicidade a restauração ecológica invista na recuperação estrutural de espécies particulares, é preciso incorporar mais e mais a preocupação com a conservação dos aspectos funcionais das complexas redes de interação nas quais cada organismo está inserido. De fato, diversos trabalhos tem demonstrado que a restauração da estrutura é menos relevante que o resgate da funcionalidade de processos ecológicos, o que significa que não importa quais espécies estão envolvidas no processo desde que a polinização esteja ocorrendo (Forup \& Memmott 2005; Forup et al. 2008; Williams 2011). Nossos dados corroboram esta afirmação: mesmo havendo diferenças na composição da comunidade de insetos visitantes entre as áreas de estudo (figura 2.5, MMRP: $A=0,11, p=0,09$ ), não foram encontradas diferenças significativas nas métricas das redes.

O resultado da ordenação da comunidade de visitantes florais chama atenção, no entanto, para um fato interessante. Embora a estrutura das comunidades estudadas não esteja aparentemente relacionada às distâncias entre reflorestamentos e fragmentos, três das áreas de estudo (RD1, RD2 e RA2) formaram um grupo coeso separado dos demais locais estudados. Apesar da localização espacial das áreas não ter sido relevante nem na determinação da composição de espécies visitantes nem na estruturação das redes de interação, algum outro fator deve ter sido responsável pela composição de espécies mais similar entre RD1, RD2 e RA2 do que entre estas e as demais áreas. Uma possível explicação seria o tipo e/ou intensidade do manejo ao qual os locais de estudo estão sendo submetidos.

Quando os seis locais foram escolhidos para estudo, a remoção de gramíneas invasoras havia sido completada recentemente e, portanto, todas as áreas apresentavam-se em condições similares quanto a este parâmetro. Contudo, ao longo do desenvolvimento do trabalho, foi observado que a prática de remoção das gramíneas foi reduzida ou cancelada nas áreas citadas anteriormente; assim, enquanto RD1, RD2 e RA2 apresentavam o solo massivamente coberto por gramíneas africanas invasoras como Panicum maximum Jacq. Cv. (colonião) ou Brachiaria sp., as demais áreas de estudo apresentavam maior quantidade de plântulas e de outras espécies ruderais espontaneamente regenerantes. A composição da comunidade floral pode organizar a comunidade de polinizadores, já que recursos florais específicos modulariam a diversidade de espécies locais em vários níveis (Potts et al. 2003). Além disso, diferenças estruturais da vegetação podem também influenciar o microclima ou a disponibilidade de locais de nidificação para algumas espécies de polinizadores, alterando a riqueza e a abundância de indivíduos. Carvalheiro et al. (2011) constataram que uma maior diversidade de 
espécies ruderais de ocorrência natural (também chamadas de plantas daninhas) em áreas agrícolas aumenta a diversidade de visitantes florais, contrapondo os efeitos negativos do isolamento dos cultivos agrícolas em relação a habitats naturais. Do mesmo modo, os efeitos positivos da vegetação ruderal sobre os polinizadores poderia contrabalancear os efeitos negativos da distância das áreas restauradas em relação aos remanescentes de área nativa.

Por outro lado, embora exista uma clara relação positiva entre diversidade de polinizadores e proporção/proximidade de áreas naturais em paisagens agrícolas (Steffan-Dewenter \& Tscharntke 1999; Ricketts 2004; Blanche et al. 2006; Ricketts et al. 2008; Carvalheiro et al. 2010), é possível que no caso em estudo a distância entre reflorestamentos e fragmentos não seja relevante devido a situação já bastante degradada da paisagem como um todo. Em toda região de estudo restam menos de $17 \%$ de coberta vegetal nativa (Rodrigues \& Hott 2010) e, além das áreas urbanas, predomina o cultivo de cana-de-açúcar. Os poucos fragmentos de vegetação remanescente encontram-se, em sua maioria, em processo acentuado de degradação e talvez por isso já não abriguem algumas das espécies mais sensíveis aos impactos negativos destas alterações. Neste caso, dentre o "pool" de espécies disponíveis para colonizar as áreas restauradas restariam somente aquelas adaptadas a persistirem em áreas altamente fragmentadas e perturbadas.

Dentre as abelhas, que são os principais polinizadores na maioria dos ecossistemas, muitas espécies são associadas com ambientes abertos e/ou degradados. Espécies solitárias e que nidificam no solo sofrem menos o impacto da perda de habitat e isolamento (Winfree et al. 2009; Williams et al. 2010) e apesar de as abelhas responderem negativamente à modificação do uso da terra, estes efeitos são pronunciados apenas em ambientes extremamente alterados (Winfree et al. 2009; Winfree et al. 2011). Nas áreas aqui avaliadas, as abelhas foram mais abundantes dentre todos os visitantes; um estudo mais aprofundado sobre os hábitos de nidificação, especialização da dieta e níveis de socialidade dos visitantes encontrados nestes ambientes poderia esclarecer melhor a resposta de diferentes guildas de polinizadores à restauração de áreas degradadas.

De qualquer maneira, os polinizadores encontrados nas áreas de estudo devem ter vindo de outros locais porque todas elas eram ocupadas por cultivos de cana-de-açúcar anteriormente à restauração. Talvez esta paisagem agrícola, embora aparentemente hostil, contenha ainda espaços dispersos entre os campos onde vegetação herbácea ruderal sirva de recurso floral justamente para polinizadores mais generalistas menos sensíveis à perturbação, e estes seriam os visitantes que estão colonizando as áreas em processo de restauração. Forup et al. 2008, ao constatarem que as espécies de visitantes florais nativas retornando para áreas restauradas não são as mesmas ocorrendo nas áreas nativas adjacentes (British heathlands), sugeriram que a adjacência a habitats naturais não precisa ser um critério para escolher áreas a serem restauradas. Contudo, os autores recomendam cautela porque outros organismos podem ser mais suscetíveis a estes efeitos, e a restauração ecológica precisa considerar também os animais que não são capazes de transpor curtas distâncias. 
Nossos dados exemplificam a complexidade da restauração ecológica de florestas tropicais. No caso particular de ambientes altamente biodiversos, a tarefa já multifacetada de restaurar se torna ainda mais complicada. É preciso enfatizar que o presente estudo avaliou áreas em processo inicial de sucessão, o que representa apenas um estágio num processo muito longo e dinâmico de restauração. Embora por razões óbvias a prática comum seja restaurar aspectos básicos da estrutura vegetal e deixar as áreas restauradas responderem naturalmente a fatores abióticos, ao "pool" de espécies locais e à configuração da paisagem, áreas restauradas precisam ser monitoradas continuamente para que tenhamos um entendimento mais profundo dos processos ecológicos dirigindo ou sendo dirigidos pela restauração. No caso específico do processo em estudo, espécies de árvores climácicas só alcançarão o estágio reprodutivo muito mais tarde, e outras espécies de plantas colonizarão o ambiente ao longo da sucessão. Todas precisarão de seus polinizadores em quantidade suficiente para alcançar o sucesso reprodutivo.

Ainda assim, a abundância e a riqueza de visitantes encontrados em cada local de estudo demonstram que uma grande diversidade de insetos encontra nestas áreas flores nas quais forragear. Nas áreas mais ricas e abundantes em visitantes, a diversidade de interações nas redes também foi maior. Portanto, muitas espécies de insetos encontram recursos necessários nas áreas restauradas, que então estão exercendo um papel importante no provimento do serviço ecológico da polinização. As comunidades de visitantes suportadas pelas áreas restauradas poderão servir como fonte potencial de polinizadores para ambientes naturais e cultivos agrícolas que dependam da polinização por animais, demonstrando que a restauração ecológica tem implicações práticas de extrema relevância para a conservação de serviços ecossistêmicos.

\section{Referências Bibliográficas}

Aizen, M.A., Garibaldi, L.A., Cunningham, S.A. \& Klein, A.M. (2008) Long-term global trends in crop yield and production reveal no current pollination shortage but increasing pollinator dependency. Current biology, 18, 1572-1575.

Aizen, M.A., Garibaldi, L. A, Cunningham, S. A \& Klein, A.M. (2009) How much does agriculture depend on pollinators? Lessons from long-term trends in crop production. Annals of botany, 103, 15791588.

Araújo, E.D., Costa, M., Chaud-Netto, J. \& Fowler, H.G. (2004) Body size and flight distance in stingless bees (Hymenoptera: Meliponini): inference of flight range and possible ecological implications. Brazilian journal of biology, 64, 563-568.

Bascompte, J., Jordano, P., Melián, C.J. \& Olesen, J.M. (2003) The nested assembly of plant-animal mutualistic networks. Proceedings of the National Academy of Sciences of the United States of America, 100, 9383-9387. 
Bazarian, S. V. (2010) Redes de interação plantas-visitantes florais e a restauração de processos ecológicos em florestas tropicais. Tese (Doutorado em Ecologia) - Instituto de Biociências, Universidade de São Paulo, São Paulo. 145p.

Biesmeijer, J., Slaa, E., Castro, M., Viana, B.F., Kleinert, A. \& Imperatriz-Fonseca, V. (2005) Connectance of Brazilian social bee: food plant networks is influenced by habitat, but not by latitude, altitude or network size. Biota Neotropica, 5, 1-9.

Blanche, K.R., Ludwig, J. A. \& Cunningham, S. A. (2006) Proximity to rainforest enhances pollination and fruit set in orchards. Journal of Applied Ecology, 43, 1182-1187.

Blüthgen, N., Fründ, J., Vázquez, D.P. \& Menzel, F. (2008) What do interaction network metrics tell us about specialization and biological traits? Ecology, 89, 3387-3399.

Blüthgen, N., Menzel, F. \& Blüthgen, N. (2006) Measuring specialization in species interaction networks. BMC ecology, 14, 6-9.

Brudvig, L.A. (2011) The restoration of biodiversity: where has research been and where does it need to go? American journal of botany, 98, 549-558.

Carvalheiro, L.G., Seymour, C.L., Veldtman, R. \& Nicolson, S.W. (2010) Pollination services decline with distance from natural habitat even in biodiversity-rich areas. Journal of Applied Ecology, 47, 810820 .

Carvalheiro, L.G., Veldtman, R., Shenkute, A.G., Tesfay, G.B., Pirk, C.W.W., Donaldson, J.S. \& Nicolson, S.W. (2011) Natural and within-farmland biodiversity enhances crop productivity. Ecology letters, 14, 251-259.

Chazdon, R. (2008) Beyond deforestation: restoring forests and ecosystem services on degraded lands. Science, 320, 1458-1460.

Devoto, M., Bailey, S., Craze, P. \& Memmott, J. (2012) Understanding and planning ecological restoration of plant-pollinator networks. Ecology letters, 15, 319-328.

Dormann, C.F., Gruber, B. \& Fründ, J. (2008) Introducing the bipartite Package : Analysing Ecological Networks. , 8, 8-11.

Dunne, J. A., Williams, R.J. \& Martinez, N.D. (2002) Network structure and biodiversity loss in food webs: robustness increases with connectance. Ecology Letters, 5, 558-567.

Ehrenfeld, J.G. (2000) Defining the limits of restoration: the need for realistic goals. Restoration Ecology, 8, 2-9.

Ferreira, P.A., Boscolo, D. \& Viana, B.F. (2013) What do we know about the effects of landscape changes on plant-pollinator interaction networks? Ecological Indicators, 31, 35-40.

Forup, M.L., Henson, K.S.E., Craze, P.G. \& Memmott, J. (2008) The restoration of ecological interactions: plant-pollinator networks on ancient and restored heathlands. Journal of Applied Ecology, 45, 742-752.

Forup, M.L. \& Memmott, J. (2005) The restoration of plant-pollinator interactions in Hay Meadows. Restoration Ecology, 13, 265-274. 
Fragoso, F.P. (2009) A entomofauna visitante floral de espécies arbóreas da Floresta da USP-RP , área de restauração de Mata Estacional Semidecidual. Dissertação (Mestrado em Entomologia) Faculdade de Filosofia, Ciências e Letras de Ribeirão Preto, Ribeirão Preto, 77p.

Fragoso, F.P. \& Varanda, E.M. (2011) Flower-visiting insects of five tree species in a restored area of semideciduous seasonal forest. Neotropical entomology, 40, 431-435.

Greenleaf, S.S., Williams, N.M., Winfree, R. \& Kremen, C. (2007) Bee foraging ranges and their relationship to body size. Oecologia, 153, 589-596.

Hobbs, R.J., Hallett, L.M., Ehrlich, P.R. \& Mooney, H. a. (2011) Intervention ecology: applying ecological science in the twenty-first century. BioScience, 61, 442-450.

Hobbs, R., Higgs, E. \& Harris, J. (2009) Novel ecosystems: implications for conservation and restoration. Trends in ecology \& evolution, 24, 599-605.

Holl, K., Crone, E. \& Schultz, C. (2003) Landscape restoration: moving from generalities to methodologies. BioScience, 53, 491-502.

Instituto Florestal (2005) Inventário florestal da vegetação natural do Estado de São Paulo. São Paulo: Imprensa oficial.

Kevan, P. \& Baker, H. (1983) Insects as flower visitors and pollinators. Annual review of entomology, 28, 407-453.

Klein, A.-M., Vaissière, B.E., Cane, J.H., Steffan-Dewenter, I., Cunningham, S. A., Kremen, C. \& Tscharntke, T. (2007) Importance of pollinators in changing landscapes for world crops. Proceedings of The Royal Society B: Biological sciences, 274, 303-313.

Legendre, P. \& Legendre, L. (1998) Numerical Ecology, second eng. Elsevier Science B.V., Amsterdam, The Netherlands.

Lewinsohn, T. \& Prado, P.I. (2006) Structure in plant-animal interaction assemblages. Oikos, 113, 174184.

Memmott, J. (1999) The structure of a plant-pollinator food web. Ecology Letters, 2, 276-280.

Nenadic, O. \& Greenacre, M. (2007) Correspondence analysis in R, with two-and three-dimensional graphics: The ca package. , 20, 1-13.

Oksanen, J. (2013) Multivariate analysis of ecological communities in R: vegan tutorial. $R$ package version, 43.

Olesen, J.M., Bascompte, J., Dupont, Y.L. \& Jordano, P. (2006) The smallest of all worlds: pollination networks. Journal of theoretical biology, 240, 270-276.

Ollerton, J., Winfree, R. \& Tarrant, S. (2011) How many flowering plants are pollinated by animals? Oikos, 120, 321-326.

Palmer, M. A \& Filoso, S. (2009) Restoration of ecosystem services for environmental markets. Science, 325, 575-576.

Pasquet, R.S., Peltier, A., Hufford, M.B., Oudin, E., Saulnier, J., Paul, L., Knudsen, J.T., Herren, H.R. \& Gepts, P. (2008) Long-distance pollen flow assessment through evaluation of pollinator foraging 
range suggests transgene escape distances. Proceedings of the National Academy of Sciences of the United States of America, 105, 13456-13461.

Pigozzo, C.M. \& Viana, B.F. (2010) Estrutura da rede de interações entre flores e abelhas em ambiente de Caatinga. Oecologia Australis, 14, 100-114.

Potts, S., Vulliamy, B., Dafni, A., Ne'eman, G. \& Willmer, P. (2003) Linking bees and flowers: how do floral communities structure pollinator communities? Ecology, 84, 2628-2642.

R Development Core Team. (2012) R: A language and environment for statistical computing. R Foundation for statistical computing, Viena, Áustria, ISBN 3-900051-07-0.

Rey Benayas, J.M., Newton, A.C., Diaz, A. \& Bullock, J.M. (2009) Enhancement of biodiversity and ecosystem services by ecological restoration: a meta-analysis. Science, 325, 1121-1124.

Ricketts, T. (2004) Tropical forest fragments enhance pollinator activity in nearby coffee crops. Conservation Biology, 18, 1262-1271.

Ricketts, T.H., Regetz, J., Steffan-Dewenter, I., Cunningham, S. A., Kremen, C., Bogdanski, A., GemmillHerren, B., Greenleaf, S.S., Klein, A.M., Mayfield, M.M., Morandin, L. A., Ochieng', A., Potts, S.G. \& Viana, B.F. (2008) Landscape effects on crop pollination services : are there general patterns? Ecology letters, 11, 499-515.

Rodrigues, C. \& Hott, M. (2010) Dinâmica da vegetação natural no nordeste do estado de São Paulo, entre 1988 e 2003. Revista Árvore, 34, 881-887.

Ruiz-Jaen, M.C. \& Aide, T.M. (2005) Restoration success: how is it being measured? Restoration Ecology, 13, 569-577.

Steffan-Dewenter, I. \& Tscharntke, T. (1999) Effects of habitat isolation on pollinator communities and seed set. Oecologia, 121, 432-440.

Suding, K.N. (2011) Toward an era of restoration in ecology: successes, failures, and opportunities ahead. Annual Review of Ecology, Evolution, and Systematics, 42, 465-487.

Tylianakis, J.M., Laliberté, E., Nielsen, A. \& Bascompte, J. (2010) Conservation of species interaction networks. Biological Conservation, 143, 2270-2279.

Tylianakis, J.M., Tscharntke, T. \& Lewis, O.T. (2007) Habitat modification alters the structure of tropical host-parasitoid food webs. Nature, 445, 202-205.

Vázquez, D. \& Aizen, M.A. (2004) Asymmetric specialization: a pervasive feature of plant-pollinator interactions. Ecology, 85, 1251-1257.

Viana, B., Boscolo, D., Neto, E., Lopes, L., Lopes, A., Ferreira, P.A., Pigozzo, C. \& Primo, L. (2012) How well do we understand landscape effects on pollinators and pollination services? Journal of Pollination Ecology, 7, 31-41.

Williams, N.M. (2011) Restoration of nontarget species: bee communities and pollination function in riparian forests. Restoration Ecology, 19, 450-459.

Williams, N., Crone, E., Roulston, T., Minckley, R., Packer, L. \& Potts, S. (2010) Ecological and life-history traits predict bee species responses to environmental disturbances. Biological Conservation, 143, 2280-2291. 
Winfree, R. (2010) The conservation and restoration of wild bees. Annals of the New York Academy of Sciences, 1195, 169-197.

Winfree, R., Aguilar, R., Vázquez, D., LeBuhn, G. \& Aizen, M.A. (2009) A meta-analysis of bees' responses to anthropogenic disturbance. Ecology, 90, 2068-2076.

Winfree, R., Bartomeus, I. \& Cariveau, D.P. (2011) Native Pollinators in Anthropogenic Habitats. Annual Review of Ecology, Evolution, and Systematics, 42, 1-22.

Zurbuchen, A., Landert, L., Klaiber, J., Müller, A., Hein, S. \& Dorn, S. (2010) Maximum foraging ranges in solitary bees: only few individuals have the capability to cover long foraging distances. Biological Conservation, 143, 669-676. 


\section{A INFLUÊNCIA DA COMUNIDADE DE PLANTAS NO ESTABELECIMENTO DA COMUNIDADE DE VISITANTES FLORAIS DURANTE OS ESTÁGIOS INICIAIS DA RESTAURAÇÃO}

\section{Introdução}

Com as crescentes perdas causadas pela fragmentação e isolamento contínuo de habitats (Tabarelli et al. 2004; Fischer \& Lindenmayer 2007), a conservação da biodiversidade do planeta não será possível somente através da manutenção de áreas protegidas (Rodrigues et al. 2004). Hoje, a demanda pela restauração de áreas degradadas é cada vez maior e exige da ciência ecológica o fornecimento e aperfeiçoamento constantes de modelos e metodologias para os praticantes da atividade.

Embora o foco atual da restauração ecológica esteja na recuperação dos processos funcionais dos ecossistemas e nos serviços ecológicos que eles provêm (Chazdon 2008; Hobbs et al. 2009; Palmer \& Filoso 2009; Rey Benayas et al. 2009; Suding 2011), na prática a maioria dos programas de restauração implementa apenas um conjunto mínimo de espécies vegetais e então assume que os processos ecológicos serão restabelecidos naturalmente ao longo do desenvolvimento da vegetação implantada. Na restauração de florestas tropicais, por exemplo, um dos métodos mais frequentemente adotados é o plantio de mudas de espécies nativas seguido de estratégias variadas de manejo durante os primeiros anos de sucessão. Este manejo geralmente limita-se ao controle de pragas que possam afetar as mudas e de espécies invasoras que possam competir com as mesmas, almejando-se que os demais organismos que se relacionam com as plantas - muitos deles parceiros mutualistas imprescindíveis para seu desenvolvimento e reprodução como espécies de micorrizas, polinizadores e dispersores - retornem sozinhos.

Todavia, dada a complexidade de interações ecológicas em ambientes de alta diversidade como as florestas tropicais, o restabelecimento das relações entre organismos pode ser um processo longo e intricado e que não necessariamente se desenvolverá de forma automática. Os animais polinizadores, que são responsáveis pela reprodução de mais de 90\% das espécies vegetais em florestas tropicais (Bawa et al. 1985; Bawa 1990), dependem de recursos para nidificação, reprodução e alimentação (Kevan \& Baker 1983) disponíveis continuamente e em quantidade suficiente para a manutenção de suas populações nas áreas restauradas. Porém, durante os estágios iniciais de desenvolvimento de florestas tropicais estabelecidas pelo plantio de mudas, somente espécies vegetais pioneiras florescem (Fragoso \& Varanda 2011) em apenas parte do ano (Fragoso 2009). 
É esperado que a qualidade e a composição dos recursos florais disponíveis interajam com traços espécie-específicos dos visitantes florais para determinar a ocorrência de suas populações e, da mesma maneira, que a disponibilidade de recursos e locais para nidificação se correlacione com a estrutura da vegetação (Roulston \& Goodell 2011). Por exemplo, espécies de abelhas oligoléticas como as da tribo Centridini dependem de óleo encontrado apenas em algumas espécies vegetais; muitas espécies de abelhas sem ferrão da tribo Meliponini nidificam em cavidades nos troncos das árvores e utilizam resina na construção de seus ninhos, enquanto que espécies da família Megachilidae coletam pedaços de folha, resina ou lama para esta tarefa (Michener 2007). A disponibilidade de qualquer um destes recursos vegetais pode vir então a ser um fator limitante no estabelecimento das populações destes insetos.

Por outro lado, é razoável supor que a abundância de visitantes aumente com mais recursos alimentares disponíveis e que a variabilidade destes recursos promova a diferenciação de nichos levando ao aumento da diversidade local de polinizadores. De fato, a diversidade de recursos florais é o fator limitante mais comum das populações de abelhas polinizadoras (Roulston \& Goodell 2011). Potts et al. (2003) encontraram que a composição da comunidade floral e a quantidade e qualidade de recursos disponíveis organizaram a comunidade de polinizadores em diversos níveis, dependendo por exemplo da diversidade de fontes de néctar, da razão energética pólen/néctar e da diversidade e abundância florais.

Assim, embora os diversos grupos de insetos polinizadores difiram amplamente nas suas características de história de vida, todos eles compartilham a mesma dependência das flores como recurso essencial. O declínio do processo de polinização leva à baixa produção de frutos (Cunningham 2000; Ghazoul 2005) e, se os efeitos da comunidade vegetal sobre o estabelecimento da comunidade de polinizadores forem negativos, um processo de retroalimentação fará com que a deficiência de polinizadores tenha consequências catastróficas para as populações vegetais. Para assegurar o sucesso da restauração de florestas tropicais, é fundamental compreendermos melhor como se dá o processo de restabelecimento das comunidades vegetais implantadas e a restituição dos visitantes florais associados a elas. Neste contexto, os objetivos deste estudo foram (1) investigar as espécies de plantas que florescem nos estágios iniciais de restauração das florestas, analisando a estrutura da comunidade vegetal formada; (2) verificar se, além das espécies arbóreas implantadas, espécies vegetais regenerantes também contribuem para o aporte de recursos florais para insetos visitantes ao longo da restauração e (3) avaliar se a estrutura da comunidade de plantas é importante na determinação da estrutura da comunidade de visitantes florais. 


\section{Material e Métodos}

\section{1. Áreas de estudo}

O estudo foi realizado em seis áreas em processo de restauração de Floresta Estacional Semidecidual, fisionomia pertencente ao bioma Mata Atlântica e caracterizada por demarcada sazonalidade climática (verão chuvoso seguido de prolongado período de estiagem). As áreas localizam-se em quatro municípios da região de Ribeirão Preto, nordeste do Estado de São Paulo, Brasil (tabela 3.1). Todas elas foram previamente ocupadas por cultivos agrícolas (na maior parte do tempo cana-de-açúcar) e suas restaurações foram iniciadas por meio do plantio de mudas de espécies arbóreas nativas. Na época do estudo as idades dos locais variavam de 5 a 10 anos. Metade das áreas restauradas foi implantada a uma distância linear maior que $1000 \mathrm{~m}$ do fragmento remanescente mais próximo e a outra metade foi implantada imediatamente ao lado de fragmentos pré-existentes (figura 2.1 do capítulo 2), mas um estudo desta mesma tese mostrou que esta configuração espacial não teve nenhum efeito significativo nas redes de interação planta-visitante floral existentes em cada local (capítulo 2). No início do levantamento de dados, a remoção de gramíneas invasoras havia sido completada recentemente em todas as áreas, que apresentavam portanto sub-bosque em condições similares. Contudo, ao longo do desenvolvimento do trabalho, foi notado que a prática de remoção das gramíneas foi reduzida ou cancelada em metade das áreas de estudo. Assim, três dos locais apresentavam o solo massivamente coberto por gramíneas africanas invasoras como Panicum maximum Jacq. Cv. (colonião) e/ou Brachiaria sp., enquanto os outros três locais apresentavam maior quantidade de plântulas e de outras espécies ruderais regenerantes espontaneamente (tabela 3.1, figura 3.1).

Tabela 3.1. Localização e características das áreas restauradas

\begin{tabular}{ccccccc}
\hline Código & Latitude & Longitude & $\begin{array}{c}\text { Data de } \\
\text { plantio }\end{array}$ & $\begin{array}{c}\text { Distância ao } \\
\text { fragmento } \\
\text { mais próximo } \\
(\mathrm{m})\end{array}$ & $\begin{array}{c}\text { Grau de } \\
\text { invasão por } \\
\text { gramíneas }\end{array}$ & $\begin{array}{c}\text { Localização (\% de } \\
\text { cobertura vegetal do } \\
\text { munićpio*) }\end{array}$ \\
\hline RA 1 & $21^{\circ} 5.816^{\prime} \mathrm{S}$ & $48^{\circ} 4.737^{\prime} \mathrm{O}$ & 2003 & 0 & moderado & Sertãozinho $(2,32)$ \\
RA 2 & $21^{\circ} 15.642^{\prime} \mathrm{S}$ & $48^{\circ} 26.453^{\prime} \mathrm{O}$ & 2007 & 0 & intenso & Monte Alto $(4,71)$ \\
RA3 & $21^{\circ} 17.970^{\prime} \mathrm{S}$ & $48^{\circ} 21.001^{\prime} \mathrm{O}$ & 2006 & 0 & moderado & Jaboticabal $(1,57)$ \\
RD 1 & $21^{\circ} 15.349^{\prime} \mathrm{S}$ & $48^{\circ} 24.856^{\prime} \mathrm{O}$ & 2007 & 1158 & intenso & Jaboticabal $(1,57)$ \\
RD 2 & $21^{\circ} 9.003^{\prime} \mathrm{S}$ & $47^{\circ} 51.759^{\prime} \mathrm{O}$ & 2002 & 3000 & intenso & Rib. Preto $(3,28)$ \\
RD 3 & $21^{\circ} 17.508^{\prime} \mathrm{S}$ & $48^{\circ} 20.992^{\prime} \mathrm{O}$ & 2005 & 1050 & moderado & Jaboticabal $(1,57)$ \\
\hline
\end{tabular}

*Dados retirados de Instituto Florestal (2005). 

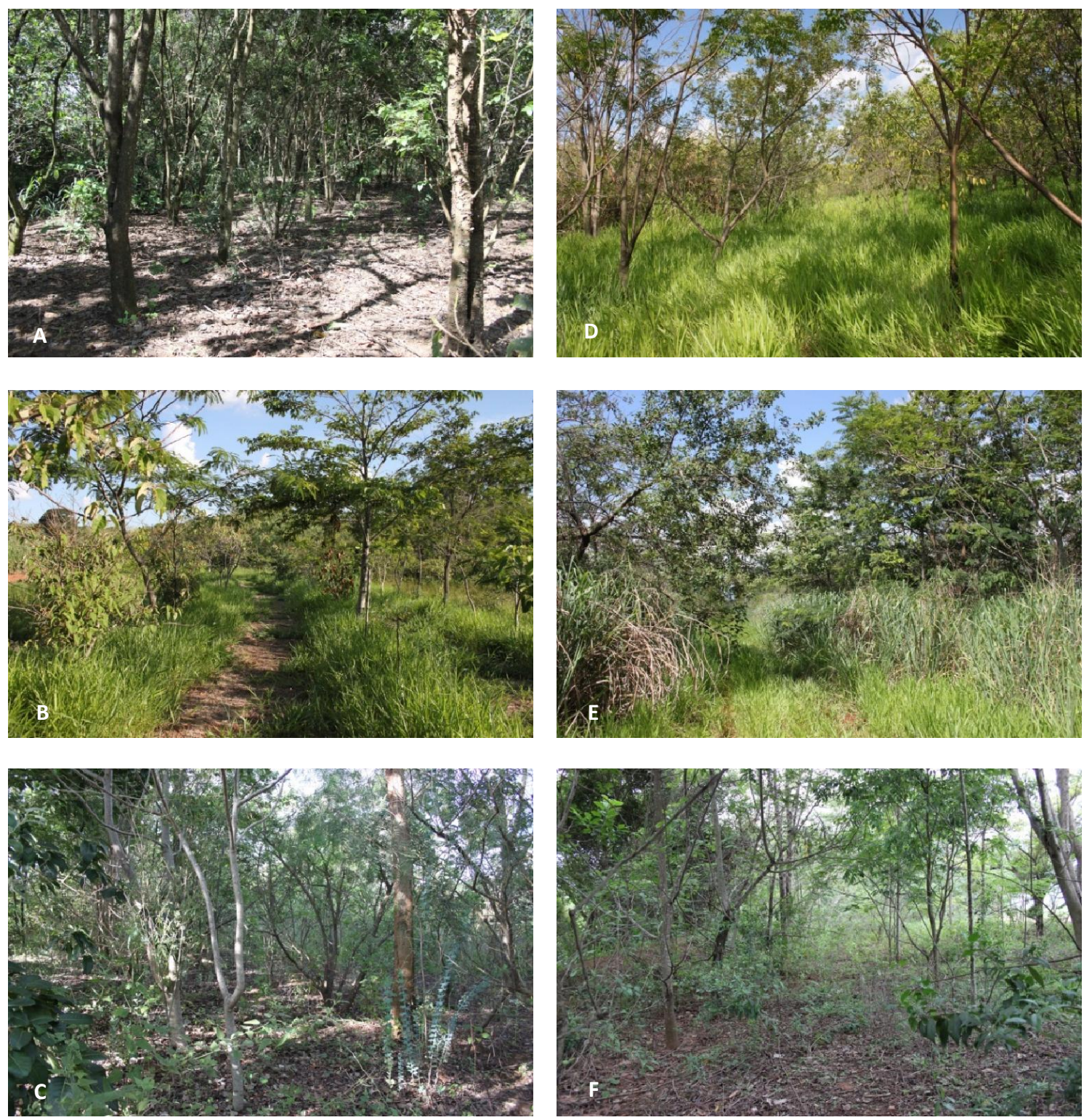

Figura 3.1. Fisionomia das áreas de estudo. A-C são áreas implantadas imediatamente ao lado de fragmentos pré-existentes (RA1, RA2 e RA3, respectivamente) e D-F são áreas implantadas a uma distância linear maior que $1000 \mathrm{~m}$ do fragmento remanescente mais próximo (RD1, RD2 e RD3, respectivamente). Note que A, C e F apresentam maior quantidade de plântulas e de espécies ruderais regenerantes espontaneamente enquanto $B, D$ e $E$ demonstram forte incidência de gramíneas africanas invasoras. 


\subsection{Amostragem}

Plantas floridas e seus visitantes florais foram registrados entre dezembro de 2011 e outubro de 2012 em expedições de campo bimestrais. Em cada local foram estabelecidos 5 transectos de aproximadamente 50 metros, totalizando cerca de 250 metros, situados sempre perpendicularmente à borda para que em todos os locais fossem amostradas proporções semelhantes de borda e interior de cada área. As amostragens foram todas realizadas em dias secos, ensolarados e com ventos, no máximo, moderados. Imediatamente antes de cada sessão de coleta, foram registradas a abundância e a riqueza de espécies em floração em cada transecto; quando possível as espécies foram identificadas in situ e para as demais foram preparadas exsicatas para posterior identificação. A abundância floral de cada indivíduo observado foi estimada por meio de uma escala decimal categórica (1-10 flores, 11-100 flores e 101-1000 ou mais flores), e inflorescências pequenas como os capítulos da família Asteraceae foram consideradas como uma unidade floral. Após este registro, dois coletores caminharam pelos transectos alternadamente durante períodos de 30 minutos a cada hora entre 07h30 e 16h30; quando não era possível completar todos os transectos dentro de 30 minutos, a amostragem no próximo período continuava do ponto onde havia parado no período anterior. Os visitantes observados nas flores foram capturados com rede entomológica na ordem em que foram avistados, e cada coletor permaneceu no máximo cinco minutos em cada planta florida. Os insetos coletados foram colocados em câmaras mortíferas contendo acetato de etila e a espécie vegetal sendo visitada foi registrada para se obter os dados de visitação. Em laboratório, todos os espécimes foram triados e identificados até o menor nível taxonômico possível.

\subsection{Análise dos dados}

Plantas registradas em floração foram separadas entre espécies plantadas e espécies regeneradas naturalmente. As riquezas de espécies das duas categorias foram comparadas por teste t pareado. 0 índice de diversidade de Shannon e o de equabilidade de Pielou foram calculados para a toda a comunidade vegetal como também para as duas categorias de plantas. Para estimar a abundância de flores, as variações inerentes à escolha da escala decimal categórica foram normalizadas multiplicando-se o valor médio dentro de cada categoria (1-10 flores, 11-100 flores e 101-1000 flores) pelo número de indivíduos floridos observados pertencentes as mesmas. Ordenação por escalonamento multidimensional não-métrico (Clarke 1993) foi utilizada para visualizar a similaridade da comunidade de plantas entre os locais de estudo. Este tipo de análise não usa a abundância absoluta de espécies nas comunidades, mas sim a ordem de seus postos (ranks), e é mais flexível por permitir o uso de diversas medidas de distância. Aqui a ordenação foi baseada no índice de Bray-Curtis repetindo-se múltiplas entradas com 200 iterações cada.

Para verificar a contribuição das espécies vegetais regenerantes para o aporte de recursos florais para insetos visitantes, foram construídas redes de interação planta-visitante floral para toda a 
comunidade e calculadas métricas importantes para a conservação da estabilidade de redes (Tylianakis et al. 2010): (1) conectância; (2) diversidade de interações; (3) equabilidade de interações; (4) número de compartimentos; (5) aninhamento e (6) nível de especialização ( $\left(2^{\prime}\right)$. Foram então excluídas as espécies vegetais regenerantes de cada rede e calculadas novamente as métricas somente considerando-se as espécies implantadas. As métricas das redes com e sem plantas regenerantes foram comparadas então utilizando-se o teste de Wilcoxon para verificar se a ausência do componente regenerante altera significativamente estas métricas.

O papel da comunidade de plantas na determinação da comunidade de visitantes florais foi testado por meio de teste de Mantel (Legendre \& Legendre 1998). Duas matrizes de similaridade entre todos os pares de áreas foram construídas - uma para as plantas floridas e outra para os visitantes florais usando o coeficiente de dissimilaridade de Bray-Curtis. A correlação (Pearson) entre estas duas matrizes foi então avaliada com o teste de Mantel utilizando-se 20.000 permutações. Para testar o papel das diferentes categorias de plantas sobre os visitantes florais, o procedimento foi repetido mais duas vezes, a primeira utilizando apenas as espécies regeneradas naturalmente e a segunda utilizando apenas as espécies arbóreas implantadas. Todas as matrizes usadas neste teste foram matrizes binárias (aquelas com dados de presença-ausência apenas) para testarmos a importância da identidade das espécies presentes ao invés do impacto da abundância relativa das espécies compartilhadas.

Todas as análises estatísticas foram efetuadas no programa R (R Development Core Team 2012), utilizando-se os pacotes bipartite (Dormann et al. 2008) para a construção das redes e cálculo de suas métricas e o pacote vegan (Oksanen 2013) para a construção das matrizes de similaridade, ordenação por escalonamento e realização dos testes de Mantel.

\section{Resultados}

No geral, foram observadas 94 espécies de plantas floridas pertencentes a 29 famílias botânicas (figura 3.2). Trinta e cinco por cento destas é composto por espécies de árvores que foram plantadas e o restante é representado por espécies regenerantes espontaneamente (57,5\% de herbáceoarbustivas e 7,5\% de trepadeiras). 0 grande número de espécies de arbustos e herbáceas regenerantes foi responsável pelo maior número de espécies de Asteraceae, na sua totalidade composta por este grupo de plantas. A segunda família mais abundante foi Fabaceae, representada por $55 \%$ de arbóreas implantadas e $45 \%$ de regenerantes espontâneas. Considerando o conjunto de áreas estudadas, a riqueza de plantas floridas regenerantes foi significativamente maior que a de espécies floridas plantadas $(t=-3,01, g l=5, p=0.02)$ : com exceção da área $R D 1$, onde as regenerantes representaram pouco mais de $40 \%$ da riqueza total de espécies floridas, todas as áreas de estudo mostraram riqueza sempre maior que $60 \%$ de regenerantes (figura 3.3). A área de estudo com maior número de espécies 
em floração foi RD3, seguida de RA3 > RA2 > RA1 > RD1 > RD2. Os índices de diversidade de Shannon encontram-se na tabela 3.2 e obedeceram aproximadamente o mesmo ordenamento que as medidas de riqueza; a equabilidade de Pielou para a comunidade vegetal florida foi maior nas áreas RD1 e RD2, demonstrando que as comunidades com menor riqueza apresentam também uma distribuição mais homogênea de indivíduos por espécie.

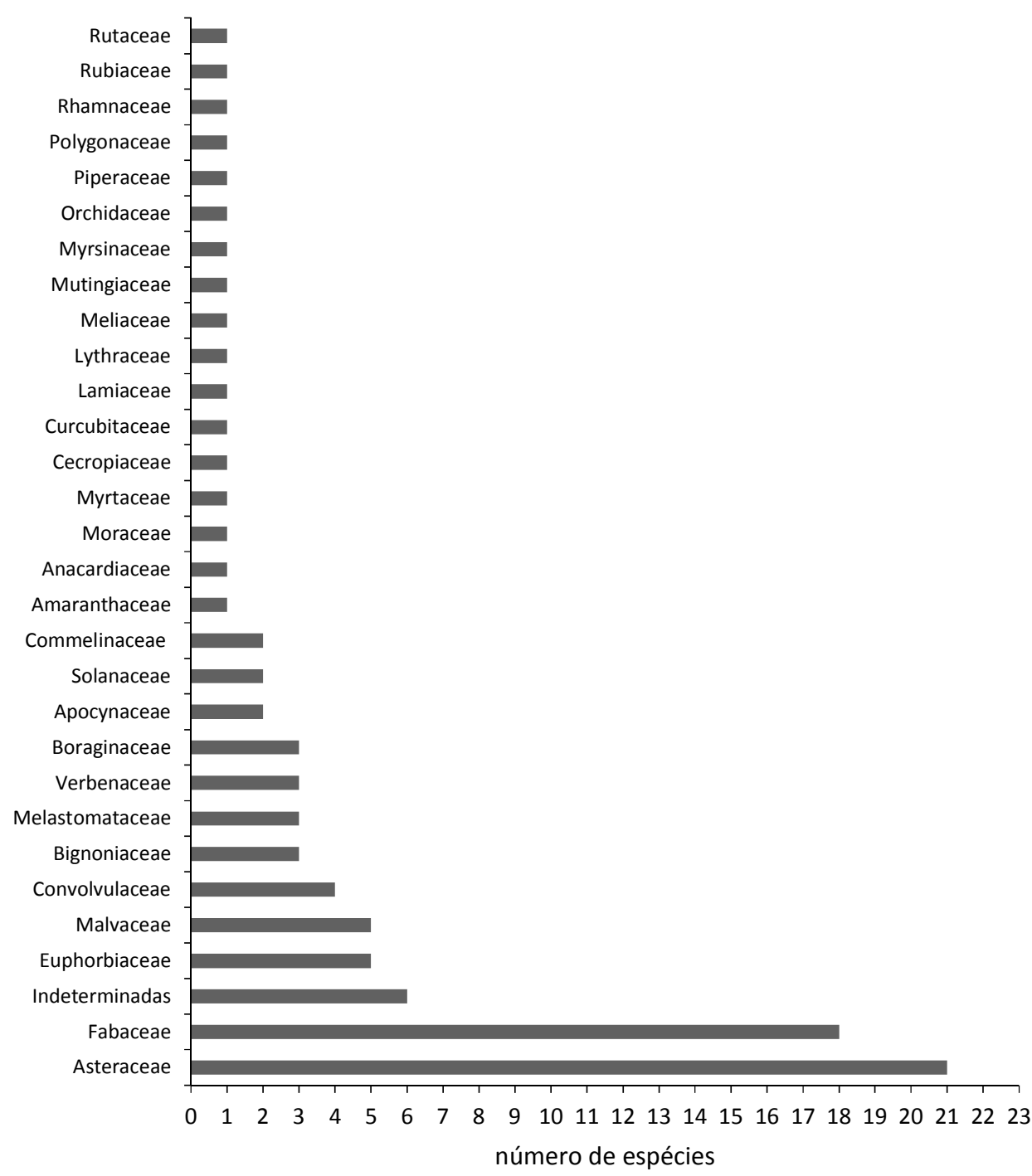

Figura 3.2. Riqueza de espécies vegetais floridas por família botânica nas seis áreas restauradas de Floresta Estacional Semidecidual. A identificação das espécies e suas ocorrências por área encontram-se no Anexo 2. 


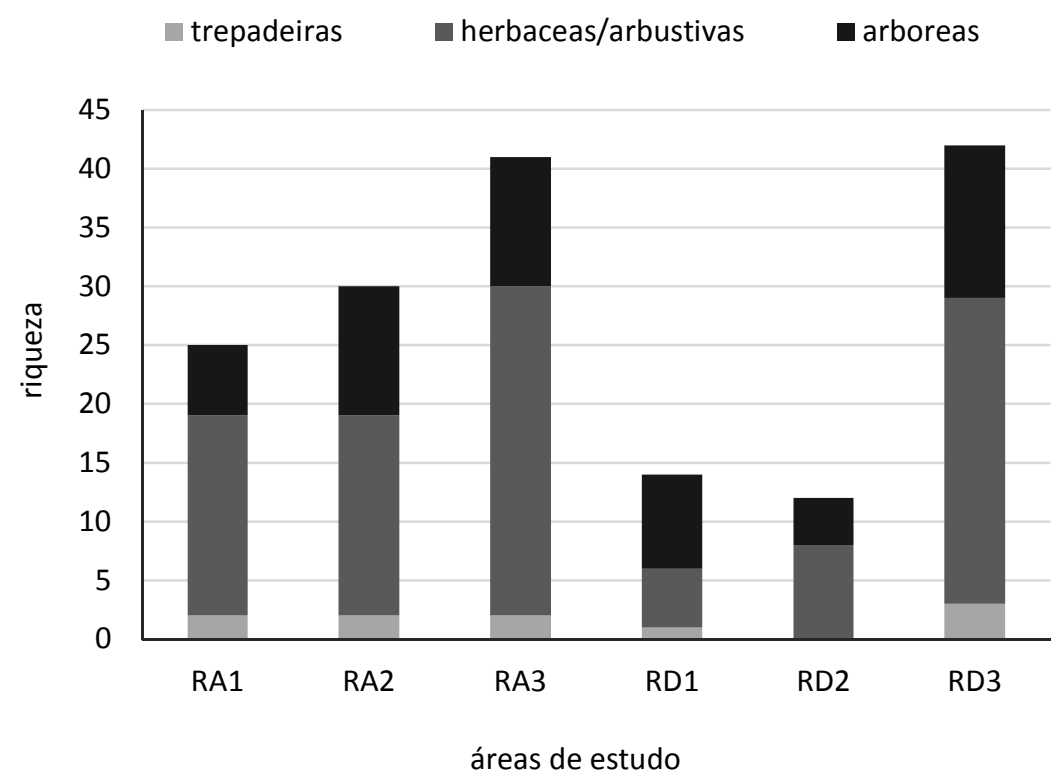

Figura 3.3. Riqueza de espécies vegetais floridas em cada uma das seis áreas restauradas de Floresta Estacional Semidecidual. As espécies implantadas são compostas apenas por indivíduos de porte arbóreos enquanto as espécies regenerantes compreendem lianas, herbáceas e arbustivas.

Tabela 3.2. Diversidade de Shannon e Equabilidade de Pielou para as espécies vegetais implantadas, espécies vegetais regenerantes e toda a comunidade vegetal florida de seis áreas restauradas de Floresta Estacional Semidecidual.

\begin{tabular}{llllllll}
\hline \multirow{2}{*}{ Implantadas } & RA1 & RA2 & RA3 & RD1 & RD2 & RD3 \\
& Diversidade & 1,46 & 2,02 & 2,11 & 1,66 & 0,95 & 2,29 \\
\cline { 2 - 6 } Regenerantes & Equabilidade & 0,81 & 0,84 & 0,88 & 0,80 & 0,68 & 0,89 \\
& Diversidade & 2,09 & 1,91 & 2,74 & 1,40 & 1,75 & 2,68 \\
& Equabilidade & 0,71 & 0,64 & 0,80 & 0,78 & 0,84 & 0,79 \\
& Diversidade & 2,36 & 2,48 & 2,99 & 2,22 & 2,08 & 2,98 \\
& Equabilidade & 0,73 & 0,73 & 0,80 & 0,84 & 0,84 & 0,79 \\
\hline
\end{tabular}

As áreas RD1 e RD2 apresentaram maior abundância floral (figura 3.4a). Apesar de serem menos ricas em espécies floridas e terem também menor abundância de indivíduos floridos, estas áreas apresentam uma proporção maior de indivíduos arbóreos cuja florada é massiva, como pode ser observado pelo maior número de indivíduos presentes na terceira categoria da escala decimal utilizada (figura 3.4b). Por outro lado, as áreas mais ricas e abundantes em espécies floridas, RA3 e RD3, mostraram um maior número de indivíduos regenerantes que possuem baixo número de flores. 
(a)

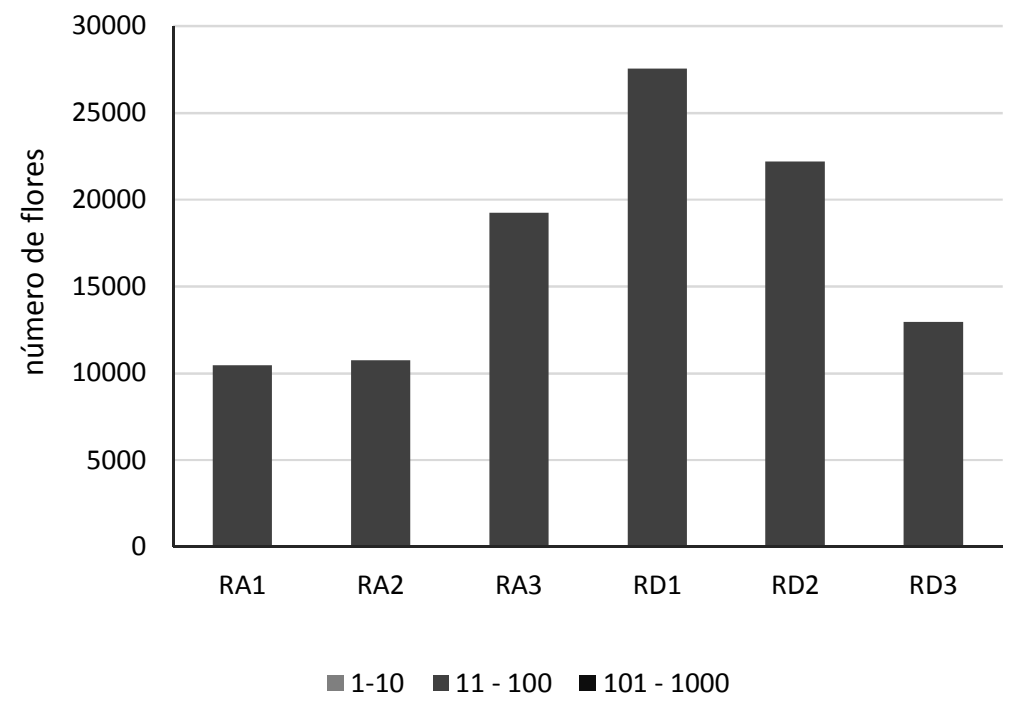

(b)

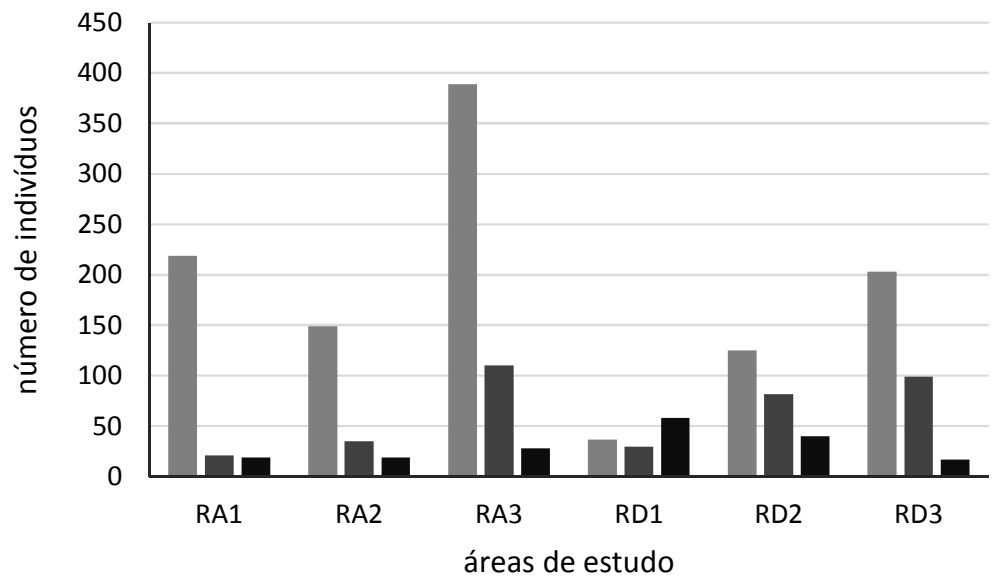

Figura 3.4. Abundância floral total (a) e abundância de indivíduos por categoria de abundância floral (b) em cada área restaurada de Floresta Estacional Semidecidual.

A ordenação das comunidades vegetais parece demonstrar que a riqueza de espécies floridas teve maior influência na separação das áreas de estudo (figura 3.5). As áreas de menor riqueza de espécies floridas (RD1 e RD2) mostraram maior similaridade de composição entre si do que com quaisquer outras áreas quando consideradas as abundâncias relativas de indivíduos floridos (figura 3.5a). As três áreas de maior riqueza (RD3, RA3 e RA2) também se situaram próximas pela ordenação. Quando levado em conta a abundância de flores, no entanto, essa disposição se torna menos aparente, com RA3 e RA2 passando a ser as áreas cuja composição da comunidade vegetal é mais similar (figura 3.5b). De qualquer maneira, a similaridade na composição destas comunidades é baixa: cinquenta e sete das espécies vegetais floridas foram de ocorrência exclusiva de alguma das áreas, sendo RD3 e RA3 as áreas com maior número de ocorrências exclusivas (19 e 14 respectivamente), seguidas de RA1 (11), RA2 (9) e RD1 e RD2 (duas espécies cada uma). Croton urucurana Baill. (Euphorbiaceae) e Schinus 
terebinhifolius Raddi (Anacardiaceae) - ambas espécies arbóreas implantadas - foram as únicas espécies comuns às seis áreas restauradas. As demais espécies de ocorrência frequente, todas regenerantes, foram: Conyza sp2, Emilia fosbergii Nicolson (Asteraceae), Stachytarpheta cayennensis (L.C.Rich.) Vahl (Verbenaceae) e Praxelis pauciflora (Kunth) R. M. King \& H. Rob. (Asteraceae) que ocorreram em cinco áreas; e Bidens sp. (Asteraceae), Commelina sp2 (Commelinaceae) e Senegalia polyphylla (DC.) Britton \& Rose (Fabaceae) que foram encontradas em quatro áreas (anexo 2).

Quando analisadas as redes de interação planta-visitante floral na ausência de plantas regenerantes, estas se mostraram menos complexas (figura 3.6). A remoção do componente regenerante diminui significativamente a riqueza de espécies vegetais das redes, e consequentemente, a riqueza de visitantes florais (tabela 3.3). As redes de interação resultantes se mostraram então menos aninhadas e compartimentalizadas e com menor diversidade de interações. A conectância aumentou devido à diminuição do tamanho das redes. A equabilidade das interações $e$ os níveis de especialização não se alteraram significativamente.

A importância do estrato regenerante nas comunidades restauradas é reforçada pelo fato deste servir como recurso floral para 425 insetos de 230 espécies, enquanto as espécies vegetais implantadas foram visitadas por 828 insetos de 212 espécies. Dentre estas últimas, as duas espécies arbóreas implantadas S. terebinhifolius e $C$. urucurana receberam a maior riqueza de visitantes, com 72 e 64 espécies respectivamente; dentre as anteriores, as espécies regenerantes que mais foram visitadas são S. cayennensis (35 espécies de visitantes), E. fosbergii (28), Conyza sp2 (28) e P. pauciflora (20). Estas seis espécies vegetais, como já citado, são também as de ocorrência mais frequente nas áreas estudadas, o que pode ter influenciado no maior registro de visitação.
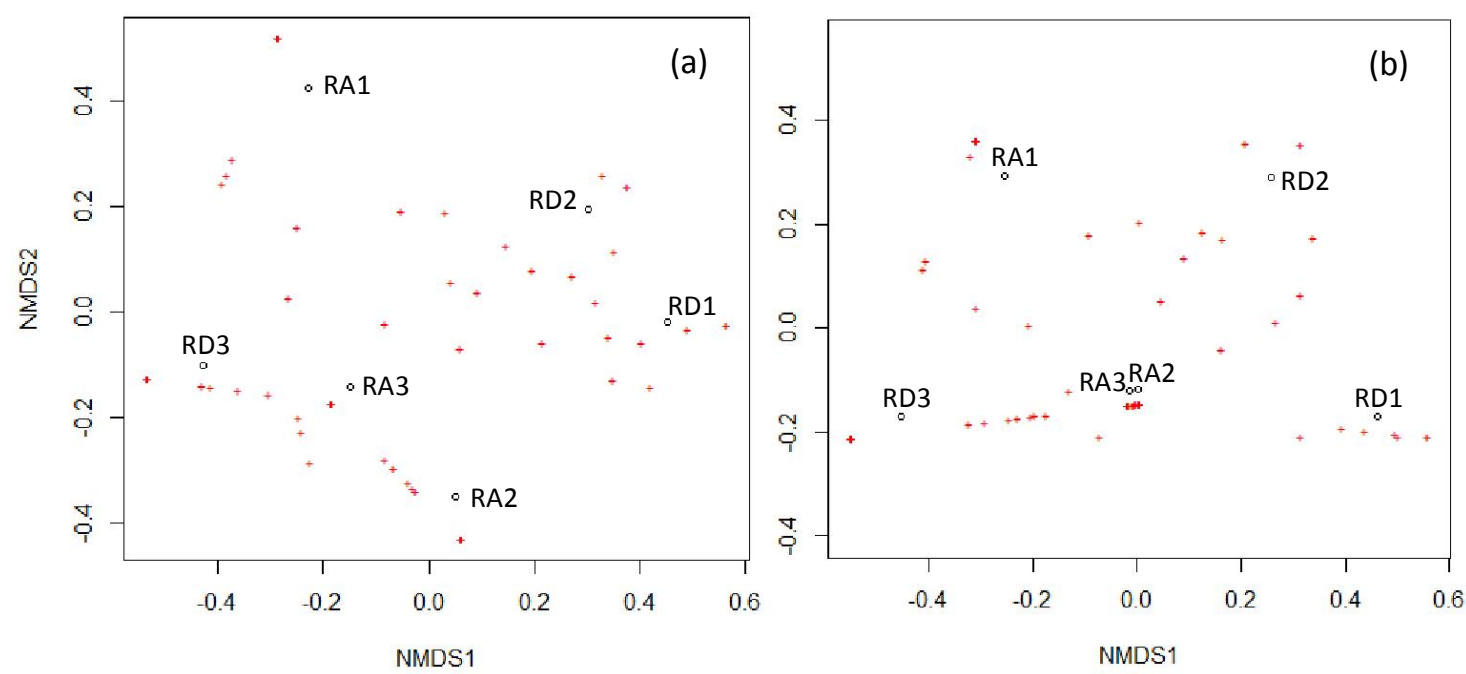

Figura 3.5. Escalonamento multidimensional não-métrico das áreas de estudo para (a) abundância de indivíduos floridos por categoria de abundância floral e (b) abundância floral total. 

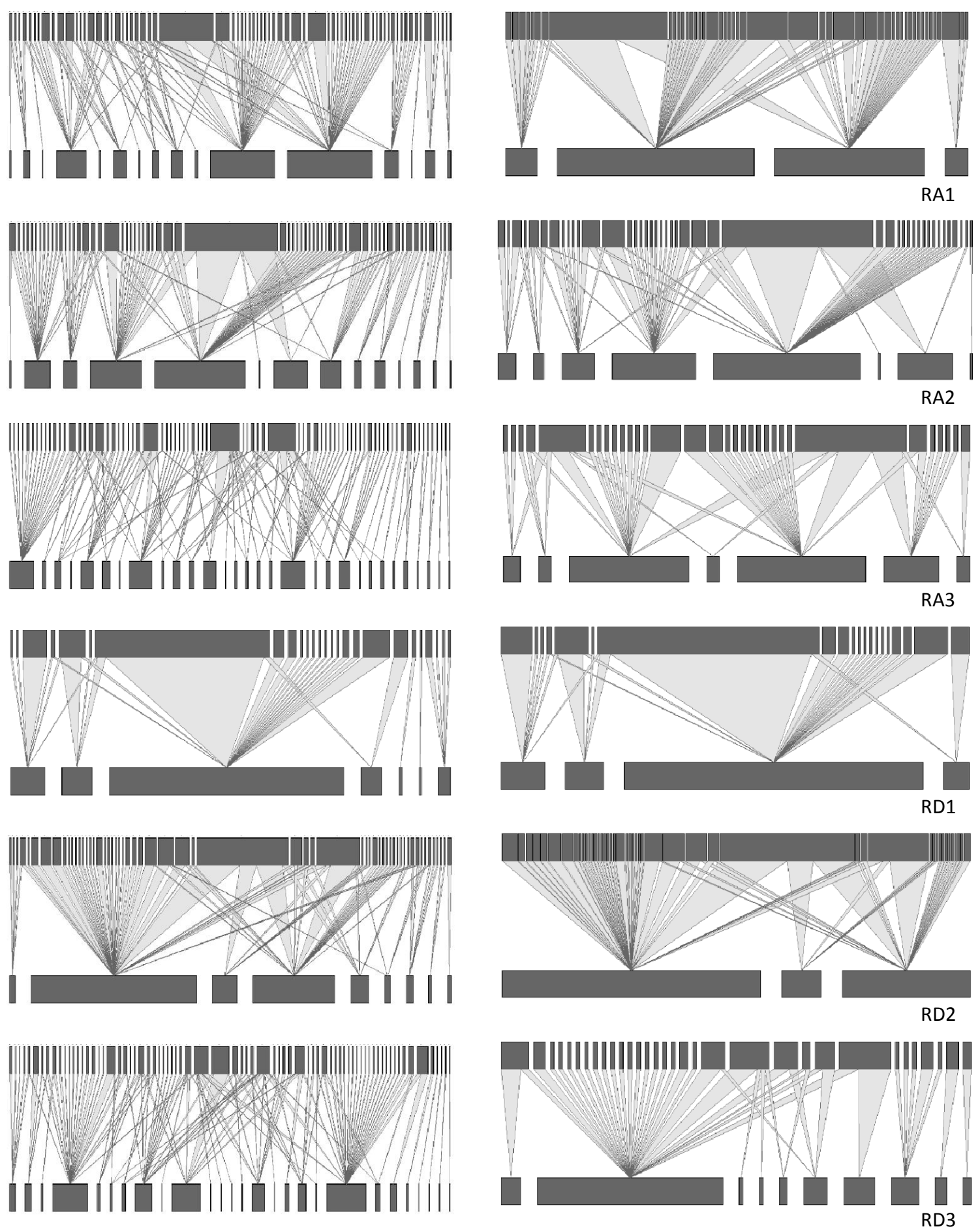

(a)

(b)

Figura 3.6. Simulação das consequências da remoção do estrato regenerante nas redes de interação planta-visitante floral: (a) redes reais incluindo todos os dados de visitação e (b) cenário onde a comunidade de plantas regenerantes foi excluída. Os retângulos de baixo representam as espécies de plantas e os retângulos de cima representam as espécies de insetos que visitam as flores. As interações são representadas pelas ligações entre os retângulos e a frequência de cada interação é indicada pela espessura da linha. 
Tabela 3.3. Média e desvio-padrão das métricas das redes completas de interação planta-visitante floral e das redes nas quais espécies floridas regenerantes foram removidas. Diferenças significativas entre as médias são mostradas pelos asteriscos seguindo os valores de $p$ (teste de Wilcoxon).

\begin{tabular}{lccccc}
\hline & \multicolumn{2}{c}{ com todas as espécies } & \multicolumn{2}{c}{ sem as espécies regenerantes } & \multirow{2}{*}{ valores de $\mathrm{p}$} \\
\cline { 2 - 4 } & média & DP & média & DP & \\
\hline riqueza de plantas floridas & 17,33 & 9,24 & 6,00 & 2,76 & $0,02^{*}$ \\
riqueza de insetos visitantes & 62,33 & 19,01 & 37,17 & 11,03 & $0,02^{*}$ \\
conectância & 0,12 & 0,07 & 0,25 & 0,11 & $0,02^{*}$ \\
diversidade de interações & 3,88 & 0,82 & 3,18 & 0,54 & $0,02^{*}$ \\
equabilidade de interações & 0,57 & 0,07 & 0,60 & 0,07 & 0,06 \\
número de compartimentos & 4,17 & 1,83 & 1,83 & 1,17 & $0,03^{*}$ \\
aninhamento & 13,79 & 10,52 & 25,96 & 9,77 & $0,02^{*}$ \\
especialização (H2') & 0,50 & 0,18 & 0,46 & 0,14 & 0,20 \\
& & & & & \\
\hline
\end{tabular}

A similaridade entre as comunidades vegetais das áreas estudadas foi significativamente correlacionada com a similaridade entre as comunidades de visitantes florais (figura 3.7a). Quando consideradas apenas as espécies regeneradas espontaneamente, a correlação permaneceu significativa (figura 3.7b); quando consideradas apenas as espécies arbóreas implantadas, não houve correlação entre as comunidades de árvores e a comunidade de visitantes (Mantel $r=-0,22, p=0,74$ ).

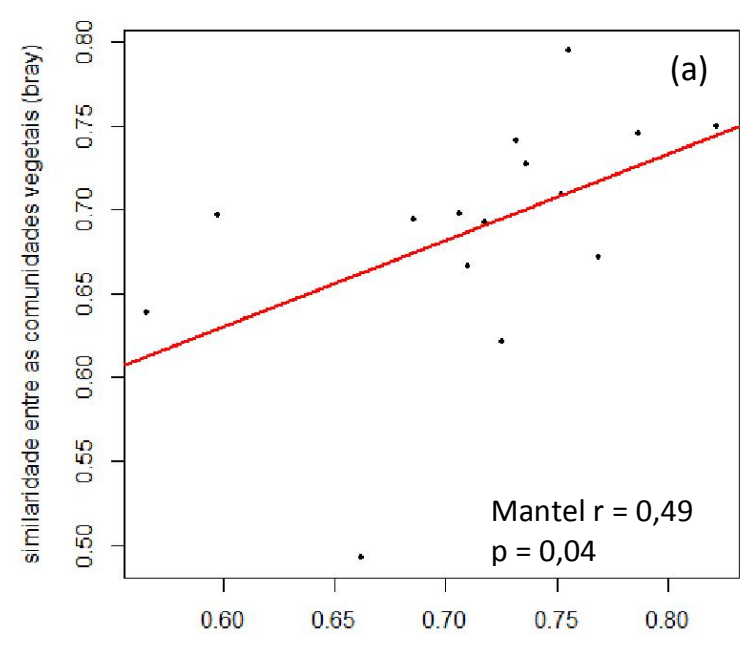

similaridade entre as comunidades de visitantes (bray)

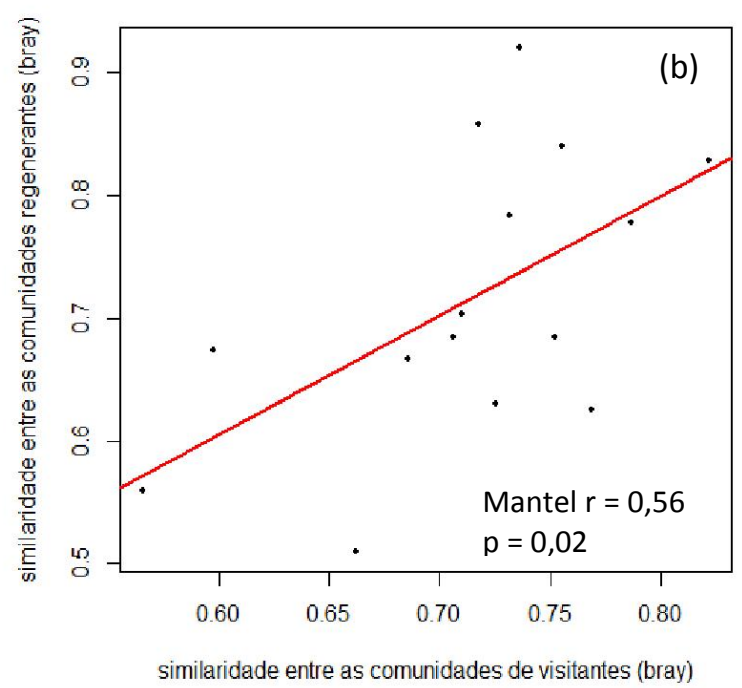

similaridade entre as comunidades de visitantes (bray)

Figura 3.7. Relação entre as similaridades das comunidades de visitantes florais e as comunidades de plantas floridas (a) e as comunidades de plantas regenerantes (b). O s valores de correlação e a significância dos testes são mostrados no canto inferior direito de cada gráfico. 


\section{Discussão}

Embora variem em riqueza e composição de espécies vegetais, todas as áreas restauradas já apresentam plantas fornecedoras de recursos florais para uma comunidade relativamente diversa de visitantes. A variação tanto do número de espécies quanto da composição das comunidades de plantas floridas foi relacionada à maior proporção de espécies regenerantes dentre as plantas de cinco dos seis locais de estudo.

Geralmente, estudos que avaliam a regeneração natural em reflorestamentos são focados na evolução estrutural das florestas plantadas e por isso costumam utilizar alguns critérios de exclusão durante o levantamento de indivíduos regenerantes, descartando por exemplo aqueles que não atingem altura ou diâmetros mínimos, que são de espécies exóticas ou aquelas espécies não florestais (e.g. Souza \& Batista 2004; Melo \& Durigan 2007; Pereira et al. 2013). Com isso, a maioria dos trabalhos tendem a amostrar somente plântulas - sejam oriundas da flora plantada ou de propágulos externos a área - de espécies arbóreas que ainda não produzem flores, negligenciando o tipo de vegetação registrada aqui. Nosso estudo, por avaliar exclusivamente plantas floridas, registrou como regenerantes espécies que normalmente recebem pouca atenção nas avaliações de áreas restauradas: o estrato formado basicamente por herbáceas, arbustivas e lianas que colonizam espontaneamente as áreas restauradas.

A maioria dentre estas espécies regenerantes são tipicamente classificadas como vegetação ruderal ou plantas infestantes: espécies altamente tolerantes a distúrbios e que primeiro colonizam ambientes degradados. Nos estágios iniciais de sucessão das áreas restauradas, espécies deste grupo parecem representar um componente de grande relevância para a disponibilidade adicional de recursos florais aos polinizadores, uma vez que dentre as espécies arbóreas implantadas, apenas poucas espécies pioneiras florescem nesta fase. De fato, em um estudo prévio em uma das áreas restauradas (RD2) quando esta tinha idade entre sete e oito anos, Fragoso \& Varanda (2011) constataram que apenas 10 dentre 45 (22\% da riqueza) das espécies arbóreas implantadas floresciam neste estágio. Nas demais áreas estudadas, esta proporção é provavelmente ainda menor porque aparentemente foram implantadas nelas uma diversidade maior de espécies (observação pessoal).

Apesar das espécies arbóreas pioneiras serem em sua maioria plantas generalistas com floração abundante (como $S$. terebinhifolius e $C$. urucurana, as duas espécies arbóreas que mais receberam visitantes neste estudo), o estrato regenerante é responsável por aumentar bastante a diversidade de recursos florais oferecidos aos polinizadores nas áreas restauradas e, consequentemente, a diversidade de visitantes. Carvalheiro et al. (2011) mostraram que a presença de vegetação ruderal (weeds) em plantações de girassol aumentou a diversidade de visitantes florais, havendo com isso um aumento também na produtividade do cultivo; a maior diversidade de visitantes aumentou inclusive a movimentação do principal polinizador da planta estudada, a abelha europeia Apis mellifera. Em um estudo com florestas restauradas, foi constatado que as plantas regeneradas espontaneamente 
contribuíram mais com a diversificação de atributos funcionais florais presentes entre as espécies do que as árvores plantadas, incluindo sistemas sexuais, modos de polinização biótica e grupos funcionais de polinizadores (Bazarian 2010).

É possível que a vegetação regenerante esteja exercendo um efeito similar nas espécies arbóreas implantadas nas áreas restauradas estudadas, atraindo polinizadores relativamente generalistas que de outra forma não estariam visitando as flores das árvores. Floradas de múltiplas espécies podem facilitar o processo de polinização e elevar o desempenho reprodutivo das plantas envolvidas mesmo quando estas apresentam morfologias distintas, relacionadas a coloração ou estrutura, por exemplo (Ghazoul 2006). A diversidade, composição e densidade de plantas florescendo simultaneamente pode afetar tanto os níveis de generalização quanto a composição da comunidade de polinizadores de uma determinada espécie de planta, com a generalização e as visitas de polinizadores raros geralmente aumentando com o aumento da riqueza e diversidade floral (Lázaro et al. 2009).

Por outro lado, algumas das espécies ruderais registradas são plantas exóticas cosmopolitas (e.g. Momordica charantia, Heliotropium indicum, dentre outras) e seria possível também que ao invés de facilitarem o processo de polinização das espécies arbóreas, elas estejam na realidade competindo com as mesmas por polinizadores. De fato, espécies exóticas invasoras podem competir com espécies nativas por uma série de recursos e limitar sua regeneração natural no sub-bosque de florestas estacionais semideciduais (Mantoani et al. 2013). Experimentos mais aprofundados seriam necessários para esclarecer os mecanismos de interação entre as espécies envolvidas, mas a princípio, a vegetação ruderal regenerante parece trazer benefícios para a comunidade restaurada. Mesmo no caso de espécies exóticas, desde que estas não se comportem como invasoras, alguns autores sugerem que o plantio simultâneo de espécies nativas em consórcio com espécies exóticas pode ser uma alternativa promissora em casos nos quais a área a ser recuperada encontra-se muito degradada e o resgate de serviços ambientais seja prioritário (Costa \& Durigan 2010).

Assim, se entre os objetivos principais da restauração estiver o resgate e a manutenção do serviço ecológico da polinização, pode-se afirmar que o estrato regenerante formado pelas espécies ruderais é crucial para a manutenção de uma comunidade diversa de visitantes, pelo menos nos estágios iniciais da restauração. A variação significativa das métricas das redes na ausência deste componente sugere que a diversidade de espécies arbóreas implantadas não é suficiente para manter os padrões de visitação nem conferir estabilidade às redes de interação da mesma forma que na presença de regenerantes. A diminuição da riqueza de interações tornaria as redes menos seguras frente à extinção de espécies (Dunne et al. 2002) e menores aninhamento e compartimentalização permitiriam a propagação mais rápida de distúrbios na comunidade interativa (Tylianakis et al. 2010). Portanto, a presença de plantas regenerantes floridas provavelmente aumenta a resiliência do serviço da polinização ao permitir que as áreas restauradas abriguem uma comunidade mais diversa de visitantes 
que promoverão a polinização não só nos reflorestamentos mas também em áreas naturais e cultivos agrícolas próximos.

As áreas que apresentaram maior similaridade na composição de espécies floridas mostraram também comunidades de visitantes mais similares, indicando que a comunidade floral influencia fortemente a organização da comunidade de visitantes. Com efeito, é esperado que recursos florais específicos modulem o conjunto de espécies de polinizadores em vários níveis, com a estrutura e diversidade de suas comunidades sendo afetadas por fatores como diversidade e abundância floral e tipo e quantidade de recurso (principalmente pólen e néctar) disponíveis (Potts et al. 2003). Nossas observações sugerem que - no estágio inicial de sucessão florestal estudado - a presença de gramíneas invasoras é um fator que pode estar afetando indiretamente a organização da comunidade de plantas floridas e, consequentemente, o restabelecimento dos polinizadores nas áreas restauradas.

As três áreas de estudo com maior cobertura de gramíneas invasoras foram as que apresentaram as menores diversidades de espécies regenerantes (tabela 3.2), reforçando a correlação negativa existente entre cobertura de gramíneas e abundância/riqueza de espécies já relatada em outros reflorestamentos (Mantoani et al. 2012). Souza \& Batista (2004) sugeriram que nas áreas restauradas estudadas por eles, a persistência da gramínea $P$. maximum poderia estar relacionada à abertura do dossel durante a estação seca - um evento comum nas florestas estacionais semideciduais - e/ou ao espaçamento usado durante o plantio das mudas. Embora não tenhamos avaliados estes aspectos em nossas áreas de estudo, acreditamos que a presença massiva de gramíneas ocorra principalmente devido à falta ou redução de manejo pós-plantio. No caso especifico da área de estudo RD2, localizada na Floresta da USP (ver item 2.1 do capítulo 1), a invasão por gramíneas decorrente do manejo inadequado resultou em dois grandes incêndios que destruíram a maior parte da área reflorestada, uma consequência negativa bastante comum em períodos secos do ano e característicos da região estudada.

Nossos dados demonstram que o controle de gramíneas invasoras em áreas restauradas é importante não só para reduzir os efeitos negativos (comumente discutidos) de sua competição com mudas e plântulas e aumento do risco de incêndios, mas parece também relevante para facilitar o estabelecimento de comunidades mutualísticas de plantas e visitantes florais mais resilientes. Sugerimos que seja dada maior atenção ao estudo de formas alternativas de manejo de gramíneas invasoras que possa promover também a regeneração de outras herbáceas benéficas como as levantadas neste estudo. Recomendamos também cautela na condução do estrato regenerante, pois a remoção da vegetação ruderal junto com as gramíneas durante o manejo poderia ser contra produtivo não só para os polinizadores, mas também para as espécies vegetais implantadas. Por exemplo, a remoção de espécies exóticas pode levar à redução da polinização de uma planta nativa rara ao provocar alterações nas populações de polinizadores que utilizam tanto nativas quanto exóticas como recurso (Carvalheiro et al. 2008). 
Alguns autores apontam que a seleção de plantas para plantio nas áreas a serem recuperadas é uma das questões mais essenciais na restauração dos serviços de polinização: plantas que forneçam pólen e/ou néctar para numerosos polinizadores (framework species), plantas que forneçam recursos durante épocas de escassez (bridging species) e plantas com flores extremamente atrativas em associação com espécies menos atraentes (magnet species) são de extrema relevância para sustentar a comunidade de polinizadores (Dixon 2009; Menz et al. 2011). Aqui, sugerimos extrapolar estes conceitos para além das espécies arbóreas tradicionalmente implantadas, enfatizando a importância de se identificar e talvez até mesmo plantar espécies ruderais que atraiam e sustentem polinizadores durante todo o período que estes necessitem. Principalmente nos estágios iniciais de restauração, quando somente poucos indivíduos arbóreos de poucas espécies pioneiras florescem, a utilização das espécies regenerantes poderia ser crucial para a fixação das populações de polinizadores nas áreas restauradas, seja pelo fornecimento de recursos mais diversos, seja pelo suprimento de recursos quando as espécies arbóreas não estiverem floridas.

Enfatizamos que este estudo avaliou as comunidades restauradas durante um curto intervalo de tempo que representa uma fase ainda inicial de um processo muito longo e dinâmico de restauração de florestas tropicais. Ainda assim, a dominância de poucas espécies arbóreas pioneiras associada à presença abundante de gramíneas invasoras e ao pequeno número de espécies regenerantes em algumas das áreas estudadas (RD1 e RD2) é preocupante pois pode prejudicar a continuidade do processo de restauração nestes locais. Espécies pioneiras tem ciclo de vida curto e podem vir a morrer antes que as espécies climácicas se tornem reprodutivas; se a cobertura de gramíneas impedir a regeneração natural tanto das pioneiras implantadas quanto das ruderais, os reflorestamentos poderão se tornar "desertos" para os polinizadores. Dependendo da evolução da paisagem no entorno das áreas restauradas e da existência ou não de áreas fonte próximas, esse intervalo sem recursos poderiam se refletir em uma perpétua falta de polinizadores mesmo quando as espécies climácicas começassem a florescer. Neste cenário, a reintrodução intencional de espécies seria a única alternativa possível, mas aumentaria ainda mais a complexidade e os custos da restauração. O monitoramento contínuo das áreas restauradas em intervalos regulares de tempo trará luz a estas e outras questões, sendo de extrema relevância para o progresso da restauração ecológica.

Finalmente, devemos ressaltar que todas as espécies interagem com outras em redes complexas. Embora as atividades de conservação e restauração até hoje tenham trabalhado com as espécies que almejam conservar principalmente de forma isolada, a negligência das redes ecológicas nas quais estas espécies estão imersas poderá comprometer o sucesso dos esforços conservacionistas. Um dos maiores desafios da ciência ecológica atual é integrar suas diversas áreas de conhecimento - neste caso biologia da polinização, ecologia de comunidades e ecologia da restauração - para alcançar um maior entendimento do funcionamento dos ecossistemas e traduzir este conhecimento de forma clara para os praticantes da restauração ecológica. 


\section{Referências Bibliográficas}

Bawa, K. (1990) Plant-pollinator interactions in tropical rain forests. Annual Review of Ecology and Systematics, 21, 399-422.

Bawa, K., Bullock, S., Perry, D., Coville, R. \& Grayum, M. (1985) Reproductive biology of tropical lowland rain forest trees. II: Pollination systems. American journal of botany, 72, 346-356.

Bazarian, S. V. (2010) Redes de interação plantas-visitantes florais e a restauração de processos ecológicos em florestas tropicais. Tese (Doutorado em Ecologia) - Instituto de Biociências, Universidade de São Paulo, São Paulo. 145p.

Carvalheiro, L.G., Barbosa, E.R.M. \& Memmott, J. (2008) Pollinator networks, alien species and the conservation of rare plants: Trinia glauca as a case study. Journal of Applied Ecology, 45, 14191427.

Carvalheiro, L.G., Veldtman, R., Shenkute, A.G., Tesfay, G.B., Pirk, C.W.W., Donaldson, J.S. \& Nicolson, S.W. (2011) Natural and within-farmland biodiversity enhances crop productivity. Ecology letters, 14, 251-259.

Chazdon, R. (2008) Beyond deforestation: restoring forests and ecosystem services on degraded lands. science, 320, 1458-1460.

Clarke, K. (1993) Non-parametric multivariate analyses of changes in community structure. Australian journal of ecology, 18, 117-143.

Costa, J. \& Durigan, G. (2010) Leucaena leucocephala (Lam.) de Wit (Fabaceae): invasive or ruderal? Revista Árvore, 34, 825-833.

Cunningham, S. A. (2000) Depressed pollination in habitat fragments causes low fruit set. Proceedings of The Royal Society B: Biological sciences, 267, 1149-1152.

Dixon, K.W. (2009) Pollination and restoration. Science, 325, 571-573.

Dormann, C.F., Gruber, B. \& Fründ, J. (2008) Introducing the bipartite Package : Analysing Ecological Networks. , 8, 8-11.

Dunne, J. A., Williams, R.J. \& Martinez, N.D. (2002) Network structure and biodiversity loss in food webs: robustness increases with connectance. Ecology Letters, 5, 558-567.

Fischer, J. \& Lindenmayer, D.B. (2007) Landscape modification and habitat fragmentation : a synthesis. Global Ecology and Biogeography, 16, 265-280.

Fragoso, F.P. (2009) A entomofauna visitante floral de espécies arbóreas da Floresta da USP-RP, área de restauração de Mata Estacional Semidecidual. Dissertação (Mestrado em Entomologia) Faculdade de Filosofia, Ciências e Letras de Ribeirão Preto, Ribeirão Preto, 77p.

Fragoso, F.P. \& Varanda, E.M. (2011) Flower-visiting insects of five tree species in a restored area of semideciduous seasonal forest. Neotropical entomology, 40, 431-435.

Ghazoul, J. (2005) Pollen and seed dispersal among dispersed plants. Biological reviews of the Cambridge Philosophical Society, 80, 413-443.

Ghazoul, J. (2006) Floral diversity and the facilitation of pollination. Journal of Ecology, 94, 295-304. 
Hobbs, R., Higgs, E. \& Harris, J. (2009) Novel ecosystems: implications for conservation and restoration. Trends in ecology \& evolution, 24, 599-605.

Instituto Florestal. (2005) Inventário florestal da vegetação natural do Estado de São Paulo. São Paulo: Imprensa oficial.

Kevan, P. \& Baker, H. (1983) Insects as flower visitors and pollinators. Annual review of entomology, 28, 407-453.

Lázaro, A., Lundgren, R. \& Totland, $\varnothing$. (2009) Co-flowering neighbors influence the diversity and identity of pollinator groups visiting plant species. Oikos, 118, 691-702.

Legendre, P. \& Legendre, L. (1998) Numerical Ecology, second eng. Elsevier Science B.V., Amsterdam, The Netherlands.

Mantoani, M.C., Andrade, G.R. De, Cavalheiro, A.L. \& Torezan, J.M.D. (2012) Efeitos da invasão por Panicum maximum Jacq. e do seu controle manual sobre a regeneração de plantas lenhosas no sub-bosque de um reflorestamento. Semina: Ciências Biológicas e da Saúde, 33, 97-110.

Mantoani, M.C., Dias, J., Orsi, M. \& Torezan, J. (2013) Efeitos da invasão por Tradescantia zebrina Heynh. sobre regenerantes de plantas arbóreas em um fragmento de floresta estacional semidecidual secundária. Revista Biotemas, 26, 63-70.

Melo, A. \& Durigan, G. (2007) Evolução estrutural de reflorestamentos de restauração de matas ciliares no Médio Vale do Paranapanema. Scientia Forestalis, 73, 101-111.

Menz, M.H.M., Phillips, R.D., Winfree, R., Kremen, C., Aizen, M. A., Johnson, S.D. \& Dixon, K.W. (2011) Reconnecting plants and pollinators: challenges in the restoration of pollination mutualisms. Trends in plant science, 16, 4-12.

Michener, C. (2007) The Bees of the World, second ed. The Johns Hopkins University Press, Baltimore.

Oksanen, J. (2013) Multivariate analysis of ecological communities in R: vegan tutorial. $R$ package version, 43.

Palmer, M. \& Filoso, S. (2009) Restoration of ecosystem services for environmental markets. Science, $325,575-6$.

Pereira, L., Oliveira, C. \& Torezan, J. (2013) Woody species regeneration in Atlantic Forest restoration sites depends on surrounding landscape. Natureza \& Conservacao, 11, 138-144.

Potts, S., Vulliamy, B., Dafni, A., Ne'eman, G. \& Willmer, P. (2003) Linking bees and flowers: how do floral communities structure pollinator communities? Ecology, 84, 2628-2642.

R Development Core Team. 2012. R: A language and environment for statistical computing. $R$ Foundation for statistical computing, Viena, Áustria, ISBN 3-900051-07-0.

Rey Benayas, J.M., Newton, A.C., Diaz, A. \& Bullock, J.M. (2009) Enhancement of biodiversity and ecosystem services by ecological restoration: a meta-analysis. Science, 325, 1121-1124.

Rodrigues, A., Andelman, S. \& Bakarr, M. (2004) Effectiveness of the global protected area network in representing species diversity. Nature, 428, 640-643.

Roulston, T.H. \& Goodell, K. (2011) The role of resources and risks in regulating wild bee populations. Annual review of entomology, 56, 293-312. 
Souza, F.M. \& Batista, J.L.F. (2004) Restoration of seasonal semideciduous forests in Brazil: influence of age and restoration design on forest structure. Forest Ecology and Management, 191, 185200.

Suding, K.N. (2011) Toward an era of restoration in ecology: successes, failures, and opportunities ahead. Annual Review of Ecology, Evolution, and Systematics, 42, 465-487.

Tabarelli, M., Silva, J. da \& Gascon, C. (2004) Forest fragmentation, synergisms and the impoverishment of neotropical forests. Biodiversity \& Conservation, 13, 1419-1425.

Tylianakis, J.M., Laliberté, E., Nielsen, A. \& Bascompte, J. (2010) Conservation of species interaction networks. Biological Conservation, 143, 2270-2279. 


\section{RESTAURANDO PROCESSOS ECOLÓGICOS: ESTRUTURA E ROBUSTEZ DAS REDES DE INTERAÇÃO PLANTA-POLINIZADOR EM FLORESTAS TROPICAIS RESTAURADAS}

\section{Introdução}

A polinização por animais é um processo ecológico critico em praticamente todos os ecossistemas terrestres, e especialmente relevante em florestas tropicais (Bawa et al. 1985; Bawa 1990; Ollerton et al. 2011). A dependência humana da polinização biótica demonstra ainda a magnitude do serviço ecossistêmico prestado pelos polinizadores: $75 \%$ dos cultivos agrícolas mais importantes globalmente apresentam maior rendimento quando polinizados por animais (Klein et al. 2007), um benefício de grande impacto também na economia (Gallai et al. 2009). No entanto, tanto o funcionamento dos ecossistemas quanto o aprovisionamento de serviços ecológicos são positivamente relacionados à biodiversidade (Loreau et al. 2001), o que indica que ambos encontram-se em risco frente a crescente perda de espécies.

Particularmente, as evidências recentes do declínio de polinizadores nativos tanto em abundância quanto em diversidade tem gerado preocupação cada vez maior (Allen-Wardell et al. 1998; Kearns et al. 1998; Kremen \& Ricketts 2000; Biesmeijer et al. 2006). A perda de recursos florais devido ao desaparecimento de populações vegetais representa uma séria ameaça aos polinizadores (Kearns et al. 1998), cujas populações tem diminuído devido à modificação contínua dos habitats (SteffanDewenter \& Tscharntke 1999; Winfree et al. 2009; Carvalheiro et al. 2010; Winfree et al. 2011). Por outro lado, existem também indícios de que a perda de polinizadores pode levar à extinção local de espécies de plantas (Biesmeijer et al. 2006) e de que a ruptura das interações planta-polinizador pode agir como filtro biológico influenciando os limites espaciais da distribuição geográfica das espécies vegetais (Chalcoff et al. 2012).

Frente a extinção crescente de populações locais e até mesmo de espécies, enfrentamos hoje o desafio de não só conservar mas também o de restaurar os ecossistemas visando a manutenção da biodiversidade. A restauração ecológica tem conseguido promover o aumento da biodiversidade e do fornecimento de serviços ecossistêmicos em relação ao estado previamente degradado (Rey Benayas et al. 2009), embora seus resultados sejam ainda bastante variáveis dependendo dos parâmetros avaliados (Godefroid et al. 2011; Suding 2011). No caso específico da restauração de floresta tropicais, embora muitas áreas mostrem uma aparentemente rápida recuperação da cobertura vegetal (Souza \& Batista 2004; Melo \& Durigan 2007; Rodrigues et al. 2009), pouco se sabe a respeito da recuperação 
das interações ecológicas. Tendo em vista a ameaça crescente enfrentada pelos polinizadores e seu papel crucial na reprodução sexual das espécies vegetais, é surpreendente a escassez de trabalhos avaliando a resposta destes organismos a restauração ecológica (mas veja Forup \& Memmott 2005; Forup et al. 2008; Bazarian 2010; Williams 2011).

Neste trabalho, utilizamos redes complexas de interação (Memmott 1999; Jordano et al. 2002; Bascompte et al. 2003) para analisar comunidades de plantas e polinizadores em seis áreas restauradas de Floresta Estacional Semidecidual. Esta ferramenta tem se mostrado bastante útil na avaliação dos resultados da restauração de alguns ecossistemas temperados (Forup \& Memmott 2005; Forup et al. 2008; Williams 2011) e, além de facilitar o exame de diversos atributos da comunidade, permite também testar o impacto da extinção de espécies na estrutura das redes tróficas (Memmott et al. 2004). Para avaliar o restabelecimento do processo de polinização nas áreas restauradas, analisamos redes de visitação e redes de transporte de pólen quantitativas e algumas métricas descritivas de sua estrutura. $\mathrm{O}$ exame da resiliência de todas as comunidades estudadas por meio do cálculo da robustez de cada tipo de rede à extinção de espécies teve por objetivo determinar quais grupos de plantas e polinizadores são mais importantes na sustentação destas comunidades. Os padrões de visitação foram comparados aos padrões de movimento de pólen para se constatar a utilidade destes dois métodos neste tipo de avaliação. Buscou-se assim verificar a eficácia dos programas de restauração em restabelecer o processo de polinização bem como gerar informações relevantes que possam contribuir para o desenvolvimento de ferramentas de avaliação e indicadores de restauração.

\section{Material e Métodos}

\section{1. Áreas de estudo}

O estudo foi realizado em seis áreas em processo de restauração de Floresta Estacional Semidecidual, fisionomia pertencente ao bioma Mata Atlântica e caracterizada por demarcada sazonalidade climática (verão chuvoso seguido de prolongado período de estiagem). Os locais estão distribuídos por quatro municípios da região de Ribeirão Preto, nordeste do Estado de São Paulo, Brasil (tabela 4.1). Toda região apresenta menos de $17 \%$ de sua área coberta por vegetação nativa (Rodrigues \& Hott 2010), sendo a terra primariamente ocupada pelo cultivo de cana-de-açúcar. Em todas as áreas escolhidas a restauração foi iniciada por meio do plantio de mudas de espécies arbóreas nativas e, no início do estudo, suas idades variavam entre 5 e 10 anos. Metade das áreas restauradas foi implantada a uma distância linear maior que 1000 m do fragmento remanescente mais próximo e a outra metade foi implantada imediatamente ao lado de fragmentos pré-existentes. No início do levantamento dos dados, a remoção de gramíneas invasoras havia sido completada recentemente em todas as áreas, que apresentavam portanto sub-bosque em condições similares. Contudo, ao longo do 
desenvolvimento do trabalho, foi notado que a prática de remoção das gramíneas foi reduzida ou cancelada em metade das áreas de estudo. Assim, três dos locais apresentavam o solo massivamente coberto por gramíneas africanas invasoras como Panicum maximum Jacq. Cv. (colonião) e/ou Brachiaria sp., enquanto os outros três locais apresentavam maior quantidade de espécies ruderais regeneradas espontaneamente.

Tabela 4.1. Características das áreas restauradas

\begin{tabular}{ccccccc}
\hline Código & Latitude & Longitude & $\begin{array}{c}\text { Data de } \\
\text { plantio }\end{array}$ & $\begin{array}{c}\text { Distância ao } \\
\text { fragmento } \\
\text { mais próximo } \\
(\mathrm{m})\end{array}$ & $\begin{array}{c}\text { Grau de } \\
\text { invasão por } \\
\text { gramíneas }\end{array}$ & $\begin{array}{c}\text { Localização (\% de } \\
\text { cobertura vegetal do } \\
\text { município*) }\end{array}$ \\
\hline RA 1 & $21^{\circ} 5.816^{\prime} \mathrm{S}$ & $48^{\circ} 4.737^{\prime} \mathrm{O}$ & 2003 & 0 & moderado & Sertãozinho $(2,32)$ \\
RA 2 & $21^{\circ} 15.642^{\prime} \mathrm{S}$ & $48^{\circ} 26.453^{\prime} \mathrm{O}$ & 2007 & 0 & intenso & Monte Alto $(4,71)$ \\
RA3 & $21^{\circ} 17.970^{\prime} \mathrm{S}$ & $48^{\circ} 21.001^{\prime} \mathrm{O}$ & 2006 & 0 & moderado & Jaboticabal $(1,57)$ \\
RD 1 & $21^{\circ} 15.349^{\prime} \mathrm{S}$ & $48^{\circ} 24.856^{\prime} \mathrm{O}$ & 2007 & 1158 & intenso & Jaboticabal $(1,57)$ \\
RD 2 & $21^{\circ} 9.003^{\prime} \mathrm{S}$ & $47^{\circ} 51.759^{\prime} \mathrm{O}$ & 2002 & 3000 & intenso & Rib. Preto $(3,28)$ \\
RD 3 & $21^{\circ} 17.508^{\prime} \mathrm{S}$ & $48^{\circ} 20.992^{\prime} \mathrm{O}$ & 2005 & 1050 & moderado & Jaboticabal $(1,57)$ \\
\hline
\end{tabular}

*Dados retirados de Instituto Florestal (2005).

\subsection{Amostragem}

Plantas floridas, visitantes florais e suas interações foram registrados entre dezembro de 2011 e outubro de 2012 em expedições de campo bimestrais. Em cada local foram estabelecidos 5 transectos de aproximadamente 50 metros, totalizando cerca de 250 metros, situados sempre perpendicularmente à borda para que em todos os locais fossem amostradas proporções semelhantes de borda e interior de cada área. As amostragens foram todas realizadas em dias secos, ensolarados e com ventos moderados. Imediatamente antes de cada sessão de coleta, foram registradas a abundância e a riqueza de espécies em floração em cada transecto; quando possível as espécies foram identificadas in situ e para as demais foram preparadas exsicatas para posterior identificação. Para cada espécie vegetal florida registrada, botões florais em pré-antese foram coletados e armazenados em álcool 70\% para posterior identificação. Após este registro, dois coletores caminharam pelos transectos alternadamente durante períodos de 30 minutos a cada hora entre $07 \mathrm{~h} 30$ e 16h30; quando não era possível completar todos os transectos dentro de 30 minutos, a amostragem no próximo período continuava do ponto onde havia parado no período anterior. Os visitantes observados nas flores foram capturados com rede entomológica na ordem em que foram avistados, e cada coletor 
permaneceu no máximo cinco minutos em cada planta florida. A espécie vegetal sendo visitada pelo inseto foi registrada para se obter os dados de visitação. Os insetos coletados foram colocados em câmaras mortíferas contendo acetato de etila e revestidas com papel filtro, o qual foi trocado por um novo após cada captura para evitar contaminação entre grãos de pólen de diferentes visitantes.

\subsection{Triagem e análise do material coletado}

Os botões armazenados em álcool foram utilizados para retirada de grãos de pólen que foram depositados em lâminas com gelatina glicerinada e seladas com parafina. Assim, foi construída uma coleção referência de grãos de pólen de todas as plantas floridas registradas nas áreas de estudo. Cada inseto coletado foi examinado sob estereomicroscópio para verificar presença ou não de pólen aderido ao corpo. Quando presentes, os grãos de pólen foram recolhidos em cubos de gelatina glicerinada sistematicamente pressionados na superfície do inseto. Os cubos contendo material polínico foram então depositados em lâminas semipermanentes seladas com parafina. Todos os insetos foram então identificados até o menor nível taxonômico possível.

As amostras de pólen retiradas dos insetos foram identificadas em microscópio ótico usando a coleção referência para comparação. No entanto, alguns grãos de pólen não eram facilmente distinguidos sob microscopia ótica e nestes casos foram criados grupos polínicos englobando espécies. Assim, os seguintes agrupamentos foram criados: (1) Tabebuia sp. e Tabebuia roseo-alba; (2) Euphorbiaceae sp1 e Mabea fistulifera; (3) Croton floribundus, Croton glandulosus, indeterminada sp6 e indeterminada sp7; (4) Sida sp1, Sida sp2 e indeterminada sp13; (5) Melastomataceae sp1 e Melastomataceae sp2; (6) Solanum sp1 e Solanum sp3; (7) Fabaceae sp4 e indeterminada sp 12; (8) Platypodium elegans e indeterminada sp2; (9) Crotalaria spectabilis e Fabaceae sp7; (10) Lafoensia pacari, Chamaecrista desvauxii e Chamaecrista sp. Esta dificuldade foi especialmente maior na família Asteraceae, onde também foram agrupadas: (1) Sonchus oleraceus e Asteraceae sp5; (2) Bidens sp. e Bidens subalternans; (3) Asteraceae sp1, Eclipta prostrata e Asteraceae sp2 e (4) Ageratum conyzoides, Baccharis sp1, Baccharis sp2, Conyza sp1, Conyza sp2, Emilia fosbergii, Emilia sonchifolia, Mikania sp, Vernonia sp1 e Asteraceae sp3. Os grãos de pólen que não pertenciam a nenhuma das espécies da coleção referência foram registrados como espécies desconhecidas.

\subsection{Análise dos dados}

Para cada área estudada, os estimadores não-paramétricos de riqueza Chao (Chao 1987), jackknife de primeira e segunda ordem (Palmer 1991) e bootstrap (Smith \& Van Belle 1984) foram calculados através da função specpool do pacote vegan (Oksanen 2013) do programa R (R Development Core Team 2012).

Para avaliar o restabelecimento do processo de polinização nas áreas restauradas, os dados coletados foram usados para construir dois tipos de rede para cada área de estudo: redes de visitação 
e redes de transporte de pólen. Redes de visitação mostram como os insetos respondem à oferta de recursos florais como pólen e néctar e tem sido consideradas como análogas às redes de interação planta-polinizador em diversos trabalhos (Memmott 1999), incluindo estudos sobre restauração (Forup \& Memmott 2005; Forup et al. 2008; Bazarian 2010; Williams 2011). Embora ignorem diferenças potenciais entre polinizadores devido a quantidades e qualidades de pólen que os mesmos transferem (Bosch et al. 2009), estas redes tem sido consideradas como um correlato razoável para a polinização. Já as redes de transporte de pólen mostram as espécies de pólen transportadas por cada espécie de inseto (Forup \& Memmott 2005; Forup et al. 2008); os insetos vetores de pólen são considerados potenciais polinizadores já que a contagem de grãos de pólen do corpo dos visitantes florais é correlacionada à sua efetividade em depositar os grãos no estigma das flores (Howlett et al. 2011). Para ambos os tipos de redes foram calculadas a riqueza de insetos (visitando flores ou transportando pólen) e a riqueza de plantas (sendo visitadas ou tendo pólen transportado). As métricas conectância, diversidade de interações, equabilidade de interações, compartimentalização, especialização e aninhamento também foram calculadas por se tratarem de atributos relacionados à estabilidade e funcionamento das redes (Tylianakis et al. 2010). Mais detalhes sobre estas métricas estão descritos na seção 2.3 do capítulo 2 . A construção das redes e o cálculo das métricas foram realizados pelo pacote bipartite (Dormann et al. 2008) também do programa $\mathrm{R}$ ( $\mathrm{R}$ Development Core Team 2012).

Para modelar a resposta de cada rede à perda de espécies, foram simuladas cascatas de extinção através da remoção de espécies de um nível trófico e observação das extinções secundárias resultantes (Dunne et al. 2002; Memmott et al. 2004). Três diferentes algoritmos de remoção de espécies foram utilizados. Na remoção aleatória, proporções crescentes de espécies foram removidas aleatoriamente e sem reposição, sendo esta operação repetida 300 vezes. A remoção aleatória representa um modelo nulo ao qual comparar os outros dois tipos de remoção sistemática, nos quais as espécies são eliminadas de acordo com o número de interações das quais participam: da espécie menos para a mais conectada na rede e contrariamente, da espécie que participa de mais interações (mais generalista) para a que participa menos (mais especialista). O procedimento foi repetido duas vezes, a primeira simulando apenas a extinção de polinizadores e a segunda simulando a extinção de plantas. A robustez de cada rede à extinção de espécies pelos três diferentes algoritmos foi então calculada como a área abaixo da curva de extinção gerada pelo procedimento de simulação descrito. Este parâmetro foi desenvolvido por Burgos et al. (2007) baseado na curva de extinção primeiramente proposta por Memmott et al. (2004), de modo a descrever o padrão de resposta das espécies na rede em uma única variável. Valores próximo a 1 correspondem a curvas que decrescem suavemente, indicando um sistema bastante robusto; em oposição, valores próximos a 0 correspondem a curvas abruptas, indicando um sistema frágil onde espécies são extintas facilmente. Todos os cálculos foram efetuados por meio das funções second.extinct e robustness do pacote bipartite (Dormann et al. 2008). 
Finalmente, a robustez e as métricas das redes de visitação e de transporte de pólen foram comparadas por meio de análises de variância (ANOVA) utilizando se a distância de implantação e a presença ou não de gramíneas como fatores fixos. Quando encontradas diferenças significativas, foi realizado o teste de Tukey para comparações múltiplas. Riqueza e abundância de insetos e plantas foram comparados por meio de testes $t$ pareados.

\section{Resultados}

No geral, foram observadas 94 espécies de plantas floridas sendo visitadas por 1244 insetos de 224 morfoespécies. Destes, 740 insetos de 132 morfoespécies transportavam grãos de 66 tipos polínicos, incluindo 19 tipos desconhecidos. Em todas as áreas de estudo, o número de insetos observado foi muito menor que a riqueza sugerida pelos estimadores não-paramétricos (tabela 4.2). Para todos os locais, a riqueza observada foi quatro-quintos daquela estimada pelo bootstrap, cerca de dois-terços da estimada pelo jackknife 1 e cerca de dois-quintos da calculada pelo jackknife 2. Chao predisse uma riqueza ainda maior, mas seu desempenho parece ter sido extremo para a área RD1.

As redes de visitação e transporte de pólen são mostradas na figura 4.1. Em todas elas, é aparente que Hymenoptera e Diptera dominam as comunidades de insetos, enquanto Lepidoptera apresenta riqueza expressiva apenas nas áreas com maior quantidade de herbáceas regenerantes (RA1, RA3 e RD3). Nas redes de transporte de pólen a quantidade de insetos pertencentes a esta ordem é ainda menor, variando de nenhuma (área RA2) a no máximo cinco espécies (RA3). Já o número de espécies de plantas que receberam visitas foi menor que a riqueza de plantas floridas registradas em todas as áreas; o número de tipos polínicos sendo transportados pelos insetos, no entanto, foi sempre maior que o de plantas visitadas e, nas áreas RA1 e RD2, maior inclusive que o número de espécies de plantas floridas (figura 4.2).

Tabela 4.2. Riqueza de espécies observada e estimada nas seis áreas restauradas de Floresta Estacional Semidecidual.

\begin{tabular}{ccccccc}
\hline \multirow{2}{*}{$\begin{array}{c}\text { Área de } \\
\text { estudo }\end{array}$} & $\begin{array}{c}\text { Riqueza de } \\
\text { plantas } \\
\text { floridas }\end{array}$ & No. espécies & Chao & Jackknife1 & Jackknife2 & Bootstrap \\
\cline { 3 - 7 } & 16 & 72 & 147,0 & 120,5 & 153,1 & 92,3 \\
& 14 & 65 & 203,8 & 114,5 & 154,9 & 84,6 \\
RA 1 & 30 & 77 & 270,3 & 135,4 & 184,7 & 100,1 \\
RA 2 & 7 & 26 & 290,5 & 48,8 & 70,4 & 34,6 \\
RA 3 & 10 & 59 & 176,55 & 104,6 & 141,0 & 77,1 \\
RD 1 & 27 & 72 & 190,2 & 122,5 & 161,9 & 92,4 \\
RD 2 & & & & & & \multicolumn{5}{c}{ Insetos } \\
RD 3 & & &
\end{tabular}



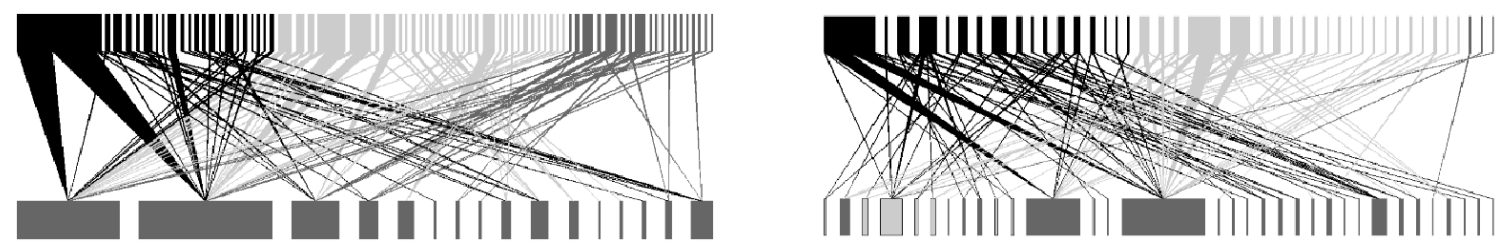

RA1
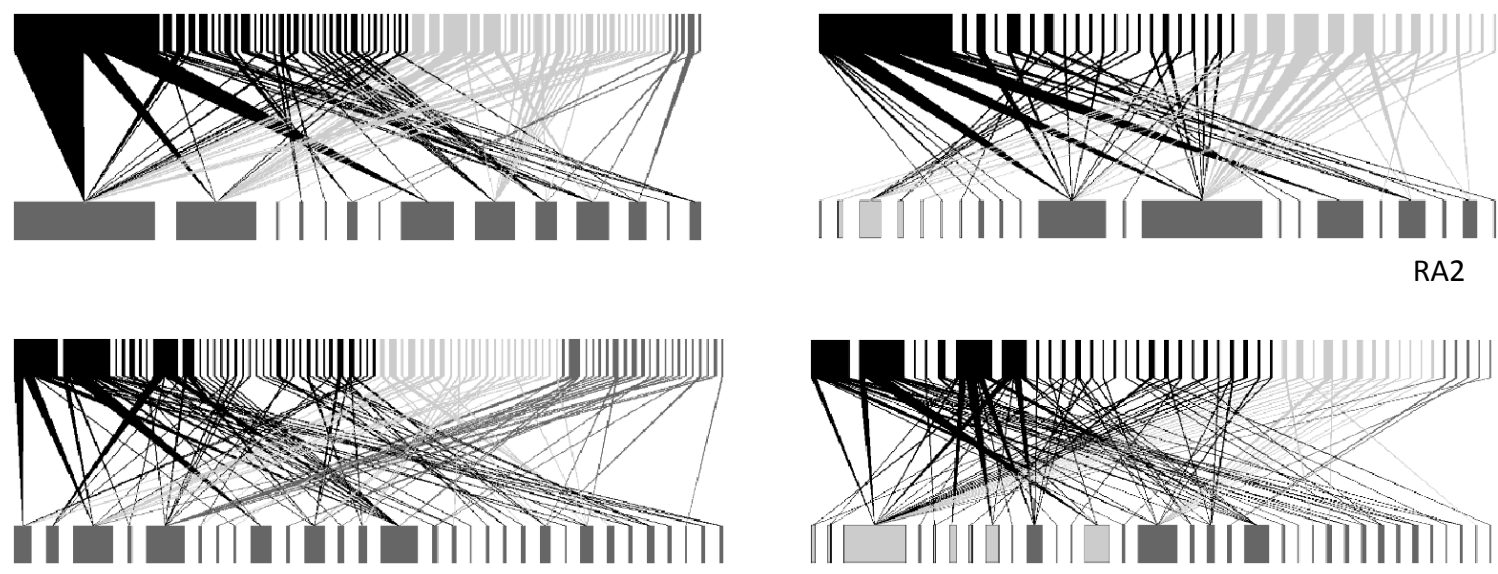

RA3
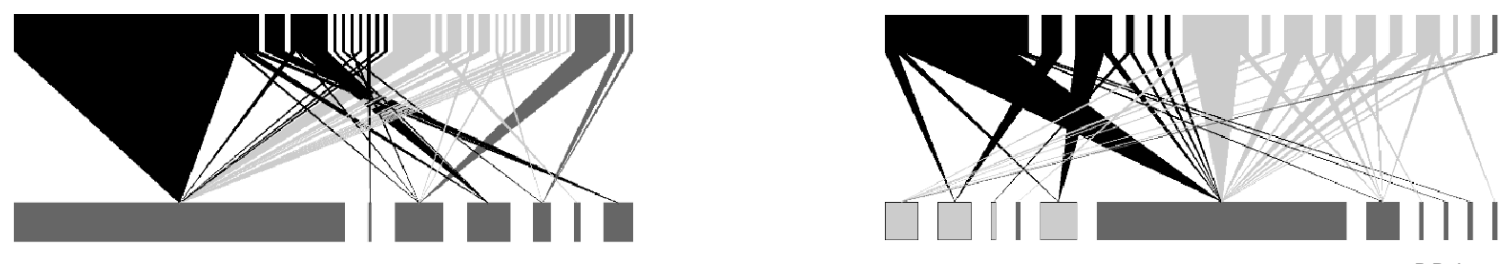

RD1
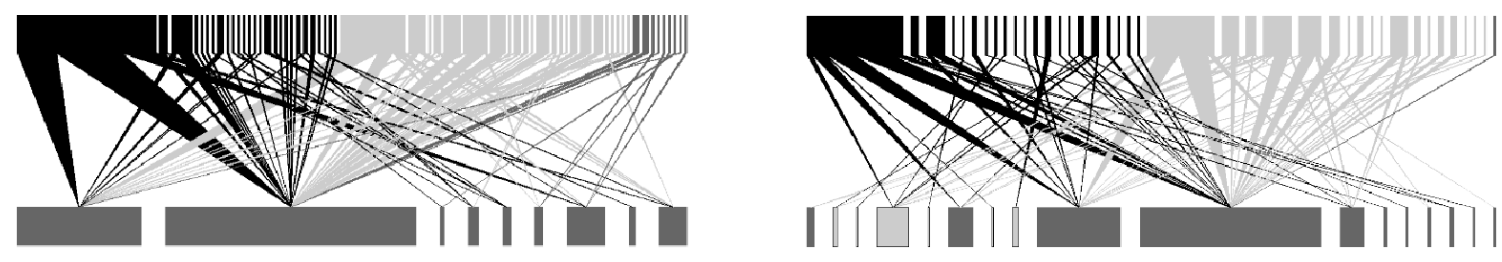

RD2
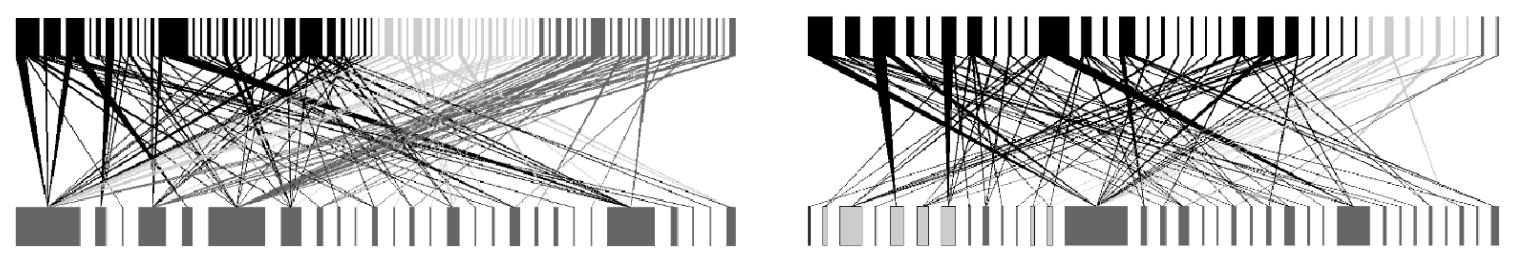

RD3

Figura 4.1. Redes de visitação (esquerda) e redes de transporte de pólen (direita) nas seis áreas restauradas de Floresta Estacional Semidecidual. Espécies de plantas/grupos de pólen são indicadas pelos retângulos abaixo de cada rede; espécies de insetos pelos retângulos acima, e interações são representadas pelas ligações entre os retângulos. A frequência de cada interação é indicada pela espessura da linha e a abundância relativa de cada espécie pela largura do retângulo. Hymenoptera está indicado em preto, Diptera em cinza claro e Lepidoptera em cinza escuro. 
As redes de visitação e de transporte de pólen diferiram somente quanto à abundância e riqueza de insetos ( $t=3,6 ; p=0,01$ para abundância e $t=6,0 ; p=0,001$ para riqueza) e à riqueza de plantas visitadas e tipos polínicos transportados $(t=-3,6 ; p=0,01)$. No geral, embora o número de espécies de insetos transportando grãos de pólen tenha sido menor que o número visitando flores, a riqueza de tipos polínicos transportados foi maior que a riqueza de plantas visitadas. As métricas estruturais das redes não apresentaram diferenças entre os dados de visitação e de transporte de pólen (tabela 4.3). Embora não tenha havido, em nenhuma das métricas dos dois tipos de rede, efeito da distância das áreas restauradas aos fragmentos mais próximos $n(F=1,6 ; p=0,19)$, há evidência de que a ocupação do estrato herbáceo por gramíneas invasoras ou ruderais tem impacto nas redes de transporte de pólen $(F=3,4 ; p=0.06)$. Quando comparadas, as áreas com maior quantidade de espécies vegetais ruderais apresentaram em média o dobro de tipos polínicos sendo transportados $(33,3 \pm 0,6)$ que as áreas com alta invasão por gramíneas $(16,3 \pm 5)$.

A remoção de polinizadores pelos três diferentes algoritmos (aleatória; espécies menos para mais conectadas; espécies mais para menos conectadas) causou, no geral, diferentes padrões de extinção secundária das espécies de plantas (figura 4.3). Estas diferenças foram, no entanto, menos pronunciadas nas redes de visitação (figura 4.3 a-f) do que nas redes de transporte de pólen (figura 4.3 g-I). Nestas últimas, a remoção aleatória de polinizadores causou sempre um declínio essencialmente linear das espécies de plantas. Já a remoção sistemática das espécies menos conectadas primeiro levou a uma perda bem pequena de espécies de plantas até que cerca de $60-70 \%$ dos polinizadores fossem eliminados, quando então a queda no número de plantas se precipitou rapidamente. Por último, a remoção sistemática começando pelas espécies mais conectadas resultou numa perda cumulativa mais rápida das espécies de plantas; embora também essencialmente regular, este decréscimo representou o cenário mais dramático de extinção das espécies vegetais. Nas redes de visitação, estes três padrões de extinção descritos foram bastante similares nas áreas RA3 e RD3 (figura 4.3 c,f) e parecidos, mas com diferenças menores entre si, nas áreas RA1 e RA2 (figura 4.3 a,b); no entanto, as redes de visitação das áreas RD1 e RD2 responderam à extinção de espécies de polinizadores da mesma maneira, independentemente do algoritmo de remoção de espécies utilizado (figura 4.3 d,e). Consequentemente, quando analisada a robustez média de cada tipo de rede à extinção de polinizadores, as redes com dados de visitação mostraram robustez diferente a ambas extinções sistemáticas daquela das redes com dados de transporte de pólen $(F=27,5 ; p=0,000)$; não houve diferença entre os tipos de rede, contudo, quanto à robustez perante a remoção aleatória de espécies (teste de Tukey, $\mathrm{p}=0,98$ ).

Já a remoção das espécies de plantas também resultou em diferentes padrões de extinção secundária das espécies de polinizadores (figura 4.4), cada um deles (em resposta à remoção aleatória; de espécies menos para mais conectadas; de espécies mais para menos conectadas) bastante similar entre os dois tipos de rede (robustez resultante não diferiu: $F=69,8 ; p=0,000$ ) e também entre as 
diferentes áreas de estudo. A remoção aleatória de plantas levou a uma queda praticamente linear das espécies de polinizadores, enquanto a remoção sistemática começando pelas espécies menos conectadas mostrou uma queda muito lenta do número de espécies de polinizadores, com perdas expressivas ocorrendo apenas quando cerca de 60\% (para as redes de visitação, figura 4.4 a-f) ou $80 \%$ (para as redes de transporte de pólen, figura $4.4 \mathrm{~g}-\mathrm{l}$ ) das espécies de plantas foram removidas. Mais uma vez, a remoção das espécies de plantas mais conectadas primeiro provocou a queda mais rápida de espécies de polinizadores; na maioria dos casos, a curva de extinção foi mais pronunciada durante a remoção de $10 \%$ das plantas mais conectadas, com a queda tornando-se então menos acentuada e mais constante com as remoções seguintes.

Quando comparadas as respostas das redes à extinção de espécies pelos diferentes algoritmos de remoção, houve diferença significativa entre os três métodos em cada uma das redes $(F=47,0 ; p=0,000$ para extinção de polinizadores; $F=618,4 ; p=0,000$ para extinção de plantas), excluindo-se a remoção aleatória e a começando pelas espécies mais conectadas de polinizadores nas redes de visitação (teste de Tukey $p=0,98$; figura 4.5). Sem exceção, a robustez das redes sempre foi maior à perda de espécies especialistas (menos conectadas) primeiro; a robustez à perda aleatória de espécies exibiu valores intermediários; e a robustez à extinção inicial de espécies generalistas (mais conectadas) foi menor, indicando que a perda deste grupo leva ao colapso mais imediato das redes de interação.

Considerando que a possível extinção das espécies mais conectadas (polinizadores generalistas que visitam um grande número de espécies de plantas ou plantas generalistas que recebem um grande número de espécies de visitantes) representa o maior risco de colapso das redes de interação plantapolinizador e, portanto, risco de colapso do processo de polinização, listamos na tabela 4.4 as espécies que participaram de mais interações considerando o conjunto total de dados coletados. Estas espécies de inseto e de planta representam um componente essencial para a manutenção das redes de polinização nas áreas restauradas.

Não houve qualquer diferença na robustez das redes de visitação e de transporte de pólen entre áreas restauradas a diferentes distâncias dos fragmentos de vegetação nativa $(F=0,2 ; p=0,6$ para extinção de polinizadores; $F=0,07 ; p=0,7$ para extinção de plantas), independente do algoritmo utilizado para remoção de espécies. No entanto, a robustez das redes de visitação à perda de polinizadores foi menor $(F=4,8 ; p=0,04)$ nas áreas com maior quantidade de espécies vegetais ruderais $(0,69 \pm 0,15)$ do que nas áreas com alta quantidade de gramíneas $(0,78 \pm 0,07)$. Não houve qualquer efeito deste fator sobre a resposta das redes à extinção de espécies de plantas $(F=0,1 ; p=0,6$ para redes de visitação; $F=0,1 ; p=0,6$ para redes de transporte de pólen). 


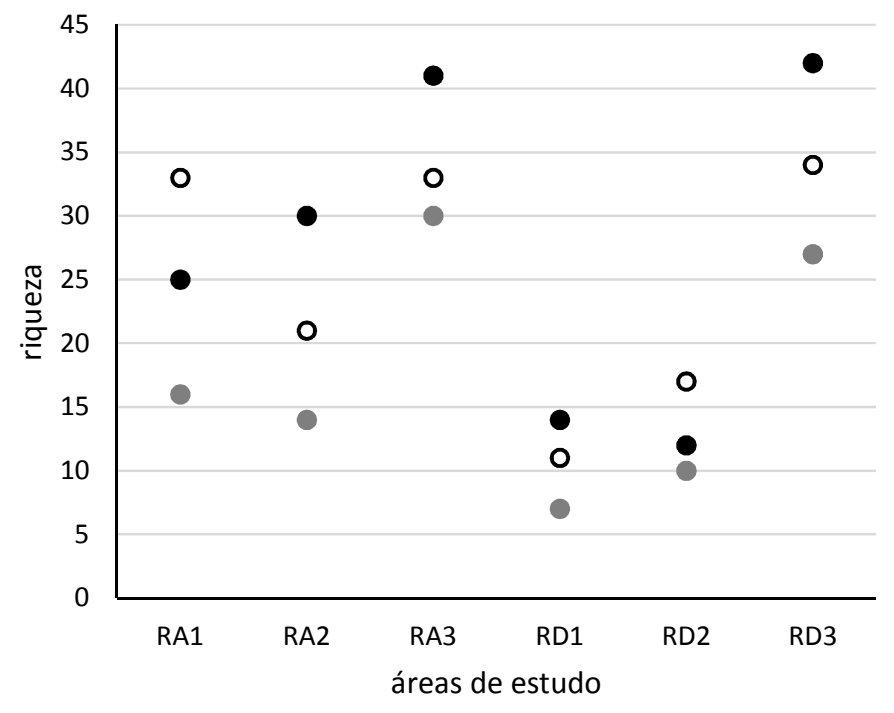

Figura 4.2. Riqueza de espécies de plantas nas seis áreas restauradas de Floresta Estacional Semidecidual. Os círculos cheios indicam o número de plantas floridas observadas em cada local; os círculos cinzas correspondem ao número de plantas visitadas por insetos e os círculos vazios mostram o número de tipos polínicos transportados pelos visitantes florais.

Tabela 4.3. Valor médio e desvio-padrão das métricas das redes de visitação e redes de transporte de pólen nas áreas restauradas de Floresta Estacional Semidecidual. Diferenças significativas entre as redes são mostradas pelos asteriscos seguindo os valores de $p$ (teste $t$ ).

\begin{tabular}{lccccc}
\hline & \multicolumn{2}{c}{ visitação } & \multicolumn{2}{c}{ transporte de pólen } & \multirow{2}{*}{ valores de $p$} \\
\cline { 2 - 5 } & média & DP & média & DP & \\
\hline riqueza de plantas/pólen & 17,33 & 9,24 & 24,83 & 11,06 & $0,01^{*}$ \\
riqueza de insetos & 62,33 & 19,01 & 35,67 & 19,78 & $0,001^{*}$ \\
abundância de insetos & 207,3 & 23,5 & 167,00 & 39,85 & $0,01^{*}$ \\
conectância & 0,12 & 0,07 & 0,11 & 1,99 & 0,9 \\
diversidade de interações & 3,88 & 0,82 & 3,86 & 1,75 & 0,9 \\
equabilidade de interações & 0,57 & 0,07 & 0,57 & 1,30 & 0,9 \\
número de compartimentos & 4,17 & 1,83 & 2,67 & 2,96 & 0,9 \\
aninhamento & 13,79 & 10,52 & 6,97 & 3,90 & 1,0 \\
especialização & 0,50 & 0,18 & 0,35 & 0,07 & 0,9 \\
& & & & & \\
\hline
\end{tabular}



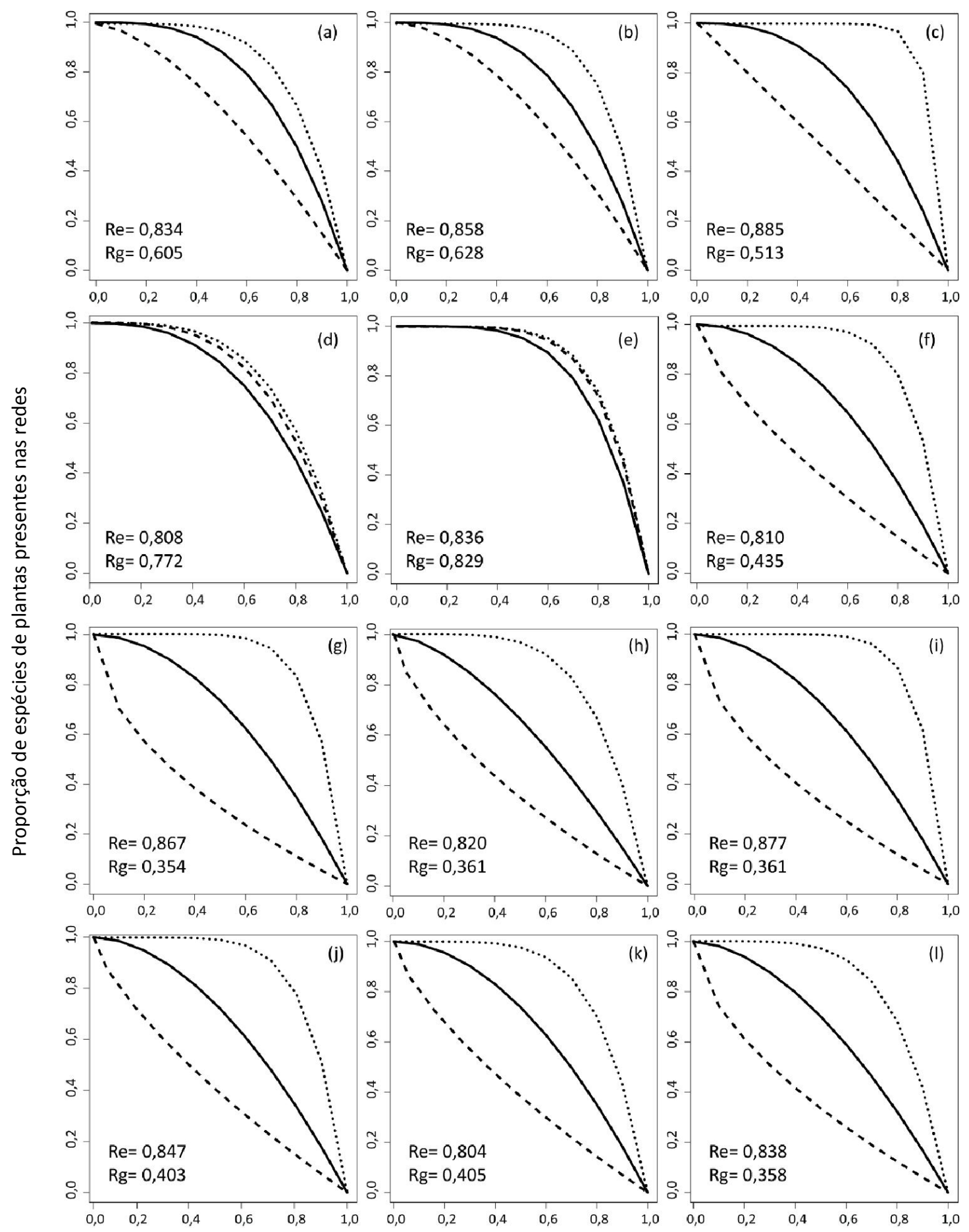

Proporção de espécies de polinizadores removidos

Figura 4.3. Proporção de espécies de plantas que sofrem extinção secundária em função da remoção de espécies de polinizadores (extinção) nas redes de visitação (a-f) e redes de polinização (gI). Os padrões de extinção em $(\mathrm{a}, \mathrm{g}),(\mathrm{b}, \mathrm{h})$ e $(\mathrm{c}, \mathrm{i})$ correspondem às redes das áreas RA1, RA2 e RA3 e aqueles em $(d, j),(e, k)$ e $(f, l)$ correspondem às áreas RD1, RD2 e RD3, respectivamente. A linha cheia representa remoção aleatória de espécies; a linha pontilhada mostra a remoção das espécies menos para mais conectadas e a linha tracejada indica a remoção das espécies mais para menos conectadas. Re=robustez à extinção das espécies menos conectadas primeiro; $\mathrm{Rg}=$ robustez à extinção das espécies mais conectadas primeiro. 


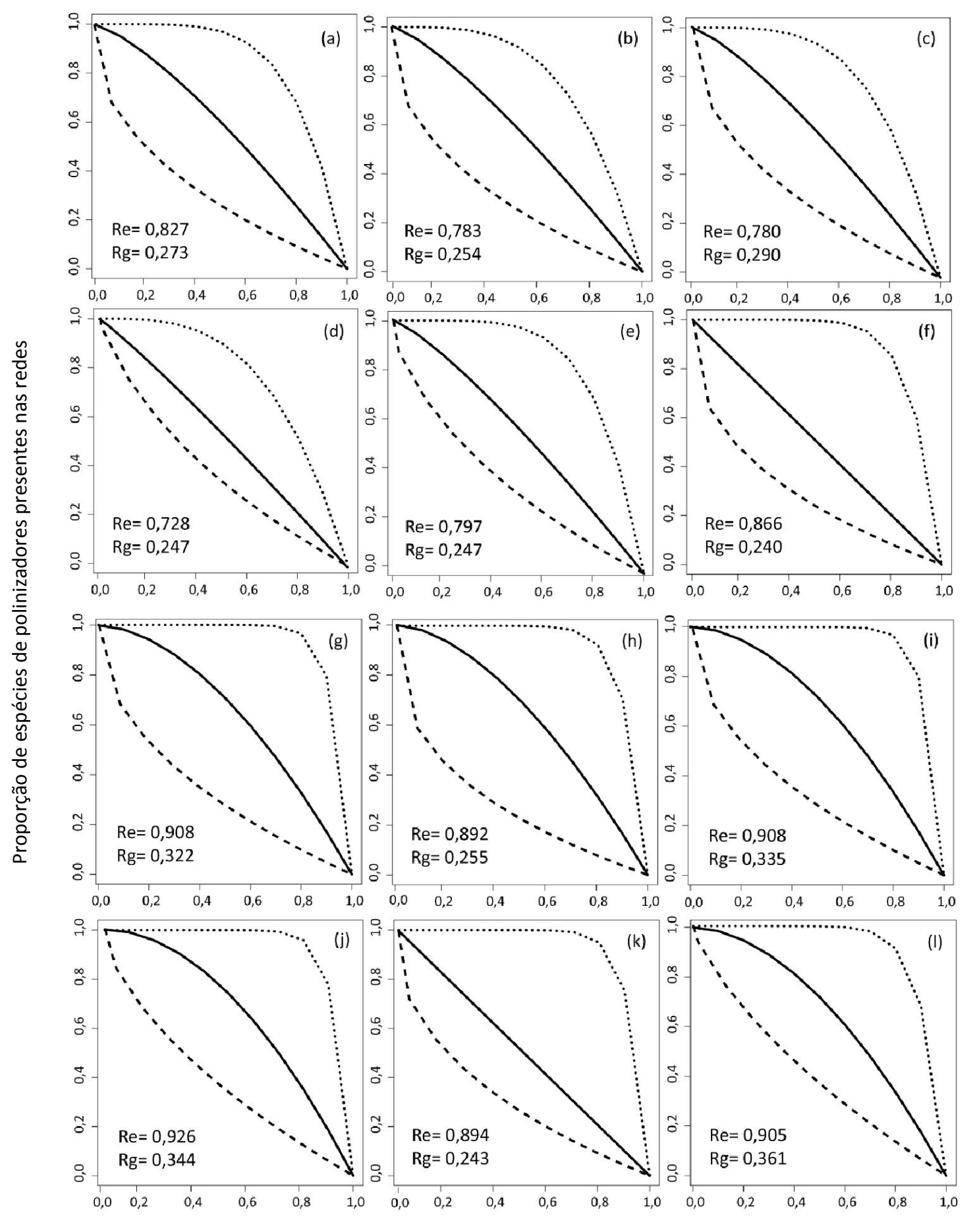

Proporção de espécies de plantas removidas

Figura 4.4. Proporção de espécies de polinizadores que sofrem extinção secundária em função da remoção de espécies de plantas (extinção ) nas redes de visitação (a-f) e redes de polinização $(\mathrm{g}-\mathrm{l})$. Os padrões de extinção em $(\mathrm{a}, \mathrm{g}),(\mathrm{b}, \mathrm{h})$ e $(\mathrm{c}, \mathrm{i})$ correspondem às redes das áreas RA1, RA2 e RA3 e aqueles em $(d, j),(e, k)$ e $(f, l)$ correspondem às áreas RD1, RD2 e RD3, respectivamente. A linha cheia representa remoção aleatória de espécies; a linha pontilhada mostra a remoção das espécies menos para mais conectadas e a linha tracejada indica a remoção das espécies mais para menos conectadas. Re=robustez à extinção das espécies menos conectadas primeiro; $\mathrm{Rg}=$ robustez à extinção das espécies mais conectadas primeiro. 

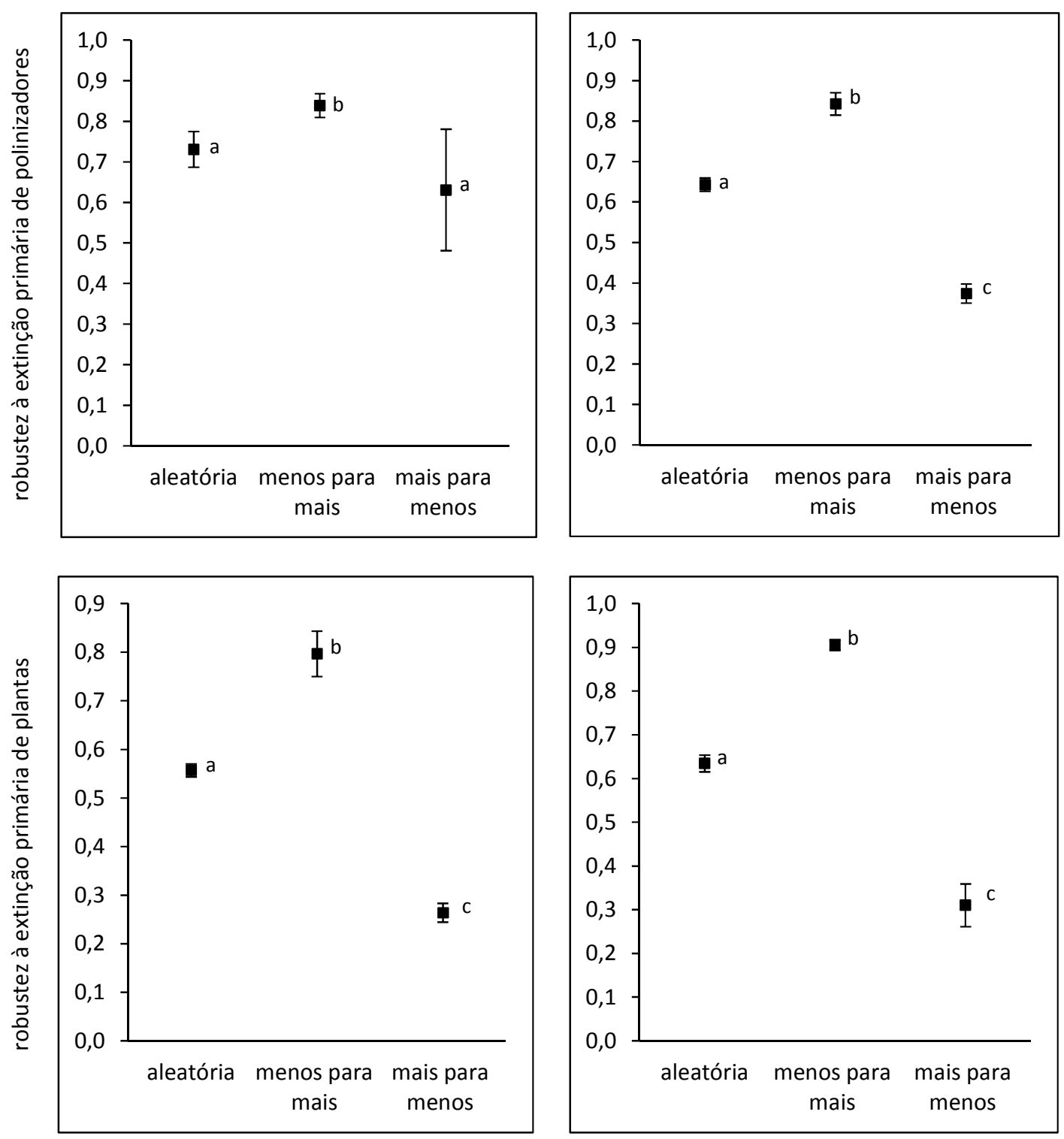

redes de visitação

redes de transporte de pólen

Figura 4.5. Robustez média das redes de visitação e de transporte de pólen à extinção de polinizadores e plantas (e consequente cascata de extinções secundárias de plantas e polinizadores, respectivamente) em resposta à remoção aleatória de espécies; à remoção das espécies menos conectadas primeiro e à remoção começando pelas espécies mais conectadas nas redes. Para cada uma das redes, valores de robustez seguidos de letras diferentes são significativamente diferentes ( $p<0,05$, teste de Tukey). 
Tabela 4.4. Insetos e plantas que participaram de mais interações no conjunto de áreas restauradas de Floresta Estacional Semidecidual. Encontram-se listadas as espécies de inseto que visitaram pelo menos mais que o dobro da média de espécies de plantas visitadas $(1,9 \pm 2,2)$ e as espécies de planta que receberam espécies diferentes de visitantes acima da média de visitas por planta $(6,9 \pm 13,1)$. hym=Hymenoptera; dip=Diptera; lep=Lepidoptera; arb=arbóreo; herb=herbáceo-arbustivo.

número de interações ordem/estrato família espécie

\section{Visitantes florais}

$\begin{array}{cccc}20 & \text { hym } & \text { Apidae } & \text { Apis mellifera } \\ 16 & \text { hym } & \text { Apidae } & \text { Trigona spinipes } \\ 11 & \text { hym } & \text { Apidae } & \text { Ceratina sp5 } \\ 9 & \text { hym } & \text { Halictidae } & \text { Dialictus sp } \\ 8 & \text { hym } & \text { Apidae } & \text { Ceratina sp4 } \\ 7 & \text { dip } & \text { Syrphidae } & \text { Ornidia obesa } \\ 7 & \text { dip } & \text { Syrphidae } & \text { Pseudodoros clavatus } \\ 7 & \text { hym } & \text { Apidae } & \text { Exomalopsis sp 2 } \\ 6 & \text { dip } & \text { Tachinidae } & \text { Tachinidae sp 1 } \\ 6 & \text { dip } & \text { Tachinidae } & \text { Tachinidae sp 3 } \\ 6 & \text { lep } & \text { Hesperidae } & \text { Hesperidae sp 7 } \\ 5 & \text { dip } & \text { Syrphidae } & \text { Palpada furcata } \\ 5 & \text { hym } & \text { Vespidae } & \text { Stenodynerus sp. } \\ 5 & \text { hym } & \text { Halictidae } & \text { Augochloropsis sp 2 } \\ 5 & \text { hym } & \text { Apidae } & \text { Trigona hyalinata } \\ 5 & \text { hym } & \text { Sphecidae } & \text { Sphecini sp. } \\ 5 & \text { hym } & \text { Scolidae } & \text { Campsomeris sp 2 } \\ 5 & \text { hym } & \text { Apidae } & \text { Exomalopsis sp 1 } \\ 5 & \text { lep } & \text { Hesperidae } & \text { Hesperidae sp 5 } \\ 5 & \text { hym } & \text { Halictidae } & \text { Augochlora sp 3 }\end{array}$

\section{Plantas}

$\begin{array}{lccc}72 & \text { arb } & \text { Anacardiaceae } & \text { Schinus terebinthifolius } \\ 64 & \text { arb } & \text { Euphorbiaceae } & \text { Croton urucurana } \\ 35 & \text { herb } & \text { Verbenaceae } & \text { Stachytarpheta cayennensis } \\ 28 & \text { herb } & \text { Asteraceae } & \text { Emilia fosbergii } \\ 28 & \text { herb } & \text { Asteraceae } & \text { Conyza sp2 } \\ 20 & \text { herb } & \text { Asteraceae } & \text { Praxelis pauciflora } \\ 17 & \text { arb } & \text { Fabaceae } & \text { Peltophorum dubium } \\ 12 & \text { herb } & \text { Convolvulaceae } & \text { Jacquemontia heterantha } \\ 9 & \text { herb } & \text { Malvaceae } & \text { Sida sp1 } \\ 9 & \text { herb } & \text { Asteraceae } & \text { Parthenium hysterophorus } \\ 8 & \text { arb } & \text { Boraginaceae } & \text { Cordia superba } \\ 7 & \text { herb } & \text { Asteraceae } & \text { Baccharis sp2 }\end{array}$




\section{Discussão}

Nossos dados mostram que embora algumas das seis áreas restauradas apresentem riqueza e composição diferentes de espécies (tanto de plantas quanto visitantes florais), todas elas são aparentemente similares nos aspectos funcionais da polinização. Ambas as redes de visitação e transporte de pólen revelaram comunidades funcionalmente complexas com um número relativamente diverso de interações entre plantas e potenciais polinizadores, indicando que o processo de polinização está sendo restabelecido pelo menos em algum nível. No entanto, os dados de visitação demonstraram que nem todas as áreas possuem o mesmo padrão de resposta à extinção simulada de espécies, e que a presença massiva de gramíneas é provavelmente um fator determinante da robustez destas redes. Ainda assim, a perda de espécies generalistas sempre provocou o colapso mais rápido e drástico das redes em todas as áreas de estudo, ressaltando a importância deste grupo de organismos para a manutenção das comunidades e do serviço ecológico. A seguir, analisaremos algumas das limitações da abordagem utilizada neste estudo e então discutiremos os principais resultados considerando o sucesso ou não da restauração da polinização. Por fim, serão abordadas as implicações práticas de nossos resultados e do uso de redes para avaliações de projetos de restauração ecológica.

\subsection{Limitações}

Em todos os locais de estudo, a riqueza observada de insetos foi muito menor do que aquela predita pelos estimadores não-paramétricos, assim como a riqueza de tipos polínicos foi sempre maior que a de plantas floridas registradas. Assim, uma amostragem mais intensiva parece necessária. No entanto, é razoável considerarmos que alguns dos estimadores não obtiveram um bom desempenho: por exemplo, a riqueza onze vezes maior sugerida pelo estimador Chao para a área RD1 parece extrema. De fato, dentre os estimadores calculados aqui, o jackknife 2 parece se comportar melhor para um número pequeno de amostras (Colwell \& Coddington 1994). Por outro lado, embora a riqueza de tipos polínicos encontrar-se subestimada - porque grãos de pólen difíceis de distinguir foram agrupados em um mesmo tipo polínico - e a diferença entre o número de tipos polínicos e de plantas floridas possa indicar subamostragem de plantas em flor, é igualmente provável que os insetos carreguem pólen de áreas externas aos reflorestamentos. De qualquer maneira, a amostragem de redes de interação planta-polinizador em sua plenitude é pouco provável em qualquer tipo de ambiente (Forup \& Memmott 2005; Devoto et al. 2012). Embora as redes aqui representadas não retratem a diversidade completa de interações existentes em cada área, acreditamos que as espécies funcionalmente mais importante foram amostradas. Portanto, estas redes permitem boas aproximações da base alimentar sobre a qual os insetos forrageiam e fornecem um bom ponto de partida para estudos comparativos.

Outro aspecto relevante é o número proporcionalmente muito menor de insetos da ordem Lepidoptera registrados nas redes de transporte de pólen do que nas redes de visitação. Como estes 
insetos são geralmente muito precisos na coleta de recursos florais, eles frequentemente apresentam um número muito pequeno de grãos de pólen aderidos às suas peças bucais - o que pode ter dificultado o registro de grãos sendo transportados. Assim, embora seja possível que Lepidoptera esteja subamostrada nas redes de transporte de pólen, este efeito teve o mesmo peso em todas as áreas estudadas e não deve ter influenciado os resultados pela natureza comparativa do trabalho.

\subsection{A restauração do processo de polinização}

Embora poucos, os estudos que avaliam a restauração do processo de polinização mostram que esta é possível independentemente das espécies de polinizadores envolvidas (Forup \& Memmott 2005; Forup et al. 2008; Williams 2011). Em outras palavras, uma perfeita congruência entre a composição de espécies de áreas restauradas e aquela de áreas referência não é necessária para que o processo de polinização se restabeleça. Quando se objetiva restaurar o serviço de polinização para toda a comunidade de plantas, o ideal seria construir comunidades ricas para promover o maior número possível de grupos funcionais diferentes de polinizadores (Williams 2011; Devoto et al. 2012). Considerando estes fatores, as áreas aqui estudadas parecem estar restabelecendo a polinização das espécies de planta presentes, pelo menos neste estágio inicial de sucessão. A conectância (proporção de interações realizadas dentre todas as possíveis) das redes de visitação $(0,12 \pm 0,07)$ e de transporte de pólen $(0,11 \pm 1,99)$ apresentaram valores próximos a outros registrados de 0,10 para redes de abelhas e flores na caatinga (Pigozzo \& Viana 2010) e 0,11 a 0,19 para abelhas sociais na Mata Atlântica (Biesmeijer et al. 2005). Além disso, tanto as redes de visitação quanto as redes de transporte de pólen exibiram características típicas das redes mutualísticas de interação entre plantas e polinizadores, como assimetria de interações (plantas especialistas tendem a se associar com polinizadores generalistas e vice-versa; Vázquez \& Aizen 2004; Bascompte et al. 2006) e aninhamento (especialistas interagem com subgrupos dentro do grupo com o qual generalistas interagem; Bascompte et al. 2003). O fato de Hymenoptera e Diptera dominarem a comunidade de visitantes florais - e de Hymenoptera ser claramente mais eficiente no transporte de pólen que qualquer outro grupo - também é congruente com a composição típica destas redes (Memmott 1999; Forup \& Memmott 2005; Forup et al. 2008; Bazarian 2010).

Obviamente, redes de visitação desconsideram as diferenças na efetividade de cada visitante como polinizador (Bosch et al. 2009), e embora a quantidade de grãos de pólen sendo transportados por um inseto seja correlacionada à deposição dos mesmos no estigma das flores (Howlett et al. 2011), as redes de transporte de pólen também podem ignorar possíveis falhas no processo de polinização. Por exemplo, o risco de fracasso da polinização aumenta se os grãos de pólen chegarem ao estigma em quantidade muito pequena ou excessiva, ou ainda muito misturados ao pólen de outras espécies; e também se os polinizadores forem muito poucos ou inconstantes (Wilcock \& Neiland 2002). Embora o 
uso de redes tróficas seja uma ferramenta poderosa para avaliar a eficácia da restauração e do resgate das funções ecológicas (Memmott 2009), nos casos onde houver interesse particular na restauração de determinada espécie, seriam interessantes experimentos adicionais que avaliassem também a produção de frutos e sementes das espécies em questão. Uma possível estratégia seria utilizar as redes de interação como ponto de partida e, depois de usá-las para identificar as espécies-chave na comunidade, aprofundar o conhecimento sobre o sucesso reprodutivo destas espécies nas áreas restauradas.

A modelagem do efeito da extinção de parceiros mutualistas na estabilidade das redes de interação mostrou que a perda de espécies generalistas causa sempre o impacto mais drástico - seja num cenário de declínio de plantas ou de polinizadores, seja utilizando os dados de visitação ou os dados de transporte de pólen. Mas mesmo na simulação deste pior caso, o padrão de extinção não diferiu muito de uma queda linear. Estes resultados condizem com o esperado para redes de interação mutualísticas entre planta e polinizadores (Memmott et al. 2004; Forup et al. 2008; Kaiser-Bunbury et al. 2010), já que elas são relativamente mais tolerantes a perturbações que outros tipos de redes. Alguns atributos típicos de sua topologia, como aninhamento e a compartimentalização por exemplo, amortecem os efeitos das extinções (desaparecendo um especialista, as espécies remanescentes ainda terão outras com a qual interagir) e desaceleram a propagação dos distúrbios (que podem ficar contidos dentro de um compartimento), aumentando a estabilidade das redes (Tylianakis et al. 2010). A robustez das redes à extinção de espécies também aumenta com a conectância (Dunne et al. 2002), com redes mais ricas em espécies e interações apresentando também maior redundância e complementaridade funcionais.

Contudo, a relativa maior tolerância de redes de polinização à perda de espécies não significa imunidade às consequências de extinções. Do ponto de vista de toda a comunidade, enquanto a perda de um certo número de espécies especialistas ainda possa ser tolerada, o declínio de espécies generalistas, mesmo que em número pequeno, pode levar ao colapso da rede. Embora o processo de polinização nas áreas estudadas pareça estar sendo restabelecido, o estágio em que os reflorestamentos se encontram representa apenas uma fase em um longo processo de sucessão. 0 fato de as redes de visitação das áreas com maior invasão por gramíneas apresentarem maior robustez à perda de polinizadores (e das áreas RD1 e RD2 apresentarem resposta semelhante à extinção independente das espécies perdidas) indica na verdade maior degradação destes ambientes. Os maiores valores de robustez ocorreram porque a menor riqueza de espécies destas áreas levou aos maiores valores de conectância (capítulo 2), e maiores valores de conectância se traduzem em maior robustez (Dunne et al. 2002). No entanto, estas áreas provavelmente representam os ambientes mais frágeis porque a menor diversidade de espécies lá encontrada representa também menor redundância e complementaridade de espécies (Blüthgen \& Klein 2011), indicando maior susceptibilidade ao declínio da biodiversidade local. Estas suposições são apoiadas pelo fato da riqueza de tipos polínicos 
transportados nestas áreas ser menor que aquela transportada nas áreas mais abundantes em espécies ruderais regenerantes. Assim, embora possam parecer mais tolerantes a distúrbios neste estágio, estas áreas poderão ter problemas adiante; atividades de monitoramento e manejo devem atentar para a possível necessidade de enriquecimento futuramente.

\subsection{Implicações práticas}

As duas abordagens utilizadas para demonstrar o funcionamento das comunidades de plantas e polinizadores - redes de visitação e redes de transporte de pólen - apresentaram resultados bastante similares. Embora a abundância e riqueza de espécies observadas tenham diferido em cada rede, não houve alteração nas métricas registradas. Quando o propósito do estudo for um entendimento mais detalhado dos aspectos funcionais da polinização e dos papéis efetivos de cada espécie envolvida, a utilização da rede de transporte de pólen claramente tem maiores benefícios (Bosch et al. 2009). Contudo, para fins de bioindicação e monitoramento da estrutura e funcionamento das comunidades restauradas, o uso de redes de visitação parece ser a alternativa de melhor custo-benefício (Hegland et al. 2010), por envolver menos tempo e esforço mas apresentar resultados igualmente relevantes.

Embora o método de simular a extinção de espécies tenha suas reservas - não consideramos, por exemplo, as diferenças de efetividade entre os polinizadores ou que aqueles remanescentes após uma extinção sejam capazes de expandir suas dietas (Kaiser-Bunbury et al. 2010) - ele se mostra uma ferramenta extremamente útil no contexto da restauração ecológica. O perigo iminente de uma crise de polinizadores (Allen-Wardell et al. 1998; Kearns et al. 1998; Biesmeijer et al. 2006) reforça o papel crucial de algumas espécies de insetos na manutenção do serviço ecológico da polinização. Embora a extinção inicial de espécies de polinizadores especialistas seja mais provável, já que elas tendem também a ser mais raras e portanto mais vulneráveis (Aizen, Sabatino \& Tylianakis 2012), o declínio de generalistas também é possível frente ao aumento crescente de extinções causadas por alterações antropogênicas. O desaparecimento de espécies generalistas pode ser ainda mais fácil se considerarmos as espécies vegetais em nível local: num cenário onde as espécies arbóreas implantadas sofressem o ataque de alguma praga ou doença, toda a população da área restaurada poderia desaparecer e, neste caso, as extinções secundárias de polinizadores associados seriam reais. Esta hipótese enfatiza a relevância de plantios de alta diversidade em áreas restauradas, uma vez que populações geneticamente mais diversas serão mais robustas a eventos aleatórios (Kettenring et al. 2014).

Em um contexto ainda mais aplicado, o resultado das simulações de extinção mostra que é possível construir redes mais robustas através do manejo da diversidade de plantas ou polinizadores. Nos casos avaliados neste trabalho, abelhas das famílias Apidae e Halictidae e moscas da família Syrphidae se mostraram polinizadores centrais nas redes enquanto duas espécies arbóreas (S.terebinthifolius e $C$. urucurana) e algumas espécies regenerantes (S.cayennensis, E. fosgergii e P.pauciflora, por exemplo) 
se mostraram plantas centrais no fornecimento de recursos florais. Este tipo de informação permite identificar grupos que trarão ganhos significativos na biodiversidade local. Dependendo do objetivo central do projeto ou de problemas detectados ao longo da sucessão de áreas em processo de restauração, estes grupos poderão ser de grande utilidade e facilitar a tomada de decisões relativas ao manejo.

\section{Referências Bibliográficas}

Aizen, M. A., Sabatino, M. \& Tylianakis, J.M. (2012) Specialization and rarity predict nonrandom loss of interactions from mutualist networks. Science, 335, 1486-1489.

Allen-Wardell, G., Bernhardt, P., Bitner, R., Burquez, A., Buchmann, S., Cane, J., Cox, P., Dalton, V., Feinsinger, P., Ingram, M., Inouye, D., Jones, E., Kennedy, K., Kevan, P., Koopowitz, H., Medelin, R., Medellin-Morales, S., Nabhan, G., Pavlik, B., Tepedino, V., Torchio, P. \& Walker, S. (1998) The potential consequences of pollinator declines on the conservation of biodiversity and stability of food crop yields. Conservation Biology, 12, 8-17.

Bascompte, J., Jordano, P., Melián, C.J. \& Olesen, J.M. (2003) The nested assembly of plant-animal mutualistic networks. Proceedings of the National Academy of Sciences of the United States of America, 100, 9383-9387.

Bascompte, J., Jordano, P. \& Olesen, J. (2006) Asymmetric coevolutionary networks facilitate biodiversity maintenance. Science, 312, 431-433.

Bawa, K. (1990) Plant-pollinator interactions in tropical rain forests. Annual Review of Ecology and Systematics, 21, 399-422.

Bawa, K., Bullock, S., Perry, D., Coville, R. \& Grayum, M. (1985) Reproductive biology of tropical lowland rain forest trees. II: Pollination systems. American journal of botany, 72, 346-356.

Bazarian, S. V. (2010) Redes de interação plantas-visitantes florais e a restauração de processos ecológicos em florestas tropicais. Tese (Doutorado em Ecologia) - Instituto de Biociências, Universidade de São Paulo, São Paulo. 145p.

Biesmeijer, J.C., Roberts, S.P.M., Reemer, M., Ohlemüller, R., Edwards, M., Peeters, T., Schaffers, A. P., Potts, S., Kleukers, R., Thomas, C.D., Settele, J. \& Kunin, W.E. (2006) Parallel declines in pollinators and insect-pollinated plants in Britain and the Netherlands. Science, 313, 351-354.

Biesmeijer, J., Slaa, E., Castro, M., Viana, B.F., Kleinert, A. \& Imperatriz-Fonseca, V. (2005) Connectance of Brazilian social bee: food plant networks is influenced by habitat, but not by latitude, altitude or network size. Biota Neotropica, 5, 1-9.

Blüthgen, N. \& Klein, A.-M. (2011) Functional complementarity and specialisation: The role of biodiversity in plant-pollinator interactions. Basic and Applied Ecology, 12, 282-291.

Bosch, J., González, A.M.M., Rodrigo, A. \& Navarro, D. (2009) Plant-pollinator networks: adding the pollinator's perspective. Ecology letters, 12, 409-419.

Burgos, E., Ceva, H., Perazzo, R., Devoto, M., Medan, D., Zimmermann, M. \& Delbue, A. (2007) Why nestedness in mutualistic networks? Journal of Theoretical Biology, 249, 307-313. 
Carvalheiro, L.G., Seymour, C.L., Veldtman, R. \& Nicolson, S.W. (2010) Pollination services decline with distance from natural habitat even in biodiversity-rich areas. Journal of Applied Ecology, 47, 810820 .

Chalcoff, V.R., Aizen, M.A. \& Ezcurra, C. (2012) Erosion of a pollination mutualism along an environmental gradient in a south Andean treelet, Embothrium coccineum (Proteaceae). Oikos, 121, 471-480.

Chao, A. (1987) Estimating the population size for capture-recapture data with unequal catchability. Biometrics, 43, 783-791.

Colwell, R. \& Coddington, J. (1994) Estimating terrestrial biodiversity through extrapolation. Philosophical Transactions of The Royal Society B: Biological Sciences, 345, 101-118.

Devoto, M., Bailey, S., Craze, P.G. \& Memmott, J. (2012) Understanding and planning ecological restoration of plant-pollinator networks. Ecology letters, 15, 319-328.

Dormann, C.F., Gruber, B. \& Fründ, J. (2008) Introducing the bipartite Package : Analysing Ecological Networks. , 8, 8-11.

Dunne, J. A., Williams, R.J. \& Martinez, N.D. (2002) Network structure and biodiversity loss in food webs: robustness increases with connectance. Ecology Letters, 5, 558-567.

Forup, M.L., Henson, K.S.E., Craze, P.G. \& Memmott, J. (2008) The restoration of ecological interactions: plant-pollinator networks on ancient and restored heathlands. Journal of Applied Ecology, 45, 742-752.

Forup, M.L. \& Memmott, J. (2005) The restoration of plant-pollinator interactions in Hay Meadows. Restoration Ecology, 13, 265-274.

Gallai, N., Salles, J.-M., Settele, J. \& Vaissière, B.E. (2009) Economic valuation of the vulnerability of world agriculture confronted with pollinator decline. Ecological Economics, 68, 810-821.

Godefroid, S., Piazza, C., Rossi, G., Buord, S., Stevens, A.-D., Aguraiuja, R., Cowell, C., Weekley, C.W., Vogg, G., Iriondo, J.M., Johnson, I., Dixon, B., Gordon, D., Magnanon, S., Valentin, B., Bjureke, K., Koopman, R., Vicens, M., Virevaire, M. \& Vanderborght, T. (2011) How successful are plant species reintroductions? Biological Conservation, 144, 672-682.

Hegland, S.J., Dunne, J., Nielsen, A. \& Memmott, J. (2010) How to monitor ecological communities costefficiently: The example of plant-pollinator networks. Biological Conservation, 143, 2092-2101.

Howlett, B.G., Walker, M.K., Rader, R., Butler, R.C., Newstrom-LLoyd, L. \& Teulon, D. (2011) Can insect body pollen counts be used to estimate pollen deposition on pak choi stigmas? New Zealand Plant Protection, 64, 25-31.

Instituto Florestal. (2005) Inventário florestal da vegetação natural do Estado de São Paulo. São Paulo: Imprensa oficial.

Jordano, P., Bascompte, J. \& Olesen, J.M. (2002) Invariant properties in coevolutionary networks of plant-animal interactions. Ecology Letters, 6, 69-81.

Kaiser-Bunbury, C.N., Muff, S., Memmott, J., Müller, C.B. \& Caflisch, A. (2010) The robustness of pollination networks to the loss of species and interactions: a quantitative approach incorporating pollinator behaviour. Ecology letters, 13, 442-452. 
Kearns, C., Inouye, D. \& Waser, N. (1998) Endangered mutualisms: the conservation of plant-pollinator interactions. Annual Review of Ecology and Systematics, 29, 83-112.

Kettenring, K.M., Mercer, K.L., Reinhardt Adams, C. \& Hines, J. (2014) Application of genetic diversityecosystem function research to ecological restoration. Journal of Applied Ecology, 51, 339-348.

Klein, A.M., Vaissière, B.E., Cane, J.H., Steffan-Dewenter, I., Cunningham, S.A., Kremen, C. \& Tscharntke, T. (2007) Importance of pollinators in changing landscapes for world crops. Proceedings of The Royal Society B: Biological sciences,, 274, 303-313.

Kremen, C. \& Ricketts, T. (2000) Global perspectives on pollination disruptions. Conservation Biology, $1226-1228$.

Loreau, M., Naeem, S., Inchausti, P., Bengtsson, J., Grime, J., Hector, A., Hooper, D., Huston, M., Rafaelli, D., Schmid, B., Tilman, D. \& Wardle, D. (2001) Biodiversity and ecosystem functioning: current knowledge and future challenges. Science, 294, 804-808.

Melo, A. \& Durigan, G. (2007) Evolução estrutural de reflorestamentos de restauração de matas ciliares no Médio Vale do Paranapanema. Scientia Forestalis, 73, 101-111.

Memmott, J. (1999) The structure of a plant-pollinator food web. Ecology Letters, 2, 276-280.

Memmott, J. (2009) Food webs: a ladder for picking strawberries or a practical tool for practical problems? Philosophical transactions of the Royal Society B: Biological Sciences, 364, 16931699.

Memmott, J., Waser, N.M. \& Price, M. V. (2004) Tolerance of pollination networks to species extinctions. Proceedings of The Royal Society B: Biological Sciences, 271, 2605-2611.

Oksanen, J. (2013) Multivariate analysis of ecological communities in R: vegan tutorial. $R$ package version, 43.

Ollerton, J., Winfree, R. \& Tarrant, S. (2011) How many flowering plants are pollinated by animals? Oikos, 120, 321-326.

Palmer, M. W. (1991) Estimating species richness: The second-order jackknife reconsidered. Ecology, 72, 1512-1513.

Pigozzo, C. \& Viana, B.F. (2010) Estrutura da rede de interações entre flores e abelhas em ambiente de Caatinga. Oecologia Australis, 14, 100-114.

R Development Core Team. 2012. R: A language and environment for statistical computing. $\mathrm{R}$ Foundation for statistical computing, Viena, Áustria, ISBN 3-900051-07-0.

Rey Benayas, J.M., Newton, A.C., Diaz, A. \& Bullock, J.M. (2009) Enhancement of biodiversity and ecosystem services by ecological restoration: a meta-analysis. Science, 325, 1121-1124.

Rodrigues, R.R., Gandolfi, S., Nave, A., Aronson, J., Barreto, T.E., Vidal, C.Y. \& Brancalion, P.H. (2011) Large-scale ecological restoration of high-diversity tropical forests in SE Brazil. Forest Ecology and Management, 261, 1605-1613.

Rodrigues, C. \& Hott, M. (2010) Dinâmica da vegetação natural no nordeste do estado de São Paulo, entre 1988 e 2003. Revista Árvore, 34, 881-887. 
Rodrigues, R.R., Lima, R. A. F., Gandolfi, S. \& Nave, A. (2009) On the restoration of high diversity forests: 30 years of experience in the Brazilian Atlantic Forest. Biological Conservation, 142, 1242-1251.

Smith, E. P. \& Van Belle, G. (1984) Nonparametric estimation of species richness. Biometrics 40, 119129.

Souza, F.M. \& Batista, J.L.F. (2004) Restoration of seasonal semideciduous forests in Brazil: influence of age and restoration design on forest structure. Forest Ecology and Management, 191, 185200.

Steffan-Dewenter, I. \& Tscharntke, T. (1999) Effects of habitat isolation on pollinator communities and seed set. Oecologia, 121, 432-440.

Suding, K.N. (2011) Toward an era of restoration in ecology: successes, failures, and opportunities ahead. Annual Review of Ecology, Evolution, and Systematics, 42, 465-487.

Tylianakis, J.M., Laliberté, E., Nielsen, A. \& Bascompte, J. (2010) Conservation of species interaction networks. Biological Conservation, 143, 2270-2279.

Vázquez, D.P. \& Aizen, M.A. (2004) Asymmetric specialization: a pervasive feature of plant-pollinator interactions. Ecology, 85, 1251-1257.

Wilcock, C. \& Neiland, R. (2002) Pollination failure in plants: why it happens and when it matters. Trends in plant science, 7, 270-277.

Williams, N.M. (2011) Restoration of nontarget species: bee communities and pollination function in riparian forests. Restoration Ecology, 19, 450-459.

Winfree, R., Aguilar, R., Vázquez, D.P., LeBuhn, G. \& Aizen, M.A. (2009) A meta-analysis of bees' responses to anthropogenic disturbance. Ecology, 90, 2068-2076.

Winfree, R., Bartomeus, I. \& Cariveau, D.P. (2011) Native Pollinators in Anthropogenic Habitats. Annual Review of Ecology, Evolution, and Systematics, 42, 1-22. 


\section{Considerações Finais}

Este trabalho demonstra a importância de se avaliar a recuperação dos aspectos funcionais de ecossistemas restaurados. $\mathrm{O}$ estudo de processos ecológicos nestes ambientes permite tanto o aprofundamento de questões ecológicas básicas quanto a geração de informações práticas que podem ser utilizadas na elaboração de protocolos de manejo e monitoramento. No caso específico do processo de polinização, seu restabelecimento é essencial não somente para a perpetuação da floresta restaurada como também pode fazer dela um recipiente de espécies cruciais para o provimento de um serviço ecológico de grande valor.

Embora a abordagem usada não permita averiguar se a transferência de grãos de pólen e fecundação das flores esteja de fato ocorrendo, a utilização de redes complexas permite a detecção de padrões emergentes na comunidade que de outra forma não seriam percebidos. Estes padrões, ao mostrarem a topologia, estabilidade e robustez das redes tróficas, fornecem uma ideia mais aproximada sobre o funcionamento da comunidade - e saber o que as espécies fazem ao invés de apenas saber se estão presentes é especialmente interessante na restauração ecológica (Ehrenfeld \& Toth 1997; Forup et al. 2008). Além disso, estas propriedades podem ser comparadas àquelas encontradas em comunidades preservadas para nos certificarmos se as comunidades em processo de restauração estão seguindo uma trajetória promissora na recuperação dos processos ecológicos.

Todas as áreas analisadas em nosso estudo apresentaram redes de interação planta-visitante floral com estrutura e atributos comuns a outras redes mutualísticas de polinização, indicando que o processo deve estar se restabelecendo. A diferença na composição de espécies de visitantes florais não resultou em diferenças nos atributos das redes de visitação, corroborando o encontrado em outros estudos (Forup \& Memmott 2005; Forup et al. 2008; Williams 2011). Também não foram encontradas diferenças entre áreas restauradas próximas e distantes de fragmentos de vegetação nativa.

O fato de a distância entre as áreas restauradas e os fragmentos de vegetação nativa não ter influenciado a composição da comunidade de visitantes pode ter múltiplas razoes. Por um lado, devido a características próprias de sua topologia e dinâmica temporal, as redes de interação plantapolinizador podem ser menos propensas a distúrbios do que se imagina (Memmott et al. 2004; Petanidou et al. 2008). Por outro, a relação positiva entre diversidade de polinizadores e proximidade de áreas naturais em paisagens agrícolas encontra-se bem estabelecida (Steffan-Dewenter \& Tscharntke 1999; Ricketts 2004; Blanche et al. 2006; Ricketts et al. 2008; Carvalheiro et al. 2010), e a não ocorrência desta relação nas áreas restauradas deste estudo poderia indicar que os 
remanescentes próximos encontram-se degradados. De fato, a região estudada conta com menos de 17\% de cobertura vegetal nativa (Rodrigues \& Hott 2010), a qual encontra-se distribuída em fragmentos cada vez menores, isolados e, portanto, suscetíveis à degradação. Também não se pode descartar a possibilidade de que os polinizadores retornando às áreas restauradas não se originem de fragmentos remanescentes de vegetação, mas sim de outros tipos de ambiente (Carvalheiro et al. 2011; Williams 2011). Talvez fosse interessante incluir em amostragens futuras visitantes florais de habitats como faixas de vegetação ruderal em áreas rurais ou terrenos abandonados, jardins e parques urbanos, cultivos agrícolas, etc.

De qualquer maneira, independente dos efeitos da proximidade de habitat nativo na colonização de áreas restauradas por insetos polinizadores, a inserção das áreas mais isoladas na paisagem é crucial também por outros motivos (Holl et al. 2003; Brudvig 2011). Por exemplo, ao examinar a chuva de sementes em áreas restauradas no interior do estado de São Paulo, Siqueira (2002) encontrou que a maioria dos propágulos eram de origem autóctone - principalmente no reflorestamento localizado em uma região bastante fragmentada e dominada por cultura canavieira. Em nosso estudo, mesmo que as espécies vegetais de todas as áreas estejam recebendo visitas de insetos e estejam sendo polinizadas, não se pode assegurar que o fluxo gênico promovido por estes polinizadores seja suficiente para garantir a perpetuação das florestas implantadas. Se a conectividade entre áreas restauradas e outros fragmentos não for observada, estas "novas florestas" não passarão de mais um dentre inúmeros fragmentos cujas plantas sofrem de depressão endogâmica porque suas populações muito pequenas encontram-se isoladas das outras. E a suscetibilidade reprodutiva das plantas à fragmentação de habitat (Ghazoul 2005; Aguilar et al. 2006) fará com que estas áreas - mesmo que aparentem estar se recuperando no presente - já estejam condenadas no futuro.

Talvez um dos resultados mais interessantes deste trabalho seja o impacto da vegetação regenerante na estruturação da comunidade de visitantes florais. Durante os primeiros anos de desenvolvimento de áreas restauradas de Floresta Estacional Semidecidual, somente espécies arbóreas pioneiras já se encontram em fase reprodutiva. Em geral, estas espécies são plantadas em maior abundância mas em menor diversidade proporcionalmente ao total de mudas implantadas. Assim, durante vários anos, as árvores desta categoria sucessional representarão a única fonte de recursos florais caso não haja a colonização das áreas restauradas por outras espécies vegetais. $\mathrm{A}$ presença de vegetação ruderal aumenta a diversidade de visitantes florais e a produtividade de cultivos agrícolas (Carvalheiro et al. 2011); nas áreas restauradas, a vegetação ruderal aumentou a diversidade de visitantes e também a complexidade das redes de interação planta-visitante floral, afetando a composição e o funcionamento das comunidades. Do ponto de vista dos polinizadores, este efeito é claramente positivo devido ao aumento da diversidade e quantidade de recursos florais sendo oferecidos; do ponto de vista das plantas, mais estudos são necessários para averiguar se processos de facilitação e/ou competição estão atuando. 
Resultados como estes - além de descrever as comunidades restauradas - podem ser usados também para construir e testar hipóteses a respeito dos papéis de diversas espécies em assegurar ou aumentar as chances de sucesso da restauração. Por exemplo, este estudo leva a crer que o manejo mais eficaz em controlar a invasão de gramíneas facilita também a regeneração de espécies ruderais, as quais por sua vez atraem maior diversidade de visitantes florais. Esta hipótese poderia ser testada através da remoção seletiva de gramíneas em experimentos replicados. Outro exemplo a ser testado seria a remoção das espécies regenerantes para verificar se esta alteração levaria a mudanças significativas no sucesso reprodutivo das espécies implantadas; a comparação com áreas controle responderia a questão sobre o predomínio de facilitação ou competição nas relações entre herbáceas regenerantes e arbóreas implantadas. Dependendo dos resultados encontrados, novas recomendações de planejamento e manejo mais específicos poderão ser feitas.

Os resultados obtidos também geram um alerta. É preciso atentar para a robustez das redes sendo restabelecidas já que redes mais robustas significam comunidades mais resilientes. Apesar das redes de visitação e transporte de pólen revelarem comunidades funcionalmente complexas com um número relativamente diverso de interações entre plantas e potenciais polinizadores, nem todas as áreas possuem o mesmo padrão de resposta à extinção simulada de espécies. A presença massiva de gramíneas invasoras parece se relacionar não somente à riqueza de espécies regenerantes, mas também à robustez das redes de interação nas áreas restauradas. Assim, embora o processo de polinização pareça estar se restabelecendo no momento, algumas das áreas restauradas representam ecossistemas ainda frágeis. Por exemplo, as áreas de estudo com as redes mais robustas à perda de polinizadores são na verdade os ambientes mais impactados por gramíneas. É natural que ambientes altamente degradados apresentem comunidades resilientes porque os organismos lá presentes são aqueles que sobrevivem aos impactos da degradação. Mas, apesar de robustas, estas comunidades são pobres e pouco complexas, ficando aquém do desejável para ambientes biodiversos como as florestas tropicais.

Ainda, no pior cenário simulado, a extinção de espécies generalistas, tanto de plantas quanto de polinizadores, poderia levar ao rápido colapso das redes mutualísticas. Além de ressaltar a importância de alguns destes organismos para a manutenção das comunidades em processo de restauração, estes dados têm aplicações práticas. Nos casos onde houver preocupação particular com a recuperação das interações planta-polinizador - por exemplo em restaurações visando melhorar o serviço da polinização para áreas de cultivo próximas ou nos casos onde se detecte um baixo sucesso reprodutivo das espécies implantadas - pode-se considerar a introdução de espécies que sejam centrais na estabilidade das redes de interação. Por exemplo, espécies de plantas herbáceas e arbustivas nativas que poderiam aumentar a oferta de recursos florais aos polinizadores. Assim, através do manejo da diversidade de plantas e polinizadores, seria possível aumentar ainda mais a biodiversidade local nas florestas restauradas. 
Entretanto, é preciso enfatizar que a maioria dos insetos polinizadores dependem de múltiplos recursos para completarem seu ciclo de vida. Por exemplo, abelhas precisam de locais de nidificação e recursos florais como pólen e néctar; borboletas e mariposas precisam de plantas como alimento larval além de néctar como alimento para os adultos; várias espécies de moscas tem necessidades ainda mais discrepantes entre os estágios juvenis e adultos (Kevan \& Baker 1983). Qualquer tentativa de manejo de suas populações exige um conhecimento aprofundado de sua biologia, seu comportamento e das interações ecológicas das quais participam. O fato destas espécies apresentarem variação temporal tanto na abundância quanto na composição e topologia das redes de interação das quais participam (Petanidou et al. 2008) demonstra também que os estudos usados de base para as tomadas de decisão precisam ser de longo-prazo. Um dos maiores desafios da ecologia da restauração é integrar diversas áreas de conhecimento em estudos multidisciplinares que abordem o maior número possível de aspectos ligados ao funcionamento dos ecossistemas.

Finalmente, o processo de restauração de ecossistemas - principalmente o de florestas tropicais que são ambientes biodiversos e altamente complexos - é bastante longo, e estudos como o presentemente discutido retratam apenas um passo numa longa escalada de eventos. Processos ecológicos ocorrem numa escala de tempo muito maior do que aquela com a qual estamos acostumados a trabalhar, e é possível (ou mesmo provável) que algumas diferenças e alguns padrões só apareçam mais tarde. Deste modo, enfatizamos a importância de monitoramento constante das áreas restauradas para melhor entendermos as trajetórias de recuperação das florestas e recomendarmos ações de manejo. Além disso, com as taxas de desmatamento nos trópicos ainda altas, a restauração de florestas é uma atividade cada vez mais importante para a preservação de espécies e manutenção de serviços ecológicos. Embora os benefícios das atividades restauradoras para a conservação de espécies sejam mais óbvios, seu impacto na economia, nas comunidades locais e no bem-estar humano é menos aparente. Além de encurtar a distância entre ciência e prática, cabe também à ecologia da restauração construir esforços para que tanto o público quanto os tomadores de decisão tenham um melhor entendimento da relevância da restauração de ambientes degradados.

\section{Referências Bibliográficas}

Aguilar, R., Ashworth, L., Galetto, L. \& Aizen, M.A. (2006) Plant reproductive susceptibility to habitat fragmentation: review and synthesis through a meta-analysis. Ecology letters, 9, 968-980.

Blanche, K.R., Ludwig, J. A. \& Cunningham, S. A. (2006) Proximity to rainforest enhances pollination and fruit set in orchards. Journal of Applied Ecology, 43, 1182-1187.

Brudvig, L.A. (2011) The restoration of biodiversity: where has research been and where does it need to go? American journal of botany, 98, 549-558. 
Carvalheiro, L.G., Seymour, C.L., Veldtman, R. \& Nicolson, S.W. (2010) Pollination services decline with distance from natural habitat even in biodiversity-rich areas. Journal of Applied Ecology, 47, 810820.

Carvalheiro, L.G., Veldtman, R., Shenkute, A.G., Tesfay, G.B., Pirk, C.W.W., Donaldson, J.S. \& Nicolson, S.W. (2011) Natural and within-farmland biodiversity enhances crop productivity. Ecology letters, 14, 251-259.

Ehrenfeld, J.G. \& Toth, L. a. (1997) Restoration Ecolog y and the Ecosystem Perspective. Restoration Ecology, 5, 307-317.

Forup, M.L., Henson, K.S.E., Craze, P.G. \& Memmott, J. (2008) The restoration of ecological interactions: plant-pollinator networks on ancient and restored heathlands. Journal of Applied Ecology, 45, 742-752.

Forup, M.L. \& Memmott, J. (2005) The Restoration of Plant-Pollinator Interactions in Hay Meadows. Restoration Ecology, 13, 265-274.

Ghazoul, J. (2005) Pollen and seed dispersal among dispersed plants. Biological reviews of the Cambridge Philosophical Society, 80, 413-43.

Holl, K., Crone, E. \& Schultz, C. (2003) Landscape restoration: moving from generalities to methodologies. BioScience, 53, 491-502.

Kevan, P. \& Baker, H. (1983) Insects as flower visitors and pollinators. Annual review of entomology, 28, 407-453.

Memmott, J., Waser, N.M. \& Price, M. V. (2004) Tolerance of pollination networks to species extinctions. Proceedings of The Royal Society B: Biological Sciences, 271, 2605-2611.

Petanidou, T., Kallimanis, A.S., Tzanopoulos, J., Sgardelis, S.P. \& Pantis, J.D. (2008) Long-term observation of a pollination network: fluctuation in species and interactions, relative invariance of network structure and implications for estimates of specialization. Ecology letters, 11, 564575.

Ricketts, T. (2004) Tropical forest fragments enhance pollinator activity in nearby coffee crops. Conservation Biology, 18, 1262-1271.

Ricketts, T., Regetz, J., Steffan-Dewenter, I., Cunningham, S., Kremen, C., Bogdanski, A., GemmillHerren, B., Greenleaf, S.S., Klein, A.M., Mayfield, M.M., Morandin, L. a, Ochieng', A., Potts, S. \& Viana, B.F. (2008) Landscape effects on crop pollination services : are there general patterns? Ecology letters, 11, 499-515.

Rodrigues, C. \& Hott, M. (2010) Dinâmica da vegetação natural no nordeste do estado de São Paulo, entre 1988 e 2003. Revista Árvore, 34, 881-887.

Siqueira, L.P. (2002) Monitoramento de Áreas Restauradas No Interior Do Estado de Sao Paulo, Brasil. Dissertação (mestrado) - Escola Superior de Agricultura Luiz de Queiroz, Piracicaba. 116p.

Steffan-Dewenter, I. \& Tscharntke, T. (1999) Effects of habitat isolation on pollinator communities and seed set. Oecologia, 121, 432-440.

Williams, N.M. (2011) Restoration of nontarget species: bee communities and pollination function in riparian forests. Restoration Ecology, 19, 450-459. 
ANEXO 1

Espécies de insetos visitantes florais nas áreas estudadas. A abundância, o número de espécies de plantas visitadas por cada espécie e o código utilizado nas redes de interação também são mostrados.

\begin{tabular}{lllllllll}
\hline & & \multicolumn{4}{c}{ Abundância por área } & No. espécies \\
\cline { 2 - 7 } & Espécies & RA1 & RA2 & RA3 & RD1 & RD2 & RD3 & $\begin{array}{c}\text { plantas } \\
\text { visitadas }\end{array}$ \\
\hline
\end{tabular}

\section{COLEOPTERA}

Indeterminado sp.

1

$1-\quad-\quad 12$

\section{DIPTERA}

Asilidae

Asilidae sp 1

Asilidae sp 2

Bombyliidae

Bombyliidae sp 1

Bombyliidae sp 2

Bombyliidae sp 3

Bombyliidae sp 4

Bombyliidae sp 5

\section{Calliphoridae}

Calliphoridae sp 1

Calliphoridae sp 2

Calliphoridae sp 3

\section{Sarcophagidae}

Sarcophagidae sp 1

Sarcophagidae sp 2

Sarcophagidae sp 3

Sarcophagidae sp 4

Sarcophagidae sp 5

Sarcophagidae sp 6

\section{Stratiomyidae}

Stratiomyidae sp 1

Stratiomyidae sp 2

\section{Syrphidae}

Syrphidae sp 1

Syrphidae $\mathrm{sp} 2$

Eristalinae

Copestylum sp 1

Copestylum sp 2

Eristalinus taeniops Wiedemann, 1818

Ornidia obesa Fabricius, 1775

Orthonevra sp.

Palpada agrorum Fabricius, 1787

Palpada furcata Wiedemann, 1819

Palpada sp 1

Palpada sp 2

Palpada vinetorum Fabricius, 1798

Syritta flaviventris Macquart, 1842

Volucella sp.

\begin{tabular}{|c|c|c|c|c|c|c|c|}
\hline 1 & - & - & - & - & - & 1 & v123 \\
\hline- & 1 & - & - & - & - & 1 & v226 \\
\hline- & 1 & - & 1 & - & - & 2 & v38 \\
\hline- & 1 & 1 & - & - & - & 2 & v55 \\
\hline- & 1 & - & - & - & - & 1 & v59 \\
\hline- & - & - & - & - & 1 & 1 & v98 \\
\hline- & - & - & - & - & 1 & 1 & v103 \\
\hline- & 3 & 3 & - & 6 & 2 & 3 & $\mathrm{v} 23$ \\
\hline 1 & - & - & - & - & - & 1 & v182 \\
\hline 1 & 1 & - & - & - & - & 2 & v205 \\
\hline- & - & - & - & 2 & - & 2 & $\mathrm{v} 21$ \\
\hline- & 4 & - & 1 & 3 & 3 & 4 & v52 \\
\hline 1 & 1 & 1 & - & 4 & 1 & 4 & v183 \\
\hline- & - & - & - & - & 1 & 1 & v268 \\
\hline- & - & - & - & - & 1 & 1 & v269 \\
\hline- & - & - & - & - & 1 & 1 & v270 \\
\hline- & - & - & - & 1 & - & 1 & $\mathrm{v} 22$ \\
\hline- & - & - & - & 1 & - & 1 & v201 \\
\hline- & 1 & - & - & - & - & 1 & v46 \\
\hline 1 & - & - & - & - & - & 1 & v185 \\
\hline- & 1 & - & - & - & 2 & 1 & v204 \\
\hline 1 & - & 1 & - & - & - & 1 & v210 \\
\hline- & 1 & - & - & 3 & - & 2 & v20 \\
\hline 7 & 6 & 3 & 13 & 31 & 1 & 7 & $\mathrm{v} 1$ \\
\hline- & - & - & - & 1 & - & 1 & v5 \\
\hline 2 & 5 & 4 & 4 & 7 & - & 4 & v17 \\
\hline 11 & 4 & 2 & 2 & 11 & - & 5 & v9 \\
\hline 1 & - & - & 3 & - & - & 2 & v114 \\
\hline 2 & - & 1 & - & - & - & 1 & v206 \\
\hline 14 & 11 & 5 & 5 & 8 & - & 4 & v8 \\
\hline 1 & 3 & 1 & - & - & - & 4 & v58 \\
\hline- & - & - & - & 1 & - & 1 & v19 \\
\hline
\end{tabular}


Anexo 1. Continuação.

\begin{tabular}{|c|c|c|c|c|c|c|c|c|}
\hline \multirow[b]{2}{*}{ Espécies } & \multicolumn{6}{|c|}{ Abundância por área } & \multirow{2}{*}{$\begin{array}{c}\text { No. espécies } \\
\text { plantas } \\
\text { visitadas }\end{array}$} & \multirow[b]{2}{*}{$\operatorname{cod}$} \\
\hline & RA1 & RA2 & RA3 & $\mathrm{RD} 1$ & $\mathrm{RD} 2$ & RD3 & & \\
\hline \multicolumn{9}{|l|}{ Syrphinae } \\
\hline Allograpta sp. & 2 & 1 & 1 & 3 & - & 3 & 1 & v 89 \\
\hline Pseudodoros clavatus Fabricius, 1794 & 6 & 2 & 2 & - & - & 2 & 7 & v50 \\
\hline Pseudodoros sp 1 & - & 1 & - & - & - & - & 1 & v57 \\
\hline Pseudodoros sp 2 & 1 & - & - & - & - & - & 1 & v121 \\
\hline Salpingogaster nigra Schiner, 1868 & 2 & 2 & 1 & - & 5 & - & 3 & v179 \\
\hline Syrphinae sp 1 & 1 & - & 1 & - & - & - & 2 & v77 \\
\hline Syrphinae sp 2 & 1 & - & - & - & - & - & 1 & v207 \\
\hline Toxomerus sp 1 & - & - & 1 & - & - & - & 1 & v88 \\
\hline Toxomerus sp 2 & - & - & - & 1 & - & - & 1 & v216 \\
\hline Toxomerus sp 3 & - & - & 1 & - & - & - & 1 & v240 \\
\hline Xanthandrus sp & - & - & 2 & - & - & 1 & 1 & v87 \\
\hline \multicolumn{9}{|l|}{ Tachinidae } \\
\hline Tachinidae sp 1 & 4 & - & 5 & 2 & 8 & 6 & 6 & v4 \\
\hline Tachinidae sp 2 & - & - & - & - & 1 & - & 1 & v28 \\
\hline Tachinidae sp 3 & - & 4 & 1 & - & 1 & 6 & 6 & v47 \\
\hline Tachinidae sp 4 & - & - & 1 & 1 & - & 1 & 2 & v86 \\
\hline Tachinidae sp 5 & - & - & - & - & - & 2 & 1 & v106 \\
\hline Tachinidae sp 6 & 1 & - & - & - & - & - & 1 & v117 \\
\hline Tachinidae sp 7 & 1 & - & - & - & - & - & 1 & v118 \\
\hline Tachinidae sp 8 & 2 & - & - & - & - & - & 2 & v119 \\
\hline Tachinidae sp 9 & 3 & - & - & - & - & - & 2 & v120 \\
\hline Tachinidae sp 10 & 6 & - & - & - & - & - & 1 & v181 \\
\hline Tachinidae sp 11 & 1 & - & - & - & - & - & 1 & v209 \\
\hline Tachinidae sp 12 & - & - & - & - & 1 & - & 1 & v217 \\
\hline Tachinidae sp 13 & - & - & - & - & 1 & - & 1 & v218 \\
\hline Tachinidae sp 14 & - & 1 & - & - & - & - & 1 & v227 \\
\hline Tachinidae sp 15 & - & - & - & 1 & - & - & 1 & v242 \\
\hline Tachinidae sp 16 & - & 1 & - & - & - & - & 1 & v243 \\
\hline Tachinidae sp 17 & - & - & 1 & - & - & - & 1 & v257 \\
\hline Tachinidae sp 18 & 1 & - & - & - & - & - & 1 & v317 \\
\hline Tachinidae sp 19 & - & - & - & - & 1 & - & 1 & v318 \\
\hline Tachinidae sp 20 & - & 1 & - & - & - & - & 1 & v319 \\
\hline Tachinidae sp 21 & - & - & - & - & - & 1 & 1 & v320 \\
\hline \multicolumn{9}{|l|}{ Phasiinae } \\
\hline Cylindromya sp 1 & - & - & - & - & 2 & 1 & 3 & v25 \\
\hline Cylindromya sp 2 & - & 1 & - & - & - & - & 1 & v53 \\
\hline Cylindromya sp 3 & 1 & - & - & - & - & - & 1 & v124 \\
\hline Trichopoda sp 1 & 1 & - & - & - & - & - & 1 & v299 \\
\hline Trichopoda sp 2 & - & - & - & - & 1 & - & 1 & v300 \\
\hline $\begin{array}{l}\text { Xanthomelanodes sp. } \\
\text { Tachininae }\end{array}$ & - & - & 1 & - & - & - & 1 & v31 \\
\hline Archytas sp. & 3 & 5 & 1 & - & 3 & - & 3 & v6 \\
\hline
\end{tabular}


Anexo 1. Continuação.

\begin{tabular}{|c|c|c|c|c|c|c|c|c|}
\hline \multirow[b]{2}{*}{ Espécies } & \multicolumn{6}{|c|}{ Abundância por área } & \multirow{2}{*}{$\begin{array}{l}\text { No. espécies } \\
\text { plantas } \\
\text { visitadas }\end{array}$} & \multirow[b]{2}{*}{ cod } \\
\hline & RA1 & RA2 & RA3 & $\mathrm{RD} 1$ & $\mathrm{RD} 2$ & RD3 & & \\
\hline \multicolumn{9}{|l|}{ Indeterminados } \\
\hline Indeterminado sp 1 & - & - & - & - & - & 1 & 1 & v100 \\
\hline Indeterminado sp 2 & 1 & - & 1 & 1 & - & - & 2 & v214 \\
\hline Indeterminado sp 3 & - & 1 & - & - & - & - & 1 & v256 \\
\hline $\begin{array}{l}\text { HYMENOPTERA } \\
\text { Apoidea } \\
\text { Apiformes }\end{array}$ & & & & & & & & \\
\hline \multicolumn{9}{|l|}{ Andrenidae } \\
\hline \multicolumn{9}{|l|}{ Oxaeinae } \\
\hline Oxaea flavescens Klug, 1807 & - & - & 3 & - & - & - & 1 & v235 \\
\hline \multicolumn{9}{|l|}{ Panurginae } \\
\hline Rhophitulus sp 1 & - & - & - & - & - & 3 & 1 & v249 \\
\hline Rhophitulus sp 2 & - & - & 1 & - & - & 3 & 1 & v262 \\
\hline \multicolumn{9}{|l|}{ Apidae } \\
\hline \multicolumn{9}{|l|}{ Apinae } \\
\hline \multicolumn{9}{|l|}{ Apini } \\
\hline Apis mellifera L., 1758 & 43 & 70 & 32 & 86 & 64 & 17 & 20 & v2 \\
\hline \multicolumn{9}{|l|}{ Bombini } \\
\hline Bombus sp. & - & 1 & - & - & - & - & 1 & v41 \\
\hline \multicolumn{9}{|l|}{ Centridini } \\
\hline Centris bicolor Lepeletier, 1841 & 2 & 1 & - & - & - & - & 2 & v290 \\
\hline Centris sp 1 & - & - & 1 & - & - & - & 1 & v70 \\
\hline Centris sp 2 & - & - & - & - & - & 1 & 1 & v234 \\
\hline Centris sp 3 & 2 & - & - & - & - & - & 1 & v292 \\
\hline Epicharis sp 1 & - & - & - & - & - & 1 & 1 & v90 \\
\hline Epicharis sp 2 & - & - & - & - & - & 3 & 1 & v237 \\
\hline \multicolumn{9}{|l|}{ Eucerini } \\
\hline Eucerini sp 1 & - & 3 & - & - & - & - & 1 & v44 \\
\hline Eucerini sp 2 & - & - & - & - & 1 & - & 1 & v220 \\
\hline \multicolumn{9}{|l|}{ Euglossini } \\
\hline Euglossa sp. & 1 & - & - & - & - & - & 1 & v291 \\
\hline Eulaema nigrita Lepeletier, 1841 & - & 4 & - & - & - & 1 & 3 & v236 \\
\hline \multicolumn{9}{|l|}{ Exomalopsini } \\
\hline Exomalopsis sp 1 & - & - & 18 & - & - & 1 & 5 & v67 \\
\hline Exomalopsis sp 2 & 3 & - & 9 & - & - & 2 & 7 & v68 \\
\hline Exomalopsis sp 3 & - & 1 & - & - & - & - & 1 & v304 \\
\hline \multicolumn{9}{|l|}{ Meliponini } \\
\hline Geotrigona sp. & - & 1 & - & 1 & - & - & 2 & v239 \\
\hline Nanotrigona testaceicornis Lepeletier, 1836 & - & 1 & - & - & - & - & 1 & v259 \\
\hline Scaptotrigona postica Latreille, 1804 & - & - & - & - & 1 & - & 1 & v223 \\
\hline Tetragonisca angustula Latreille, 1811 & - & 4 & - & 33 & 3 & - & 3 & v31 \\
\hline Trigona hyalinata Lepeletier, 1836 & - & 3 & 2 & - & 1 & 13 & 5 & v34 \\
\hline Trigona spinipes Fabricius, 1793 & 2 & 4 & 35 & 7 & 10 & 12 & 16 & v10 \\
\hline
\end{tabular}


Anexo 1. Continuação.

\begin{tabular}{|c|c|c|c|c|c|c|c|c|}
\hline \multirow[b]{2}{*}{ Espécies } & \multicolumn{6}{|c|}{ Abundância por área } & \multirow{2}{*}{$\begin{array}{c}\text { No. espécies } \\
\text { plantas } \\
\text { visitadas }\end{array}$} & \multirow[b]{2}{*}{ cod } \\
\hline & RA1 & RA2 & RA3 & RD1 & $\mathrm{RD} 2$ & RD3 & & \\
\hline \multicolumn{9}{|l|}{ Tetrapedini } \\
\hline Tetrapedia sp. & 1 & - & - & - & - & - & 1 & $\mathrm{v} 212$ \\
\hline \multicolumn{9}{|l|}{ Xylocopinae } \\
\hline \multicolumn{9}{|l|}{ Ceratinini } \\
\hline Ceratina sp1 & - & - & 3 & - & - & - & 2 & v311 \\
\hline Ceratina sp2 & - & - & 1 & - & - & - & 1 & v312 \\
\hline Ceratina sp3 & - & - & - & - & - & 1 & 1 & v313 \\
\hline Ceratina sp4 & - & 1 & 1 & - & 1 & 7 & 8 & v314 \\
\hline Ceratina sp5 & - & - & 2 & - & 1 & 15 & 11 & v315 \\
\hline Ceratina sp 6 & - & - & - & - & 1 & - & 1 & v27 \\
\hline Ceratina sp 7 & - & - & - & 1 & - & - & 1 & v36 \\
\hline Ceratina sp 8 & - & 1 & 1 & - & 1 & 3 & 4 & v45 \\
\hline \multicolumn{9}{|l|}{ Xylocopini } \\
\hline Xylocopa sp. & - & 4 & 3 & - & - & 1 & 4 & v40 \\
\hline \multicolumn{9}{|l|}{ Colletidae } \\
\hline Colletidae sp 1 & - & - & - & - & 1 & - & 1 & v12 \\
\hline \multicolumn{9}{|l|}{ Colletinae } \\
\hline Colletes sp. & - & - & - & - & 1 & - & 1 & v13 \\
\hline \multicolumn{9}{|l|}{ Hylaeinae } \\
\hline Hylaeus sp. & - & - & 1 & - & - & - & 1 & v193 \\
\hline \multicolumn{9}{|l|}{ Hallictidae } \\
\hline Halictidae sp 1 & - & - & - & - & 4 & - & 2 & v3 \\
\hline Halictidae sp 2 & - & - & 1 & - & - & - & 1 & v194 \\
\hline Halictidae sp 3 & - & - & - & - & 1 & - & 1 & v222 \\
\hline \multicolumn{9}{|l|}{ Halictinae } \\
\hline \multicolumn{9}{|l|}{ Augochlorini } \\
\hline Augochlora sp 1 & 2 & - & 1 & - & - & - & 2 & v82 \\
\hline Augochlora sp 2 & - & - & 1 & - & - & - & 1 & v196 \\
\hline Augochlora sp 3 & - & 2 & - & 1 & 1 & 2 & 5 & v308 \\
\hline Augochlora sp 4 & - & - & 1 & - & - & 1 & 1 & v309 \\
\hline Augochlorella sp 1 & - & - & - & - & - & 2 & 2 & v107 \\
\hline Augochlorella sp 2 & 4 & - & - & - & 1 & 21 & 4 & v108 \\
\hline Augochlorella sp 3 & 1 & - & 1 & - & - & - & 1 & v313 \\
\hline Augochlorella sp 4 & - & - & - & - & - & 1 & 1 & v246 \\
\hline Augochlorella sp 5 & - & - & - & - & - & 1 & 1 & v267 \\
\hline Augochloropsis sp 1 & - & - & - & - & 1 & - & 1 & v18 \\
\hline Augochloropsis sp 2 & 4 & - & 1 & 1 & - & - & 5 & v32 \\
\hline Augochloropsis sp 3 & - & - & - & - & 3 & - & 1 & v306 \\
\hline Augochloropsis sp 4 & - & - & - & - & - & 1 & 1 & v307 \\
\hline Ceratalictus sp & - & - & 1 & - & - & - & 1 & v310 \\
\hline Paroxystoglossa sp. & - & - & - & - & - & 1 & 1 & v305 \\
\hline $\begin{array}{l}\text { Pseudaugochlora sp. } \\
\text { Halictini }\end{array}$ & - & - & 2 & - & - & 3 & 2 & v83 \\
\hline Dialictus sp & 3 & 2 & 4 & - & - & 6 & 9 & v316 \\
\hline
\end{tabular}


Anexo 1. Continuação.

\begin{tabular}{|c|c|c|c|c|c|c|c|c|}
\hline \multirow[b]{2}{*}{ Espécies } & \multicolumn{6}{|c|}{ Abundância por área } & \multirow{2}{*}{$\begin{array}{c}\text { No. espécies } \\
\text { plantas } \\
\text { visitadas }\end{array}$} & \multirow[b]{2}{*}{ cod } \\
\hline & RA1 & RA2 & RA3 & $\mathrm{RD} 1$ & $\mathrm{RD} 2$ & RD3 & & \\
\hline \multicolumn{9}{|l|}{ Megachilidae } \\
\hline \multicolumn{9}{|l|}{ Megachilinae } \\
\hline \multicolumn{9}{|l|}{ Anthidiini } \\
\hline Anthidiini sp. & 1 & - & - & - & - & - & 1 & v294 \\
\hline \multicolumn{9}{|l|}{ Megachilini } \\
\hline Coelioxys sp 1 & - & - & 1 & - & - & - & 1 & v84 \\
\hline Coelioxys sp 2 & - & - & - & - & 1 & - & 1 & v303 \\
\hline Megachile sp 1 & - & 1 & 1 & - & - & - & 1 & v42 \\
\hline Megachile sp 2 & - & - & 1 & - & - & - & 1 & v69 \\
\hline Megachile sp 3 & - & - & 1 & - & - & - & 1 & v71 \\
\hline Megachile sp 4 & - & - & 1 & - & - & - & 1 & v72 \\
\hline Megachile sp 5 & - & - & - & - & - & 1 & 1 & v96 \\
\hline Megachile sp 6 & 4 & - & - & - & - & - & 1 & v213 \\
\hline \multicolumn{9}{|l|}{ Spheciformes } \\
\hline \multicolumn{9}{|l|}{ Cabronidae } \\
\hline Cabronidae sp 1 & - & 1 & - & - & - & - & 1 & v54 \\
\hline Cabronidae sp 2 & - & 1 & - & - & - & - & 1 & v231 \\
\hline \multicolumn{9}{|l|}{ Bembicinae } \\
\hline \multicolumn{9}{|l|}{ Bembicini } \\
\hline Bembicini sp. & - & 2 & - & - & - & - & 1 & v61 \\
\hline Bembix sp. & - & 1 & - & - & - & - & 1 & v65 \\
\hline \multicolumn{9}{|l|}{ Cabroninae } \\
\hline \multicolumn{9}{|l|}{ Cabronini } \\
\hline Cabronini sp. & - & - & 1 & - & - & - & 1 & $\mathrm{v} 238$ \\
\hline \multicolumn{9}{|l|}{ Oxybelini } \\
\hline Oxybelus sp 1 & - & - & - & - & - & 1 & 1 & v254 \\
\hline Oxybelus sp 2 & - & 1 & - & - & - & 1 & 2 & v255 \\
\hline \multicolumn{9}{|l|}{ Philanthinae } \\
\hline \multicolumn{9}{|l|}{ Cercerini } \\
\hline Cerceris sp 1 & - & 1 & - & - & - & - & 1 & v49 \\
\hline Cerceris sp 2 & - & - & - & - & 1 & - & 1 & v202 \\
\hline Cerceris sp 3 & - & 1 & - & - & - & - & 1 & v228 \\
\hline Cerceris sp 4 & - & - & - & 1 & 1 & - & 2 & v241 \\
\hline \multicolumn{9}{|l|}{ Sphecidae } \\
\hline Spechidae sp 1 & - & - & - & - & 2 & - & 2 & v29 \\
\hline \multicolumn{9}{|l|}{ Ammophilinae } \\
\hline Eremnophila sp 1 & - & 1 & - & - & - & - & 1 & v62 \\
\hline Eremnophila sp 2 & - & - & - & - & 1 & - & 1 & v230 \\
\hline \multicolumn{9}{|l|}{ Sphecinae } \\
\hline Sphecini sp. & 4 & 2 & 1 & - & - & - & 5 & v51 \\
\hline \multicolumn{9}{|l|}{ Vespoidea } \\
\hline Pompilidae & & & & & & & & \\
\hline Pompilidae sp & 1 & - & - & - & - & - & 1 & v295 \\
\hline Pepsinae & & & & & & & & \\
\hline Pepsini & & & & & & & & \\
\hline Hemipepsis sp. & 2 & - & - & - & - & - & 2 & v115 \\
\hline
\end{tabular}


Anexo 1. Continuação.

\begin{tabular}{|c|c|c|c|c|c|c|c|c|}
\hline \multirow[b]{2}{*}{ Espécies } & \multicolumn{6}{|c|}{ Abundância por área } & \multirow{2}{*}{$\begin{array}{c}\text { No. espécies } \\
\text { plantas } \\
\text { visitadas }\end{array}$} & \multirow[b]{2}{*}{$\operatorname{cod}$} \\
\hline & RA1 & RA2 & RA3 & $\mathrm{RD} 1$ & $\mathrm{RD} 2$ & RD3 & & \\
\hline \multicolumn{9}{|l|}{ Scolidae } \\
\hline \multicolumn{9}{|l|}{ Scolinae } \\
\hline Campsomeris sp 1 & - & - & - & - & 1 & - & 1 & v15 \\
\hline Campsomeris sp 2 & 1 & 3 & - & - & - & 3 & 5 & v63 \\
\hline Campsomeris sp 3 & 1 & - & - & - & - & - & 1 & v186 \\
\hline Campsomeris sp4 & - & - & 1 & - & - & 1 & 2 & v94 \\
\hline \multicolumn{9}{|l|}{ Tiphiidae } \\
\hline Tiphiidae sp. & - & - & - & - & - & 1 & 1 & v248 \\
\hline \multicolumn{9}{|l|}{ Myzininae } \\
\hline Myzinum sp 1 & - & - & - & 1 & - & - & 1 & v215 \\
\hline Myzinum sp 2 & - & 2 & - & - & - & - & 2 & v225 \\
\hline \multicolumn{9}{|l|}{ Vespidae } \\
\hline \multicolumn{9}{|l|}{ Eumeninae } \\
\hline Alphamenes sp. & 1 & - & - & - & - & - & 1 & v211 \\
\hline Eumeninae sp 1 & - & - & - & 1 & - & - & 1 & v33 \\
\hline Eumeninae sp 2 & - & 1 & - & - & - & - & 1 & v233 \\
\hline Stenodynerus sp. & 1 & - & 4 & - & 2 & - & 5 & v30 \\
\hline Zethus sp. & - & 1 & - & - & - & - & 1 & v56 \\
\hline \multicolumn{9}{|l|}{ Polistinae } \\
\hline \multicolumn{9}{|l|}{ Epiponini } \\
\hline Epiponini sp 1 & - & 1 & - & - & - & - & 1 & v60 \\
\hline Epiponini sp 2 & 2 & - & - & - & - & - & 1 & v301 \\
\hline Epiponini sp 3 & - & 1 & - & - & - & - & 1 & v302 \\
\hline Protonectarina sylveirae Saussure, 1854 & - & - & - & - & 1 & - & 1 & v221 \\
\hline \multicolumn{9}{|l|}{ Polistini } \\
\hline Polistes sp. & - & - & - & - & 2 & - & 1 & v200 \\
\hline Polistes versicolor Olivier, 1791 & - & 1 & - & - & - & - & 1 & v232 \\
\hline \multicolumn{9}{|l|}{ LEPIDOPTERA } \\
\hline \multicolumn{9}{|l|}{ Arctiidae } \\
\hline \multicolumn{9}{|l|}{ Hesperidae } \\
\hline Hesperidae sp 1 & - & 1 & - & - & - & - & 1 & v24 \\
\hline Hesperidae sp 2 & - & - & - & 3 & - & 3 & 1 & v35 \\
\hline Hesperidae sp 3 & - & 1 & - & - & - & - & 1 & v66 \\
\hline Hesperidae sp 4 & - & 3 & 2 & - & - & 2 & 2 & v91 \\
\hline Hesperidae sp 5 & 2 & - & 3 & - & 1 & 4 & 5 & v110 \\
\hline Hesperidae sp 6 & - & 1 & 2 & - & - & 1 & 1 & v116 \\
\hline Hesperidae sp 7 & 6 & - & 1 & - & 1 & 6 & 6 & v122 \\
\hline Hesperidae sp 8 & - & - & - & - & - & 1 & 1 & v188 \\
\hline Hesperidae sp 9 & - & - & 1 & - & - & - & 1 & v199 \\
\hline Hesperidae sp 10 & 1 & - & - & - & 1 & - & 2 & v282 \\
\hline Hesperidae sp 11 & 1 & - & 1 & - & - & - & 2 & v284 \\
\hline Hesperidae sp 12 & - & - & 2 & - & - & - & 1 & v285 \\
\hline Hesperidae sp 13 & & & & & & & & v286 \\
\hline
\end{tabular}


Anexo 1. Continuação.

\begin{tabular}{|c|c|c|c|c|c|c|c|c|}
\hline \multirow[b]{2}{*}{ Espécies } & \multicolumn{6}{|c|}{ Abundância por área } & \multirow{2}{*}{$\begin{array}{c}\text { No. espécies } \\
\text { plantas } \\
\text { visitadas }\end{array}$} & \multirow[b]{2}{*}{$\operatorname{cod}$} \\
\hline & RA1 & RA2 & RA3 & $\mathrm{RD} 1$ & $\mathrm{RD} 2$ & RD3 & & \\
\hline Hesperidae sp 14 & - & - & - & - & - & 1 & 1 & v287 \\
\hline Hesperidae sp 15 & 1 & - & 2 & - & - & 4 & 1 & v289 \\
\hline Hesperidae sp 16 & 1 & - & - & - & - & - & 1 & v298 \\
\hline \multicolumn{9}{|l|}{ Eudaminae } \\
\hline Eudaminae sp 1 & - & - & 1 & - & 1 & - & 2 & v80 \\
\hline Eudaminae sp 2 & - & - & 4 & - & - & 1 & 3 & v81 \\
\hline Eudaminae sp 3 & 1 & - & - & - & - & - & 1 & v281 \\
\hline \multicolumn{9}{|l|}{ Pyrginae } \\
\hline Heliopetes sp. & - & - & - & - & 1 & - & 1 & v26 \\
\hline \multicolumn{9}{|l|}{ Lycaenidae } \\
\hline Lycaenidae sp 1 & - & 1 & 1 & - & - & 1 & 3 & v43 \\
\hline Lycaenidae sp 2 & - & - & - & - & - & 1 & 1 & v288 \\
\hline \multicolumn{9}{|l|}{ Theclinae } \\
\hline Theclinae sp 1 & - & - & - & - & 3 & - & 1 & v16 \\
\hline Theclinae sp 2 & 1 & - & - & - & - & - & 1 & v272 \\
\hline \multicolumn{9}{|l|}{ Nymphalidae } \\
\hline \multicolumn{9}{|l|}{ Danainae } \\
\hline \multicolumn{9}{|l|}{ Ithomiini } \\
\hline Episcada sp. & - & - & - & - & - & 2 & 2 & v277 \\
\hline \multicolumn{9}{|l|}{ Heliconiinae } \\
\hline \multicolumn{9}{|l|}{ Acraeini } \\
\hline Actinote sp. & - & - & 1 & - & - & 1 & 2 & v276 \\
\hline \multicolumn{9}{|l|}{ Heliconiini } \\
\hline Agraulis vanillae L., 1758 & - & - & - & 1 & - & - & 1 & v37 \\
\hline Dryadula phaetusa L., 1758 & - & - & 1 & - & - & - & 1 & v78 \\
\hline Dryas iulia Fabricius, 1775 & 1 & - & 1 & - & - & - & 2 & v192 \\
\hline Heliconius erato L., 1758 & 2 & - & 2 & - & - & - & 3 & v191 \\
\hline Heliconius sp. & - & - & - & - & - & 1 & 1 & v112 \\
\hline \multicolumn{9}{|l|}{ Nymphalinae } \\
\hline \multicolumn{9}{|l|}{ Nymphalini } \\
\hline Vanessa braziliensis Moore, 1883 & 1 & - & - & - & - & - & 1 & v296 \\
\hline \multicolumn{9}{|l|}{ Victorinini } \\
\hline $\begin{array}{l}\text { Anartia amathea L., } 1758 \\
\text { Satyrinae }\end{array}$ & \multicolumn{7}{|c|}{ Satyrinae } & v79 \\
\hline \multicolumn{9}{|l|}{ Brassolini } \\
\hline $\begin{array}{l}\text { Caligo sp. } \\
\text { Pieridae }\end{array}$ & \multicolumn{7}{|c|}{ Pieridae } & v278 \\
\hline $\begin{array}{l}\text { Pieridae sp. } \\
\text { Coliadinae }\end{array}$ & - & - & 1 & - & - & - & 1 & v198 \\
\hline \multicolumn{9}{|l|}{ Euremini } \\
\hline Eurema daira Godart, 1819 & - & - & 8 & - & - & 4 & 4 & v73 \\
\hline Eurema sp 1 & 2 & - & 1 & - & - & 3 & 4 & v74 \\
\hline Eurema sp 2 & 5 & - & - & - & 1 & 3 & 3 & v271 \\
\hline Eurema sp 3 & - & - & - & - & - & 2 & 1 & v280 \\
\hline
\end{tabular}


Anexo 1. Continuação.

\begin{tabular}{|c|c|c|c|c|c|c|c|c|}
\hline \multirow[b]{2}{*}{ Espécies } & \multicolumn{6}{|c|}{ Abundância por área } & \multirow{2}{*}{$\begin{array}{c}\text { No. espécies } \\
\text { plantas } \\
\text { visitadas }\end{array}$} & \multirow[b]{2}{*}{ cod } \\
\hline & RA1 & RA2 & RA3 & $\mathrm{RD} 1$ & $\mathrm{RD} 2$ & RD3 & & \\
\hline \multicolumn{9}{|l|}{ Coliadini } \\
\hline $\begin{array}{l}\text { Phoebis sennae L., } 1758 \\
\text { Pierinae }\end{array}$ & - & - & 1 & - & - & - & 1 & v297 \\
\hline \multicolumn{9}{|l|}{ Pierini } \\
\hline Ascia monuste L., 1764 & 5 & - & - & - & - & 10 & 4 & v99 \\
\hline \multicolumn{9}{|l|}{ Indeterminados } \\
\hline Indeterminado sp 1 & - & - & - & - & - & 1 & 1 & v109 \\
\hline Indeterminado sp 2 & - & - & - & - & - & 1 & 1 & v187 \\
\hline Indeterminado sp 3 & 1 & - & - & - & - & - & 1 & v274 \\
\hline Indeterminado sp 4 & - & - & - & - & - & 1 & 1 & v279 \\
\hline Indeterminado sp 5 & 1 & - & - & - & - & - & 1 & v283 \\
\hline
\end{tabular}


ANEXO 2

Espécies vegetais em floração nas áreas estudadas. As áreas de ocorrência, o número de espécies de visitantes recebidos (nv) e o código utilizado nas redes de interação também são mostrados.

\begin{tabular}{|c|c|c|c|c|c|c|c|c|}
\hline \multirow{2}{*}{ Espécie } & \multicolumn{6}{|c|}{ Áreas de estudo } & \multirow{2}{*}{$\mathrm{nv}$} & \multirow{2}{*}{ cod } \\
\hline & RA1 & RA2 & RA3 & RD1 & RD2 & RD3 & & \\
\hline \multicolumn{9}{|l|}{ Amaranthaceae } \\
\hline Gomphrena celosioides Mart. & & & & & & $x$ & - & p75 \\
\hline \multicolumn{9}{|l|}{ Anacardiaceae } \\
\hline Schinus terebinhifolius Raddi & $x$ & $x$ & $x$ & $x$ & $x$ & $x$ & 72 & p3 \\
\hline \multicolumn{9}{|l|}{ Apocynaceae } \\
\hline Apocynaceae sp1 & & & & $x$ & & $x$ & 4 & p28 \\
\hline Apocynaceae sp2 & & & $x$ & & & & - & p64 \\
\hline \multicolumn{9}{|l|}{ Asteraceae } \\
\hline Ageratum conyzoides L. & & & & & & $x$ & - & p76 \\
\hline Baccharis sp1 & & & $x$ & & & & - & p66 \\
\hline Baccharis sp2 & & & $x$ & $x$ & & & 7 & p100 \\
\hline Bidens sp. & $x$ & $x$ & $x$ & & $x$ & & 6 & p51 \\
\hline Bidens subalternans DC. & $x$ & & & & & & 4 & $\mathrm{p} 81$ \\
\hline Conyza sp1 & & & & & & $x$ & 1 & p30 \\
\hline Conyza sp2 & $x$ & $x$ & $x$ & & $x$ & $x$ & 28 & $\mathrm{p} 48$ \\
\hline Conyza sp3 & & & $x$ & & & & - & p67 \\
\hline Eclipta prostrata (L.) L. & & $x$ & & & & & - & p49 \\
\hline Emilia fosbergii Nicolson & $x$ & $x$ & $x$ & & $x$ & $x$ & 28 & p15 \\
\hline Emilia sonchifolia (L.) DC. & & $x$ & & & & $x$ & 1 & p60 \\
\hline Eupatorium sp. & $x$ & & & & & $x$ & 4 & p103 \\
\hline Mikania sp. & & & $x$ & $x$ & $x$ & & 6 & p101 \\
\hline Parthenium hysterophorus L. & $x$ & & & & & & 9 & p79 \\
\hline Praxelis pauciflora (Kunth) R. M. King \& H. Rob. & & $x$ & $x$ & & $x$ & $\mathrm{x}$ & 20 & p57 \\
\hline Sonchus oleraceus L. & $x$ & & & & & & 1 & p83 \\
\hline Vernonia sp1 & $x$ & & $x$ & $x$ & & & 1 & p106 \\
\hline Asteraceae sp1 & $x$ & & & & & & - & p80 \\
\hline Asteraceae sp2 & & & $x$ & & & & 6 & p87 \\
\hline Asteraceae sp3 & & & $x$ & & & $\mathrm{x}$ & 1 & $\mathrm{p} 11$ \\
\hline Asteraceae sp4 & & & & & & $\mathrm{x}$ & 1 & p112 \\
\hline \multicolumn{9}{|l|}{ Bignoniaceae } \\
\hline Jacaranda mimosifolia D. Don & & & $x$ & & & & - & p32 \\
\hline Tabebuia roseo-alba (Ridl.) Sand. & & $x$ & & & & & 2 & p118 \\
\hline Tabebuia sp. & & $x$ & $x$ & & & & 4 & p117 \\
\hline \multicolumn{9}{|l|}{ Boraginaceae } \\
\hline Cordia superba Cham. & $x$ & & & & & & 8 & p113 \\
\hline Cordia sp. & & & & & & $x$ & 3 & p119 \\
\hline Heliotropium indicum L. & & & & & & $x$ & 1 & p54 \\
\hline \multicolumn{9}{|l|}{ Cecropiaceae } \\
\hline Cecropia pachystachya Trécul & & & & & $x$ & & - & p58 \\
\hline \multicolumn{9}{|l|}{ Commelinaceae } \\
\hline Commelina sp1 & & $x$ & $x$ & & & & - & p61 \\
\hline Commelina sp2 & $x$ & $x$ & $x$ & & & $x$ & 4 & p68 \\
\hline
\end{tabular}


Anexo 2. Continuação.

\begin{tabular}{|c|c|c|c|c|c|c|c|c|}
\hline \multirow{2}{*}{ Espécie } & \multicolumn{6}{|c|}{ Áreas de estudo } & \multirow{2}{*}{$\mathrm{nv}$} & \multirow{2}{*}{ cod } \\
\hline & RA1 & RA2 & RA3 & RD1 & RD2 & RD3 & & \\
\hline \multicolumn{9}{|l|}{ Convolvulaceae } \\
\hline Ipomoea cairica (L.) Seet. & & $x$ & & & & & 2 & $\mathrm{p} 14$ \\
\hline Ipomoea hederacea (L.) Jacq. & $x$ & & & & & & - & p84 \\
\hline Ipomoea triloba L. & & $x$ & & & & & 1 & $\mathrm{p} 45$ \\
\hline Jacquemontia heterantha (Nees\&Mart.) Hallier f. & & & $x$ & & & $\mathrm{x}$ & 12 & p105 \\
\hline \multicolumn{9}{|l|}{ Curcubitaceae } \\
\hline Mormodica charantia L. & $x$ & & & & & $x$ & 5 & p53 \\
\hline \multicolumn{9}{|l|}{ Euphorbiaceae } \\
\hline Croton floribundus Spreng. & & & & & & $x$ & 1 & $\mathrm{p} 20$ \\
\hline Croton glandulosus L. & & & & & & $\mathrm{x}$ & - & p73 \\
\hline Croton urucurana Baill. & $x$ & $x$ & $\mathrm{x}$ & $x$ & $\mathrm{x}$ & $\mathrm{x}$ & 64 & $\mathrm{p} 12$ \\
\hline Mabea fistulifera Mart. & & & & $x$ & & & 2 & p108 \\
\hline Euphorbiaceae sp1 & $x$ & & & & & & - & p85 \\
\hline \multicolumn{9}{|l|}{ Fabaceae } \\
\hline Anadenathera colubrina (Vell.) Brenan. & & & & & & $x$ & - & p120 \\
\hline Caesalpinia ferrea Mart & & & $x$ & & & & - & p88 \\
\hline Chamaecrista desvauxii (Collad.) Killip & & $x$ & $x$ & & & $x$ & 2 & $\mathrm{p} 42$ \\
\hline Chamaecrista sp. & $x$ & & & & $\mathrm{x}$ & & 2 & p99 \\
\hline Clitoria fairchildiana R.A. Howard & & $x$ & $x$ & & & & 6 & p62 \\
\hline Crotalaria spectabilis Roth. & & $x$ & & & & & - & p96 \\
\hline Enterolobium contortisiliqum (Vell.) Morong & & & $x$ & & & & 2 & p116 \\
\hline Erythrina speciosa Andrews & & & & & & $\mathrm{x}$ & 1 & p109 \\
\hline Machaerium aculeatum Raddi & & & & & & $x$ & 1 & p91 \\
\hline Mimosa invisa Mart. & & & $\mathrm{x}$ & & & & 2 & p102 \\
\hline Mimosa pudica L. & & $x$ & $\mathrm{x}$ & & & & 1 & p98 \\
\hline Peltophorum dubium (Spreng.) Taub. & & $x$ & $x$ & & & & 17 & p59 \\
\hline Senegalia polyphylla (DC.) Britton \& Rose & & $x$ & & $x$ & $x$ & $x$ & 5 & p92 \\
\hline Fabaceae sp1 & & & $x$ & & & & 3 & p63 \\
\hline Fabaceae sp2 & & & $\mathrm{x}$ & & & & 1 & p69 \\
\hline Fabaceae sp3 & $x$ & & & & & & 5 & p82 \\
\hline Fabaceae sp4 & & & & $x$ & & $x$ & 5 & p90 \\
\hline Fabaceae sp5 & & $x$ & $x$ & & & & 1 & p115 \\
\hline \multicolumn{9}{|l|}{ Lamiaceae } \\
\hline Lamiaceae sp1 & & & & & $\mathrm{x}$ & & - & $\mathrm{p} 46$ \\
\hline \multicolumn{9}{|l|}{ Lythraceae } \\
\hline Lafoensia pacari A.St.-Hil. & & & & $x$ & & & 3 & $\mathrm{p} 18$ \\
\hline \multicolumn{9}{|l|}{ Malvaceae } \\
\hline Bombacopsis glabra (Pasq.) A. Robyns & & & & & & $x$ & 1 & p94 \\
\hline Guazuma umifolia Lam. & & & $x$ & & & & - & p1 \\
\hline Sida sp1 & & $x$ & $x$ & & & $x$ & 9 & p26 \\
\hline Waltheria americana $\mathrm{L}$. & & & & $x$ & & $x$ & 1 & p5 \\
\hline Malvaceae sp & & & & & & $\mathrm{x}$ & 2 & p78 \\
\hline \multicolumn{9}{|l|}{ Melastomataceae } \\
\hline Melastomataceae sp1 & & & $x$ & & & $x$ & 2 & p86 \\
\hline Melastomataceae sp2 & & & & & & $x$ & - & p93 \\
\hline Melastomataceae sp3 & & $x$ & & & & & - & p97 \\
\hline
\end{tabular}


Anexo 2. Continuação.

\begin{tabular}{|c|c|c|c|c|c|c|c|c|}
\hline \multirow{2}{*}{ Espécie } & \multicolumn{6}{|c|}{ Áreas de estudo } & \multirow{2}{*}{ nv } & \multirow{2}{*}{$\operatorname{cod}$} \\
\hline & RA1 & RA2 & RA3 & RD1 & RD2 & RD3 & & \\
\hline \multicolumn{9}{|l|}{ Meliaceae } \\
\hline Guarea guidonia (L.) Sleumer & & & & & & $\mathrm{x}$ & - & p110 \\
\hline \multicolumn{9}{|l|}{ Moraceae } \\
\hline Ficus eximia Schott. & & & $\mathrm{x}$ & & & & - & p35 \\
\hline \multicolumn{9}{|l|}{ Mutingiaceae } \\
\hline Muntingia calabura $\mathrm{L}$. & & $x$ & & & & & 2 & p47 \\
\hline \multicolumn{9}{|l|}{ Myrsinaceae } \\
\hline Rapaneae gardneriana $\mathrm{Mez}$ & & $x$ & & $x$ & & & - & p107 \\
\hline \multicolumn{9}{|l|}{ Myrtaceae } \\
\hline \multicolumn{8}{|l|}{ Orchidaceae } & p2 \\
\hline Oeceoclades maculata (Lindl) Lindl. & $x$ & & & & & $x$ & - & p95 \\
\hline \multicolumn{9}{|l|}{ Piperaceae } \\
\hline Piper aduncum L. & $x$ & & $x$ & & & $x$ & 2 & p41 \\
\hline \multicolumn{9}{|l|}{ Polygonaceae } \\
\hline Triplaris sp. & $x$ & & & & & & - & p114 \\
\hline \multicolumn{9}{|l|}{ Rhamnaceae } \\
\hline Colubrina glandulosa Perk. & $x$ & & & & & & 3 & p27 \\
\hline \multicolumn{9}{|l|}{ Rubiaceae } \\
\hline Manettia cordifolia Mart. & & $x$ & $x$ & & & & - & p23 \\
\hline \multicolumn{9}{|l|}{ Rutaceae } \\
\hline Helietta apiculata Benth. & & $x$ & & & & & 2 & p13 \\
\hline \multicolumn{9}{|l|}{ Solanaceae } \\
\hline Solanum sp1 & & & $x$ & & $x$ & & 3 & p9 \\
\hline Solanum sp2 & & & $x$ & & & & - & p70 \\
\hline \multicolumn{9}{|l|}{ Verbenaceae } \\
\hline Lantana trifolia L. & & & $x$ & & & & 2 & $\mathrm{p} 40$ \\
\hline Lantana camara L. & & & $x$ & & & $x$ & 2 & p43 \\
\hline Stachytarpheta cayennensis (L.C.Rich.) Vahl & $x$ & $x$ & $x$ & $x$ & & $x$ & 35 & p24 \\
\hline \multicolumn{9}{|l|}{ Indeterminadas } \\
\hline Indeterminada sp1 & & $x$ & & & & & - & p17 \\
\hline Indeterminada sp2 & & & $x$ & & & & 1 & p65 \\
\hline Indeterminada sp3 & & & & & & $x$ & - & p71 \\
\hline Indeterminada sp4 & & & & & & $x$ & 7 & p72 \\
\hline Indeterminada sp5 & & & & & & $x$ & - & p74 \\
\hline Indeterminada sp6 & & & & & & $x$ & 1 & p77 \\
\hline
\end{tabular}

